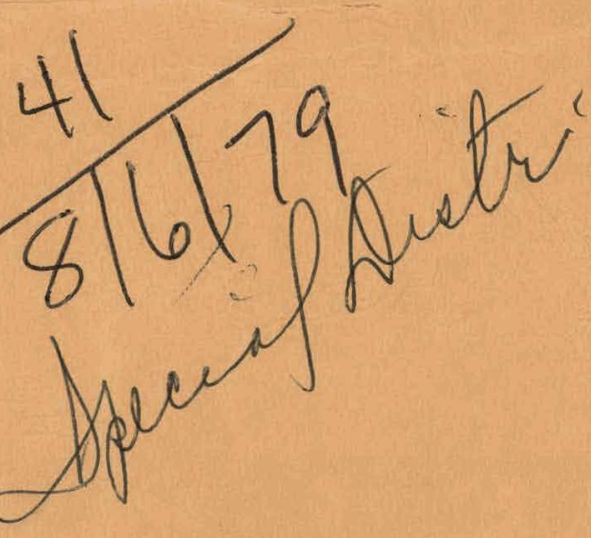

WAPD-TM-1449 DEPARTMENT OF ENERGY RESEARCH AND DEVELOPMENT REPORT

\title{
INTEGRAL TESTING OF THORIUM AND U233 DATA FOR THERMAL REACTORS
} (AWBA Development Program)

\section{MASTER}

JUNE 1979

CONTRACT EY-76-C-11-0014

\section{BETTIS ATOMIC POWER LABORATORY WEST MIFFLIN, PENNSYLVANIA}

Operated for the U. $\mathbf{S}$. Department of Energy by WESTINGHOUSE ELECTRIC CORPORATION 


\section{DISCLAIMER}

This report was prepared as an account of work sponsored by an agency of the United States Government. Neither the United States Government nor any agency Thereof, nor any of their employees, makes any warranty, express or implied, or assumes any legal liability or responsibility for the accuracy, completeness, or usefulness of any information, apparatus, product, or process disclosed, or represents that its use would not infringe privately owned rights. Reference herein to any specific commercial product, process, or service by trade name, trademark, manufacturer, or otherwise does not necessarily constitute or imply its endorsement, recommendation, or favoring by the United States Government or any agency thereof. The views and opinions of authors expressed herein do not necessarily state or reflect those of the United States Government or any agency thereof. 


\section{DISCLAIMER}

Portions of this document may be illegible in electronic image products. Images are produced from the best available original document. 


\section{The following pages are an exact representation of what is in the original document folder.}


INTEGRAL TESTING OF THORIUM AND U233

DATA FOR THERMAL REACTORS

(AWBA DEVELOPMENT PROGRAM)

\author{
J. Hardy, Jr. \\ J. J. Ullo \\ N. M. Steen
}

CONTRACT NO. EY-76-C-11-0014

JUNE 1979
Printed in the Unfted States of America Available from the

National Technical Information Service

U. S. Department of Commerce 5285 Port Royal Road

Springfield, Virginia 22151

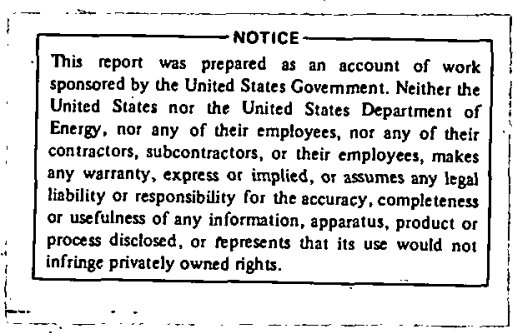

NOTE

This document is an interim memorandun prepared primarily for internal reference and does not represent a final expression of the opinion of Westinghouse. When this memorandum is distributed externally, it is with the express understanding that Westinghouse makes no representation as to completeness; accuracy, or usability of information contained therein.

Operated for the U. S. Department of Energy by WESTINGHOUSE ELECTRIC CORPORATION 
NOTICE

This report. was prepared as an account of work sponsorec by the United States Government. Ne1ther the United States, nor the United States Department of Energy, nor any of their employees, nor any of their contractors, subcontractors, or their employees, makes any warranty, expressed or implled, or assumes any legal liablilty or responsibility for the accuracy, completeness, or usefulness of any information, apparatus, product, or process disclosed, or represents that its use would not infringe privately owned rights. 
FOREWORD

The Shippingport Atomic Power Station located in Shippingport, Pennsylvania was the first large-scale, central-station nuclear power plant in the United States and the first plant of such size in the world operated solely to produce electric power. This program was started in 1953 to confirm the practical application of nuclear power for large-scale electric power generation. It has provided much of the technology being used for design and operation of the cominercial, centralstation nuclear power plants now in use.

Subsequent to development and successful operation of the Pressurized Water Reactor in the DOE-owned reactor plant at the Shippingport Atomic Power Station, the Atomic mergy Commission in 1965 urlertook a recearch and develnpment program to design and build a Light Water Breeder Reactor core for operation in the Shippingport station.

The objective of the Light Water Breeder Reactor (IWBR) program has been to develop a technology that would significantly lmprove the utilization of the nntion's nuclear fuei resources employing the well-established water reactor technology. To achieve this objective, work has been directed toward analysis, design, component tests, and fabrication of a water-cooled, thorium oxide fucl cycle breeder reactor for installation and operation at the Shippingport Station. The LWBR core started operation in the Shippingport Station in the Fall of 1977 and is expected to be operated for about 3 to 4 years. At the end of this period, the core will be removed and the spent fuel shipped to the Naval Reactors Expended Core Facility for a detailed examination to verify core performance including an evaluation of breeding characteristics.

In 1976, with fabrication of the Shippingport IWBR core nearing completion, the Energy Research and Development Administration established the Advanced Water Breeder Applications (AWBA) program to develop and disseminate technical information which wmlld assist U. S. industry in evaluating the LWBK concept for curmercial-3calc applications. The program will explore some of the proulems that would be faced by industry in adapting technology confirmed in the IWBR program. Information to be developed includes concepts for commercial-scale prebreeder cores which would produce uranium-233 for light water breeder cores while producing electric power, improvements for breeder cores based on the technology developed to fabricate and operate the Shippingport LWBR core, and other Information and tcchnology to aid in evaluating commercial-scale application of the LWBR concept.

All three development programs (Pressurized Water Reactor, Light Water Breeder Rcactor, and Advanced Water Breeder Applications) have been administered by the Division of Naval Reactors with the goal of developlng practical improveriunts in the utilization of nuclear fuel resources for generation of electrical energy using water-cooled nuclear reactors.

Technical information developed under the Shippingport, LWBR, and AWBA programs has been and will continue to be published in technical memoranda, one of which is this present report. 


\section{ABSTRACT}

A survey is made of integral experiments useful for testing thorium and U233 nuclear data in thermal reactor applications: Emphasis is on homcgeneous $\mathrm{U} 233-\mathrm{IH}_{2} \mathrm{O}$ criticals and simple, water-moderated U233-thorium and U235-thoriurs lattice experiments. Thorium-U233-graphite experiments are also discussed briefly. Although the available experiments provide a fairiy conisistent test of important nuclear data, their accuracy and scope leave much to be desired. In detailed. Monte Carlo analjses, ENDF/B-IV data are found to perform reasonably well. Adequate (though partly fortuitous) agreement is found with integral measurements of thorium rescnance capture in lattices. A new, harder fission spectrum for U233 can correct, the principal discrepancy observed with ENDF/B-IV, a bias trend in $\mathrm{K}_{\mathrm{eff}}$ attributed to an underprediction of leakage. 
I. Introduction

II. Homogeneous Aqueous U233 Critical Experiments

A. Survey of Experiments

B. Results of Analysis of Homogeneous U233 Critical Experiments

1. Calculational Methods

2. Criticality Versus Hydrogen/Uranium Ratio

3. Sensitivities of Calculated Eigenvalues to Nuclear Data

4. Fission Spectra

5. Thermal Criticality Parameter Constraint

6. Summary of Results for Homogeneous Criticals

III. Thorium U233 and Thorium U235 Lattice Experiments $\left(\mathrm{H}_{2} \mathrm{O}\right.$ and $\mathrm{D}_{2} \mathrm{O}$ Moderated)

A. Survey of Experiments

B. Resu1ts of Analysis of Th-U233 and Th-U235 Lattice

Integral Experiments

1. Resonance Integrals for Thorium Capture

2. TUPE Lattices (Th-U235- $\mathrm{H}_{2} \mathrm{O}$ )

3. THUD Lattices $\left(T h-U 235-D_{2} 0\right)$

4. BNL Exponential Lattices (Th-U233- $\mathrm{H}_{2} \mathrm{O}$ and $\mathrm{D}_{2} \mathrm{O}$ )

5. ETA-I and ETA-II Lattices (Th-U235-D 20 and Th-U2 33-D 2 )

6. LWBR Criticals (Th-U233- $\mathrm{H}_{2} \mathrm{O}$ )

7. Consistency of Calculated Results for Uranium-Thorium Lattices 
IV. U233-Thorium Graphite Moderated Experiments

Page

A. High Temperature Lattice Test Reactor Experiments 96

B. HTGR Critical Experiments

V. Summary

116

REFERENCES

118 
1 - Summary of Homogeneous U233 Critical Experiments of Potential Use for Data Testing

2 - Results for Homogeneous U233 Critical Experiments Calculated with ENDF/B-IV Data

3 - Results for Homogeneous U235 Critical Experiments Calculated with ENDF/B-IV Data

4 - Results of Studies Using Eqn: 1,

5 - Sensilivities of Eigenvalues to Uranium Capture and Fission Resonance Integrals

6 - Uranium Resonance Capture and Fission Integrals

7 - Sensitivities of U233 Critical Assemblies to Changes in Nuclear Data

8 - Sensitivities of U235 Critical Assemblies to Changes in Nuclear Data

9 - Flux Age to $1.47 \mathrm{eV}$ in $\mathrm{H}_{2} \mathrm{O}$ (U235 Fission Source)

10 - Fission Spectrum Averaged Cross Sections

1 I - Thermal Criticality Parameter Constraint K2 Derived from the Gwin-Magnus on Criticals

12 - Summary of Th-U233 and Th-U235 Exponential and Critical Experiments of Potent1a? Use for Data Testing

13 - Calculated Criticality of TUPE Lattices (Full Core RCPO1)

14 - Comparison of $K_{\text {eff }}$ from MUFT7 and PTMG with the Full-Core RCPOI Results

15 - Comparison of ENDF/B-IV Calculated Eigenvalues for TUPE Lattices

16 - Comparison of Calculated and Measured Values of $\rho^{02}$ for TURE Cores 


\section{List of Tables (Cont'd)}

17 - Calculated Criticality of THUD Lattices (Full Core RCPOI)

18 - Calculated Values of $\mathrm{K}_{\text {ef }}$ for the BNL U233-Th232- $\mathrm{H}_{2} \mathrm{O}$ Exponential Experiments

19 - Comparison of Several Methods for Computing $\mathrm{K}_{\mathrm{eff}}$ for the BNL U233-Th232- $\mathrm{H}_{2} \mathrm{O}$ Exponential Experiments

20 - Comparison of Several Methods for Compliting $k_{\text {eff }}$ for the BNS U233-Th232- $D_{2} O$ Exponentia? Experiments

21 - Comparison of Calculated and Measured Values of $\rho^{Y \prime}$ for the Unpoisoned $\mathrm{BNL}$ U233-Th232- $\mathrm{H}_{2} \mathrm{O}$ Lattices

22 - Comparison of Calculated aria Measured Values of $0^{02}$ for the BII U233-Th232-D 0 Lattices

23 - Comparison of Measured and Calculated Integral Parameters for ETh-I (U235-Th- $\mathrm{D}_{2}$ O)

24 - Comparison of Measured and Calculated Integral Parameters fOr ET $A$ II ( U233-Th- $D_{2}$ O)

25 - Eigenvalues of LWBIR Criticals Calculated with RCPOI and ENDF/B-IV Data.

26 - Properies of the HTLTR U233-ThO 2 Lattices

27 - Experimental and Calculated Values of $\mathrm{K}_{\infty}$ for HWTR Lattice \#2 99

28 - Experimental and Calculated values of $\mathrm{K}_{\infty}$ for FTTR Iattice \#3 100

29 - Experimental and calculäted Values of $K_{\infty}$ for HTIT Lattire \#5 1.02 (MSRR)

30 - Comparison of Thorium Data Sets used in HTLTR Analyses

31 - Calculated Values of the 'lemperature Curficient Blat

Parameter $B$ for the HTLTR Lattices

32 - Comparison of Calculated and Measured v233 Reactivity Worths in HTGR Lattices 
List of Tables (Cont'd)

Page

33 - U233 Cross Section Data used in RTGR Analyses

?211

34 - Summary of U233 Reactivity Worth Perturbations in HTGR

113

35 - Comparison of Calculated and Measured Thorium Reactivity

$114-115$ Worths in HTGR Lattices 


\section{List of Figiares}

Fig. No.

1

2

3

4

5

6

7

20

11

12

13
Title

Page

Calculated Eigenvalue Versus Total Leakage Fraction for Homogeneous U233 Criticals

Calculated Elgenvalue Versus Total Leakage Fraction for

20 Homogeneous U235 Criticals

Eigenvalues of' Gwin-Magnuson U233 Criticals as a Function

22 of Epithermal/Thermal U233 Fission Ratio

Calculs ied Eigenvalue Versus Total Leakage Fraction for Homogeneous U233 Criticals. Obtained with the Standard Fission Spectrum Model

Effects of Alternative Fission Spectra on Elgenvalues of Ue35 Criticals

Thermal Criticality Parameter K2 Versus FP, Calculated with ENDF/B-IV and with Augmented Leakage fo: U233 Criticals

Calculated $K_{\text {ef }} \geq$ Versus Moderator/Fuel Volume Ratio for TUPE Lattices

Comparison of Keff Values for TUPE Lattices Obtained by Different Methocs

Comparison of Eigenvalues Based on EIDF/B-IV for the BNL Le33- $\mathrm{ThO}_{2}-\mathrm{H}_{2} \mathrm{O}$ Lattices

33

34

40

34

57

69

72 B.VL IV33 $\mathrm{ThO}_{2}-\mathrm{H}_{2} \mathrm{O}$ Lattices. ENDF/B-TV Data Were Used Throuighout

Calculatco $k$ eff (Method 1) vs. $M / F$ Volume Katio : or the BNL 2233 ThO $0_{2}-D_{2} 0$ Lattices

RCPOl Planar Representation of a Symmetric One-Third of the LWBR BMing lattice

85

RCPOI Nxial Fepresertetion of the LWPR BRIBI Lattice

86 (schematic) 
List of Figures (Cont'd)

Fig. No.

Titie

Page

14

Planar View of the LWBR Detailed Cell Lattice

Axial Arrangement of the LWBR Detalled Cell Showing Fuel Zoning

$K_{\text {eff }}$ Versus Neutron Leakage Fraction for 1233 Systems

Keff Versus Neutron Leakage Fraction for U233 Systems, obtained with the Standard fission spectrum model 
Integral Testing of Thorium and U233 Data for Thermal Reactors*

$$
\begin{aligned}
& \text { J. Hardy, Jr. } \\
& \text { J. J. "Ulio } \\
& \text { N. M. Steen }
\end{aligned}
$$

\section{Introduction}

This paper surveys Ue33 and thorium critical experiments of potential use as thermal reactor sata-testing benchmarks. Two major questions are a.jaressed: (1) To what extent do avallable integral experiments provide a consistent and adequately detailed test of the differential data?

How well do current differential data predict the results of these experiments?

We have selected a number of integral experiments which appear to be useful. for data testing. Where analyses have been reported with recent data sets (such $a \equiv E I D F / B-I V$ ), the results are summarized. In addition, we have done some exploratory studies intended to identify promising integral experiments.

The experiments are separated into two main categories: homogeneous U233 criticals and U233-Th (and U235-Th) lattice experiments. Lattice criticals are supplemented by the $\mathrm{BNL}$ U233- $\mathrm{ThO}_{2}$ exponentials and by experiments to measure effective resonance integrals of thorium and $\mathrm{ThO}_{2}$ rods. In addition, references to a number of other experiments are listed, some of which may turn out to be useful.

* This work was done as part of the program to qualify Monte Carlo methods and nuclear data sets for Advanced Water Breeder Application (AWBA) studies and Light Water Breeder Reactor (LWBR) core-follow analyses. 
For the purpose of testing nuclear data, integral experiments must be clearly interpretable and should embody selected configurations of interest (materials, resonance shielding conditions, flux spectra, etc.). Aside from $\mathrm{K}_{\mathrm{eff}}$, it is desirable that spectrum-sensitive integral parameters (reaction rate ratios) be measured in lattice experiments because these provide much more specific tests of important cross sectlons. Experiments should be carefully performed, with attention to systematic errors and determination of material compositions, and they should be thoroughly documented.

Homogeneous criticals can provide useful information about fissile materials - from calculated $\mathrm{K}_{\text {eff }}$ versus composition, hydrogen/uranium ratio and leakage, for example. The next step--introduction of a fertile material and spatial resonance shielding--is best obtained with simple, uniform critical lattices. Such experiments have seldom been performed, due to limitations of time, materials, and money. Of necessity, recourse has been had to exponential lattice experiments, critical sub-lattices with drivers, and single-rod shielded resonance integral experiments, all of which can provide useful information. Unfortunately, these have nearly always been more difficult to interpret than simple criticals. Useful information about the adequacy of nuclear data sets can be obtained from the complex mock-up experiments provided that they can be accurately modeled. Even then, interpretation of such experiments in terms of specific nuclear data inadequacies is rendered difficult by their complexity. 
II. Homogeneous Aqueous Ue33 Critical Experiments

A large number of W233-fueled, aqueous homogeneous experiments have been carried out to determine the critical parameters for a variety of configurations, densities, poisons, and reflectors. Many of the configurations, which were studied for criticality-safety purposes, are not particularly useful for testing nuclear data for $\mathrm{U} 233$ and $\mathrm{H}_{2} \mathrm{O}$. This section is limited to consideration of those experiments which bear most directly on the question of nuclear data. A compilation of such critical experiments, ordered by increasing $\mathrm{H} / \mathrm{U} 233$ atom density ratio, is shown in Table 1 of Section A. Salient critical parameters and reflector characteristics are provided, as well as notes on possible errors in the measurements. Section B sumarizes recent analyses of selected homogeneous U233 criticals with ENDF/B-IV data. Results for U235 criticals are also shown for comparison.

\section{A.. Survey of Experiments}

(1) In support of fuel processing plant nuclear safety, a large number of critical experiments in simple geometry were performed at Oak Ridge in the mid1950's (Ref. 1). These consisted of aqueous uranyl nitrate or uranyl fluoride solutions enriched to $98.7 \%$ U233. Except for two unreflected assemblies, the cylindrical or spherical aluminum vessels in these experiments had effectively infinite hydrogeneous reflectors of water or of paraffin. Properties of these critical experiments. are shown in Table 1 . Only unreflected and $\mathrm{H}_{2}$-reflected systems are included, since it is judged that a paraffin reflector unduly complicates Interpretation of a system for basic data testing purposes. 
In some cases, due to limitations of vessel size and solution inventory, the critical condition was determined by extrapolation of source-neutron miltiplication curves. In Table 1, the critical parameters deduced by this procedure are enclosed in parentheses and include an error which is dependent on the length of the extrapolation.

These experiments are easily analyzable with Monte Carlo techniques: However, the critical parameters are subject to the ucusl arrors in urantium analysis, solution densities, and in the calibration of vessel capacilite. Each of these effects was estimated to be $\pm 0.5 \%$. In addition, for some of the experiments using uranyl fluoride there was a bias resulting from the use of a corrosion-inhibiting coating which consisted of 30 w/o chlorine. An approximately $2 \%$ increase in the critical mass due to absorption of neutrons by the chlorine was later deduced through an auxiliary experiment. Those experiments for which this bias possibly exists are noted in. Table 1, but this does not significantly affect calculated $\mathrm{K}_{\text {eff }}$.

(2) In other early work at ORNL (Ref. 2), critical experiments using U233 and U235 were performed in identical geometry to compare $\bar{n}(U 233)$, the number of fission neutrons produced per thermal neutron absorbed in UR33, with the better-known $\bar{n}(\mathrm{U} 235)$.

Aqueous solutions of uranyl oxyfluoride containing uranium enriched to 98.7\% and 90\%, for U233 and U235 respectively, were made critical in waterreflected spherical containers having nominal diameters of 26.4 and $32.0 \mathrm{~cm}$. Solution temperatures ranged from $20^{\circ} \mathrm{C}$ to $100^{\circ} \mathrm{C}$. The specific critical parameters for the U233 solutions appear in Table 1. 
The aluminum vessels were $1.27 \mathrm{~mm}$-thick and can be easily included in any calculation. The volumes of the critical solutions were determined to the nearest $5 \mathrm{~cm}^{3}$, which implies that the critical radii can be determined to within $0.01 \mathrm{~cm}$. Chemical analyses of the solutions were-reliable to within $\pm 0.5 \%$, and temperatures were maintained to within $\pm 0.5^{\circ} \mathrm{C}$. For the larger sphere, it was stated that a systematic error existed which caused the critical masses and concentrations to be $2 \%$ high.

(3) In Ref. 3, further investigations of the criticality of U-233 solutions in simple geometries were reported. For one series of experiments, the criticality of water-reflected and unreflected spherical and cylindrical assemblies was determined. Again the solutions were uranyl nitrate containing 97.45\% U233. These experiments (which are included in Table 1) have H/ U233 ratios ranging from 73.0 to 581 , which implies high neutron leakage fractions. For a given H/U-233 ratio, very often the critical dimensions of a sphere and several cylindrical volumes were given, along with information on the solution vessels. Aluminum cylinders had a $1.5 \mathrm{~mm}$-thick wall and a $1.27 \mathrm{~cm}$-thick base. Spheres were also of aluminum with a $1.22 \mathrm{~mm}$-thick wall. For the unreflected cylinders, correctiono have been made for the aluminum base, so that the results describe cylindrical volumes having aluminum on the lateral surface only. For the water-reflected assemblies, there was no top reflector. Since no corrections have been made for the base plate, it would have to be accounted for in analyses of these assemblies. Despite the complications, these experiments are suitable for Monte Carlo analysis, and they can also be analyzed (as one-dimensional systems) by deterministic transport theory. 
(4). In a program designed to establish the thermal-energy value of eta for U233 and U235, a series of experiments were performed by Gwin and Magnuson (Ref. 4) to establish the critical conditions of unreflected homogeneous aqueous uranyl nitrate solutions of U233 and U235. In addition to the critical dimensions of. cylinders and spheres, spatial neutron flux distributions were measured to define the buckling of these systems; the kinetic behavior was investigated to determine experimentảl nọnleakage probabilicles and neutrui age in these solutions; and epithermal neutron energy distributions were measured with bare and cadmium covered fisston foils to determine integral corrections for eplthermal fissions and absorptions.

Analyses of the $\mathrm{U} 2,33-\mathrm{H}_{2} \mathrm{O}$ critical experiments and detailed consideration of systematic corrections have been reported in Refs. 5 and 6, and recent r.alcillations employing ENDF/B-IV nuclear data and Monte Carlo methods have been reported in Refs. 7 and. 8 . Some results of the latter calcularions appear. latei: in this paper.

In the cylinders, solution heights were adjusted to achieve criticality. These critical heights included a U.b3-1n. correction for the effecLs of the stainless steel baseplate of the 5-ft. diameter cylinder. In Kef. 6, the room return correction to the measured $\mathrm{K}_{\mathrm{eff}}$ was estimated to be $14 \times 10^{-4}$, approximately twice that obtained in Ref. 5. For the spherical assemblies, $\mathrm{K}_{\mathrm{eff}}$ was determined from small positive periods. Hence, a correction for delayed neutrons was necessary to obtain the fundamental mode eigenvalue. (This correction is discussed in Ref. 5.) The reactivity worths of the aluminum containers for the 27.24-in. diameter and 48.04-in. diameter spheres were estimated experimentally 
to be approximately $7 \times 10^{-4}$. The solution fill and drain tubes at the top and bottom of the spheres had measured worths of $0.7 \times 10^{-4}$ and $0.2 \times 10^{-4}$ for the 27.24-in. and 48.04-in.-diameter spheres, respectively. For the 5-foot-diameter cylinders, the worth of the solution fill tube was not estimated experimental1y, but was considered to be $<0.1 \times 10^{-4}$. Because of the smallness of the various corrections, these assemblies are easily analyzable by one-dimensional transport theory and by three-dimensional Monte Carlo techniques. 


\section{Summary of Homogeneous U233 Critical Experiments of Potential Use for Data Testing}

Moderator/Fissile
Atorn Ratio
Geometry
Critical
Dimensions
Refiector
Critical Mass

Reference

Notes and Comments

I.D.*

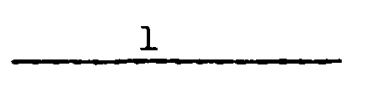

73.0

Cylinder

$\mathrm{H}=13.36 \mathrm{~cm}$

$R=25.4 \mathrm{~cm}$

None

$8.8 \mathrm{~kg}$ of $\mathrm{Le} 33$ 3

Aluminum cylinder had a

$1.5 \mathrm{~mm}$-thick wall and 1.27

$\mathrm{cm}$-thick bottom.

Results were

corrected for

the $1.27 \mathrm{cn}$ -

thick base.

$\frac{2}{122}$
Cjlinder
$\mathrm{H}=13.51,15.14,24.65$
$\mathrm{~F}=24.80,19.05,12.15$
None
$5.59,3.52,2.53 \mathrm{~kg}$
$C=\mathrm{U} 233$

\section{3}

See note for No. 1

L1

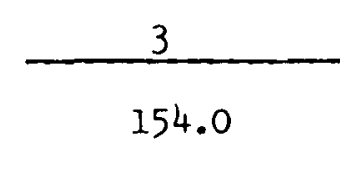

Cylinder

$\mathrm{H}=24.0+0.05 \mathrm{~cm}$ $\mathrm{R}=12.75^{-} \mathrm{cm}$

\section{None}

$2.02+0.05 \mathrm{~kg}$ of $12 \overline{3} 3$

1

No reported aluminum vessel correction to the data.

L2

$\begin{array}{cc}\frac{4}{194} & \frac{5}{194} \\ \text { Cylinders } & \text { Sphere }\end{array}$

$\mathrm{H}=13.42,17.22,22.86 \mathrm{~cm} \quad \mathrm{R}=11.17 \mathrm{~cm}$ $R=19.05,12.15,10.15 \mathrm{~cm}$

Water

Water

$1.726,1.112,0.952 \mathrm{~kg}$ of U233

$0.749 \mathrm{~kg}$ of U233

3

3

Aluminum cylinders had $1.5 \mathrm{~mm}$-thick wall and 1.2 ? $\mathrm{cm}$-thick bcttom. Results were not corrected far bottom plate. There was no reflector on top of any cylinder.

\section{Spheres}

was of aluminum with a $1.22 \mathrm{~mm}$ thickness.

*I.D. is that used in Ref. 4 and Ref. 8. 
Table I (Cont' $a$ )

Moderator/Fissile Atom Ratic

\section{Geometry}

Critical

Dimensions

Reflector

Critical Mass

Reference

Notes and Comments

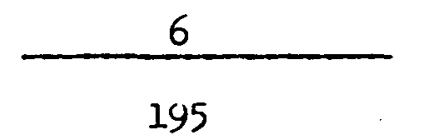

Cylinders

$\mathrm{H}=14.07,16.35,28.52$ $R=25.4,19.05,12.15$

None

$3.545,2 \cdot 378,1.832$ $\mathrm{kg}$ of U233

3

See note for No. I

$\frac{7}{195}$
Sphere
R=14.579 cm
None
$\begin{aligned} & 1.657 \mathrm{~kg} \\ & \text { of U233 }\end{aligned}$

See note for No. 5

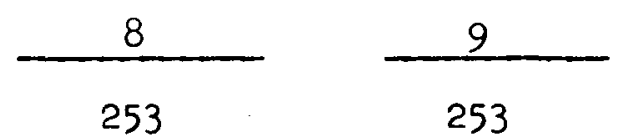

Sphere

\section{Cylinders}

$\mathrm{H}=17.60,33.40$ $R=19.05,12.65$.

\section{None}

$1.998,1.666$

$\mathrm{kg}$ of U233

3

See note for No. 1

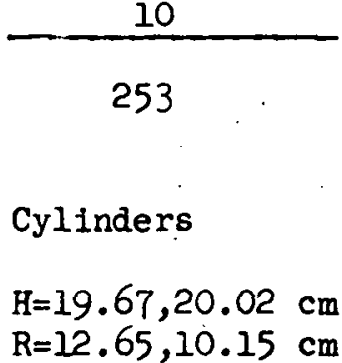

Water

$1.111,0.951 \mathrm{~kg}$ of U233

3

See note for No. It

I.D.

\author{
(Continued)
}


Table 1 (Cont'd)

\begin{tabular}{|c|c|c|c|c|c|c|}
\hline & 11 & 12 & 13 & 14 & 15 & 16 \\
\hline $\begin{array}{l}\text { Moderator/Fissile } \\
\text { Atom Ratio }\end{array}$ & 273 & 349 & 349 & 378 & 381 & 390 \\
\hline Geometry & Sphere & Cylinders & Sptere & Sphere & Sphere & Sphere \\
\hline $\begin{array}{l}\text { Critical } \\
\text { Dimensions }\end{array}$ & $\mathrm{R}=11.84 ? \mathrm{~cm}$ & $\begin{array}{l}\mathrm{H}=19.35,43.69 \mathrm{~cm} \\
\mathrm{R}=19.05,12.65 \mathrm{~cm}\end{array}$ & $\mathrm{R}=15.821 \mathrm{~cm}$ & $\mathrm{R}=13.25 \mathrm{~cm}$ & $\mathrm{R}=15.95 \mathrm{~cm}$ & $R=13.240 \mathrm{~cm}$ \\
\hline Reflector & Water & None & Yone & Water & None & Water \\
\hline Critical Mass & $\begin{array}{l}0.645 \mathrm{~kg} \\
\text { of ve33 }\end{array}$ & $\begin{array}{l}1.608,1.598 \mathrm{~kg} \\
0=\mathrm{UE} 33\end{array}$ & $\begin{array}{l}1.208 \mathrm{~kg} \\
\text { of } \mathrm{U} 233\end{array}$ & $\begin{array}{l}0.638 \mathrm{~kg} \\
\text { of } \mathrm{U} 233\end{array}$ & $\begin{array}{l}1.14 \mathrm{~kg} \\
\text { of } \mathrm{v233}\end{array}$ & $\begin{array}{l}0.623 \mathrm{~kg} \\
\text { of } \mathrm{U} 233\end{array}$ \\
\hline Reference & 3 & 3 & 3 & 2 & 1 & 2 \\
\hline $\begin{array}{l}\text { Notes and } \\
\text { Comments }\end{array}$ & $\begin{array}{l}\text { See note } \\
\text { for No. } 5\end{array}$ & $\begin{array}{l}\text { See note for } \\
\text { No. I }\end{array}$ & $\begin{array}{l}\text { See note } \\
\text { for No. } 5\end{array}$ & $\begin{array}{l}\text { Aluminum } \\
\text { vessel } \\
\text { was } 1.27 \\
\text { mm-thick. } \\
\text { Critical } \\
\text { volume was } \\
9.737 \\
\text { liters at } \\
96.5^{\circ} \mathrm{C} \text {. }\end{array}$ & $\begin{array}{l}\text { See note } \\
\text { for No. } 3 \text {. } \\
\text { There was } \\
40-\mathrm{cm}^{3} \text { void } \\
\text { above the } \\
\text { critical } \\
\text { solution. }\end{array}$ & $\begin{array}{l}\text { Aluminum } \\
\text { vessel was } \\
1.27 \mathrm{~mm}- \\
\text { thick. } \\
\text { Critical } \\
\text { volume was } \\
9.723 \text { at } \\
83.2^{8} \mathrm{C} \text {. }\end{array}$ \\
\hline I.D. & & & & & L3 & \\
\hline
\end{tabular}


Table 1 (Cont'd)

\begin{tabular}{|c|c|c|c|c|c|c|c|}
\hline & 17 & 18 & 19 & 20 & 21 & 22 & 23 \\
\hline $\begin{array}{l}\text { Moderator/Fissile } \\
\text { Atom Ratio }\end{array}$ & 390 & 400.5 & 405 & 414.6 & 418.3 & 419 & 426 \\
\hline Geometry & Sphere & Sphere & Sphere & Spbere & Sphere & Sphere & Sphere':": \\
\hline $\begin{array}{l}\text { Critical } \\
\text { Dimensions }\end{array}$ & $\mathrm{R}=13.3 \mathrm{~cm}$ & $\mathrm{R}=13.23 \mathrm{~cm}$ & $\mathrm{R}=13.3 \mathrm{~cm}$ & $\mathrm{R}=13.22 \mathrm{~cm}$ & $\mathrm{R}=13.21 \mathrm{~cm}$ & $\mathrm{R}=13.3 \mathrm{~cm}$ & $R=13.3 \mathrm{~cm}$ \\
\hline Reflector & Water & Water & Water & Water & Water & Water & Water : \\
\hline Critical Mass & $\begin{array}{l}0.61 \mathrm{~kg} \\
\text { of } \mathrm{ve33}\end{array}$ & $\begin{array}{l}0.611 \mathrm{~kg} \\
\text { of } \mathrm{ve} 33\end{array}$ & $\begin{array}{l}0.60 \mathrm{~kg} \\
\text { of } \mathrm{v} 33\end{array}$ & $\begin{array}{l}0.596 \mathrm{~kg} \\
\text { of } \mathrm{l} 233\end{array}$ & $\begin{array}{l}0.591 \mathrm{~kg} \\
\text { of } \mathrm{U} 233\end{array}$ & $\begin{array}{l}0.59 \mathrm{~kg} \\
\text { of } \mathrm{U233}\end{array}$ & $\begin{array}{l}0.59 \pm \\
0.06 \mathrm{~kg} \\
\text { of U233 }\end{array}$ \\
\hline Reference & 1 & 2 & 1 & 2 & 2 & 1 & 1 \\
\hline $\begin{array}{l}\text { Notes and } \\
\text { Comments }\end{array}$ & $\begin{array}{l}\text { See note } \\
\text { for No. } 3 \text {. } \\
\text { There was } \\
380 \mathrm{~cm}^{3} \\
\text { void above } \\
\text { the crit- } \\
\text { lcal soiu- } \\
\text { tion. }\end{array}$ & $\begin{array}{l}\text { Aluminum } \\
\text { vessel was } \\
1.27 \mathrm{mn} \\
\text { thick. } \\
\text { Critical } \\
\text { volume was } \\
9.704{ }^{\circ} \\
\text { at } 65.5^{\circ} \mathrm{C} .\end{array}$ & $\begin{array}{l}\text { See note } \\
\text { for No. } 3 .\end{array}$ & $\begin{array}{l}\text { Aluminum } \\
\text { vessel was } \\
1.27 \text { m- } \\
\text { thick. } \\
\text { Critical } \\
\text { volume was } \\
9.675 \text { l at } \\
39.5 \mathrm{c} \text {. }\end{array}$ & $\begin{array}{l}\text { Aluminum } \\
\text { sphere } \\
\text { was } 1.27 \\
\text { mm-thick. } \\
\text { Critical } \\
\text { volume } \\
\text { was } 9.666 \\
\ell \text { at } 32.0 \\
\text { C. }\end{array}$ & $\begin{array}{l}\text { See note } \\
\text { for No. } 3 \text {. } \\
\text { There was } \\
\text { a } 40-\mathrm{cm}^{3} \\
\text { vold above } \\
\text { the crit- } \\
\text { ical solu- } \\
\text { tion pre- } \\
\text { sumably at } \\
\text { room } \\
\text { temperature. }\end{array}$ & $\begin{array}{l}\text { See note } \\
\text { for No. } 3 \text {. } \\
\end{array}$ \\
\hline
\end{tabular}

I.D.

(Continued) 
Table 1 (Cont' $\dot{\alpha}$ )

\begin{tabular}{|c|c|c|c|c|c|c|c|}
\hline & 24 & 25 & 26 & 27 & 28 & 29 & 30 \\
\hline $\begin{array}{l}\text { Moderator/Fissile } \\
\text { Atom Ratio }\end{array}$ & 514 & 522 & 548 & 548 & 581 & 581 & 602.8 \\
\hline Geometry & Cylinder & Cylinder & Cylinders & Sphere & Cylincier & Sphere & Sphere \\
\hline $\begin{array}{l}\text { Critical } \\
\text { Dimensions }\end{array}$ & $\begin{array}{l}H=25.5 \pm .1 \mathrm{~cm} \\
R=12.75 \mathrm{~cm}\end{array}$ & $\begin{array}{l}\mathrm{H}=25.9 \pm 0.1 \mathrm{~cm} \\
\mathrm{R}=12.75 \mathrm{~cm}\end{array}$ & $\begin{array}{l}\mathrm{H}=19.6,31.53 \mathrm{~cm} \\
\mathrm{~F}=19.05,12.65 \mathrm{~cm}\end{array}$ & $\mathrm{R}=14.579 \mathrm{~cm}$ & $\begin{array}{l}H=26.37 \mathrm{~cm} \\
\mathrm{R}=19.05 \mathrm{~cm}\end{array}$ & $\mathrm{R}=18.378 \mathrm{~cm}$ & $\mathrm{R}=15.97 \mathrm{~cm}$ \\
\hline Reflector & Water & Water & Nater & Water & None & None & Water \\
\hline Critical Mass & $\begin{array}{c}0.64 \pm 0.03 \\
\text { of } \pm 233\end{array}$ & $\begin{array}{l}0.65+0.5 \mathrm{~kg} \\
\text { of } \mathrm{U} 2 \frac{\mathrm{3}}{3} 3\end{array}$ & $\begin{array}{l}1.043,0.738 \mathrm{~kg} \\
\text { of } \mathrm{U} 233\end{array}$ & $\begin{array}{l}0.605 \mathrm{~kg} \\
\text { of } \mathrm{v233}\end{array}$ & $\begin{array}{l}1.306 \mathrm{~kg} \\
\text { of } \mathrm{U} 233\end{array}$ & $\begin{array}{l}1.130 \mathrm{~kg} \\
\text { of } 1233\end{array}$ & $\begin{array}{l}0.703 \mathrm{~kg} \\
\text { of } \mathrm{U} 233\end{array}$ \\
\hline Reference & 1 & 1 & 3 & 3 & 3 & 3 & 2 \\
\hline $\begin{array}{l}\text { Notes and } \\
\text { Comments }\end{array}$ & $\begin{array}{l}\text { See note } \\
\text { for No. } 3\end{array}$ & $\begin{array}{l}\text { See note for } \\
\text { No. } 3\end{array}$ & $\begin{array}{l}\text { See note zor } \\
\text { Vo. } \dot{ }+\end{array}$ & $\begin{array}{l}\text { See note } \\
\text { for No. } 5\end{array}$ & $\begin{array}{l}\text { See note } \\
\text { for No. } 1\end{array}$ & $\begin{array}{l}\text { See note } \\
\text { for No. } 5\end{array}$ & $\begin{array}{l}\text { Aluminum } \\
\text { vessel was } \\
1.27 \mathrm{~mm}-\text { thk. } \\
\text { Critical } \\
\text { volume was } \\
17.074 \text { l at } \\
99.5^{\circ} \mathrm{C} \text {. Con- } \\
\text { centrations } \\
\text { may be } 2 \% \\
\text { high due to } \\
\text { systematic } \\
\text { error. }\end{array}$ \\
\hline
\end{tabular}

(Continued) 
Table I (Cont'd)

Moderator/Fissile

\section{Atom Ratio}

\section{Geometry}

Critical

Dimensions

Reflector

Critical Mass

Reference

Notes and Comments

I.D.
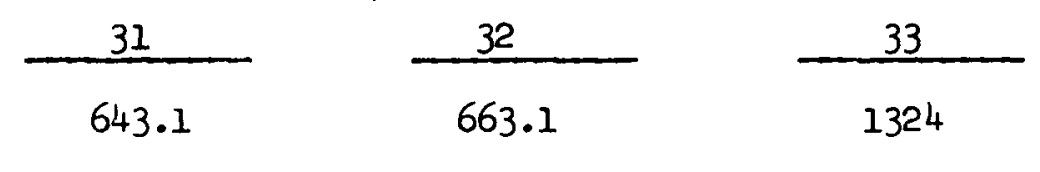

\section{Sphere}

$R=15.96 \mathrm{~cm}$

Water

$0.659 \mathrm{~kg}$ of U233

2

See note

for No. 30.

Critical

volume

was 17.020 i

at $26.3^{\circ} \mathrm{C}$.

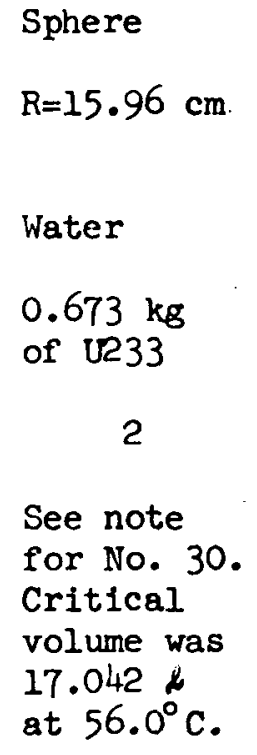

Sphere

Sphere

$\mathrm{R}=34.595 \mathrm{~cm}$

None

$3.358 \mathrm{~kg}$

of U233

4

Aluminum

sphere was

$0.33 \mathrm{~cm}-$

thick with

a measured

worth of

0.00072 .

$\frac{34}{1368}$
Sphere
$\mathrm{R}=34.595 \mathrm{~cm}$
None
$\begin{aligned} & 3.250 \mathrm{~kg} \text { of } \\ & \text { U233 }\end{aligned}$

4

See note

for No. 33 .

8

7
35

1417

Sphere

$\mathrm{R}=34.595 \mathrm{~cm}$

None

$3.212 \mathrm{~kg}$ of U233

4

See note

for No. 33 .

(Continued) 


\begin{tabular}{|c|c|c|c|c|c|c|c|}
\hline . & 36 & 37 & 38 & 39 & 40 & 41 & 42 \\
\hline $\begin{array}{l}\text { Moderator/Fissile } \\
\text { Atom Ratio }\end{array}$ & 1470 & 1533 & 1819 & 1900 & 1986 & 1996 & 2106 \\
\hline Geometry & Sphere & Sphere & Cylinder & Cylinder & Sphere & Cylinder & Cylinder \\
\hline $\begin{array}{l}\text { Critical } \\
\text { Dimensions }\end{array}$ & $\mathrm{R}=34.595 \mathrm{~cm}$ & $\mathrm{R}=34.595 \mathrm{~cm}$ & $\begin{array}{l}H=50.851 \mathrm{~cm} \\
\mathrm{R}=77.368 \mathrm{~cm}\end{array}$ & $\begin{array}{l}\mathrm{H}=60.579 \mathrm{~cm} \\
\mathrm{R}=77.368 \mathrm{~cm}\end{array}$ & $\mathrm{R}=61.01 \mathrm{C} 8 \mathrm{~cm}$ & $\begin{array}{l}\mathrm{H}=79.045 \mathrm{~cm} \\
\mathrm{R}=77.368 \mathrm{~cm}\end{array}$ & $\begin{array}{l}H=140.157 \mathrm{~cm} \\
R=77.368 \mathrm{~cm}\end{array}$ \\
\hline Reflectior & None & None & None & None & None & None & None \\
\hline Critical Mass & $\begin{array}{l}3.098 \mathrm{~kg} \\
\text { of } \mathrm{U} 233\end{array}$ & $\begin{array}{l}2.972 \mathrm{~kg} \\
\text { of } \mathrm{L} 233\end{array}$ & $\begin{array}{l}13.530 \mathrm{~kg} \\
\text { of } \mathrm{U} 233\end{array}$ & $\begin{array}{l}15.404 \mathrm{~kg} \\
\text { of } \mathrm{U} 233\end{array}$ & $\begin{array}{l}12.310 \mathrm{Hg} \\
\text { of } \mathrm{U} 233\end{array}$ & $\begin{array}{l}19.120 \mathrm{kB} \\
\text { of } \mathrm{U} 233\end{array}$ & $\begin{array}{l}32.128 \mathrm{~kg} \\
\text { of } \mathrm{U} 233\end{array}$ \\
\hline Reference & 4 & 4 & 4 & 4 & 4 & 4 & 4 \\
\hline Notes and Comments & $\begin{array}{l}\text { See note } \\
\text { for No. } \$ 3 .\end{array}$ & $\begin{array}{l}\text { See note } \\
\text { for No. } 33 \text {. }\end{array}$ & $\begin{array}{l}\text { Critical } \\
\text { height } \\
\text { includes } \\
\text { a carrec- } \\
\text { tion for } \\
\text { the } 1.346 \\
\text { cm-thick } \\
\text { aluminum } \\
\text { bottom } \\
\text { stricture. }\end{array}$ & $\begin{array}{l}\text { See note } \\
\text { for No. } 38 \text {. }\end{array}$ & $\begin{array}{l}\text { Aluminun } \\
\text { sphere was } \\
0.762 \text { cr- } \\
\text { thick w-th } \\
\text { an estinated } \\
\text { worth of } \\
0.00069 \text {. }\end{array}$ & $\begin{array}{l}\text { See note } \\
\text { for No. } 38 \text {. }\end{array}$ & $\begin{array}{l}\text { See note for } \\
\text { No. } 38 \text {. }\end{array}$ \\
\hline I.D. & 6 & 5 & 17 & 18 & 11 & 19 & 20 \\
\hline
\end{tabular}




\section{B. Results of Analys1s of Homogeneous U233 Critical Experiments}

In a study done at Oak Ridge (Ref. 7) to compare Hanson-Roach and ENDF/B-IV data sets, McNeany and Jenkins reported that ENDF/B-IV produced errors of several percent in calculated neutron multiplication factors for homogeneous U233 assemblies with low: hydrogen/uranium atom ratios $(\mathrm{H} / \mathrm{U})$. It was concluded that the ENDF/B-IV data file was not satisfactory for calculating criticality of such assemblies. Conley (Ref.9) had previously observed similar behavior with a somewhat different data set.

More recently, fourteen U233 criticals (including several of those considered in the Oak Ridge study) were analyzed at Bettis, and a set of seventeen U2 35 criticals was also analyzed for comparison (Ref. 6 ). The purpose was to examine in detail the ability of ENDF/B-IV data to predict criticality of such systems over a wide range of $\mathrm{H} / \mathrm{U}$, with the intent of drawing specific conclusions about the data set. These systems spanned a wide range of spectrum hardness (with as much as $50 \%$ epithermal fission) and of leakage (from 1\%-50\%). The critical eigenvalue and detailed reaction rates were calculated, and eigenvalue sensitivities to certain major data changes were determined.

\section{Calculational Methods}

For the calculations in Ref. 8, nuclear data were from ENDF/B-TV, multigroup processed with the ETOMX and ETWIX programs (Bettis versions of ETXG (Ref. 10) and ET $\phi T$ (Ref. 11), respectively). Thermal scattering kernels were generated with FLAN2 (a Bettis version of FLANGEII (Ref. 12)) from the ENDF/B $S(\alpha, \beta)$ files based on the Haywood kernel. 
The criticals were analyzed with the Monte Carlo program RCPOI' (Ref. 13) and with PTMG, an extension of P3MG (Ref. 14), a one-dimensional, multigroup $\mathrm{P}_{\ell}$ program. RCPOl was used for the overall study of criticality versus H/U ratio. Cross section sensitivities were derived from PTMG, which was also used for the analysis of the Gwin-Magnuson criticals to infer constraints on the $2200 \mathrm{~m} / \mathrm{s}$ parameters for U233 and U235. The agreement between RCPOI and PTMG was checked for five specific experiments and found to be very good.

\section{Criticality Versus Hydrogen/Uranium Ratio}

Eigenvalues for the U233 criticals (Table 2) show generally good agreement with the Oak Ridge calculations. This suggests that the use of different analysis programs and nuclear data processing procedures has little effect on the calculated results. For comparison, the 0235 results are shown in Table 3 . For both U233 and U235, the ENDF/B-IV-calculated eigenvalues become increasingly high relative to experiment as the $\mathrm{H} / \mathrm{U}$ ratio is decreased from well thermalized systeins.

Although there remain questions of interpretation about individual experiments, these are judged not to be significant for the overall pattern. Errors in calculated eigenvalue can stem from energy-dependent errors of eta which are emphasized as the spectrum hardens (for example, uranium capture and fission resonance integrals, and thermal capture and fission cross sections). The hydrogen thermal $\sigma_{A}$ affects the very thermalized assemblies, and $\bar{v}$ affects all assemblies equally. The other major source of eigenvalue error is underprediction of leakage, which is emphasized in the smaller cores (see Figures 1 and 2). The most significant factors which could affect leakage are considered to be: 
Table 2 - Results for Homogeneous U233 Critical Experiments Calculated with ENDF/B-IV Data

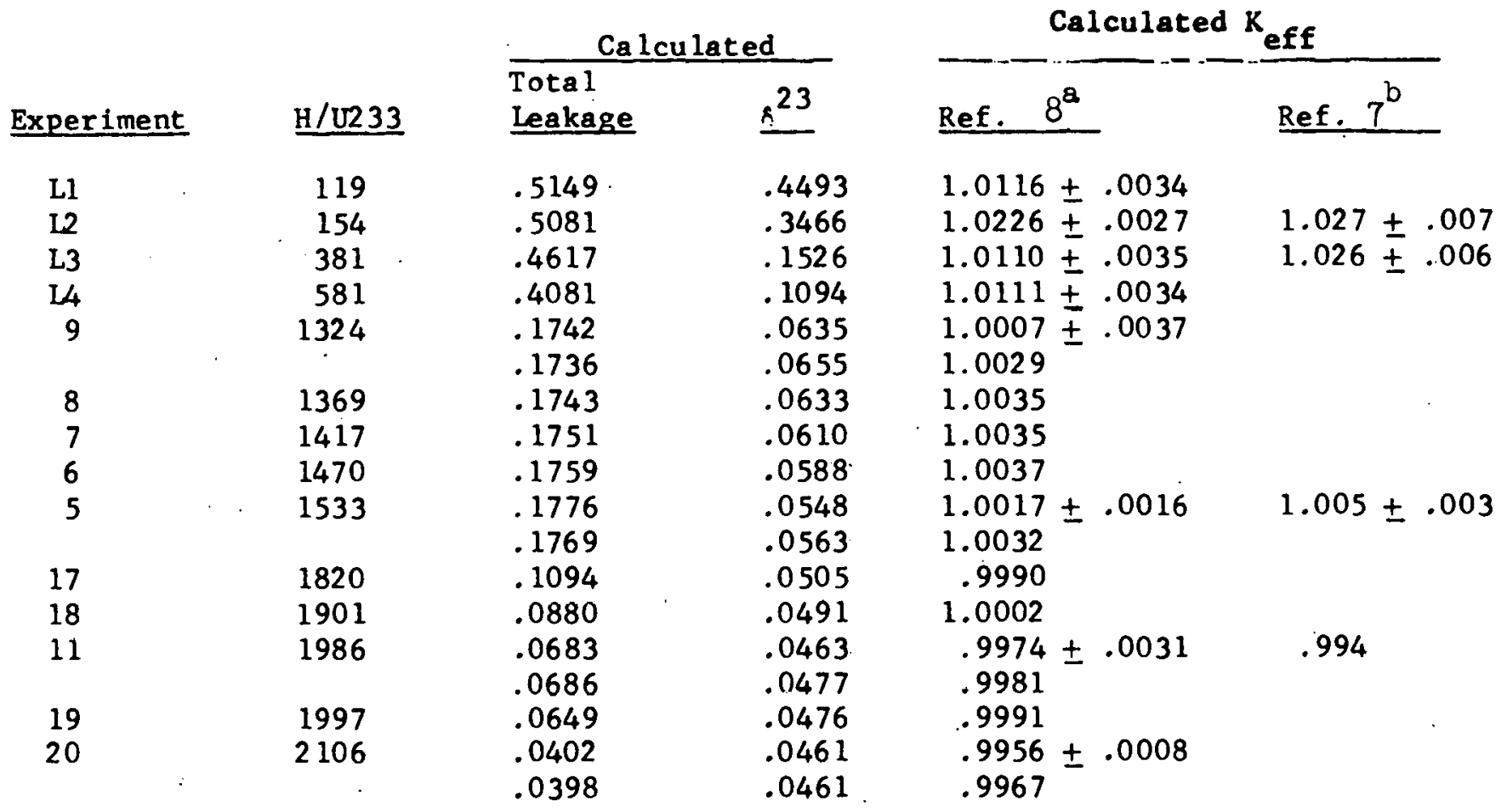

${ }^{a}$ Uncertainty is two standard deviations for RCP01 results. Eigenvalues without uncertainties are from PTMG.

${ }^{b}$ Uncertainty is one standard deviation.

$\delta^{23}$ is the ratio of epithermal/thermal UR33 fieEion. 
Table 3 - Results for Homogeneous U235 Critical Experiments Calculated with ENDF/B-IV Data

\begin{tabular}{|c|c|c|c|c|}
\hline \multirow[b]{2}{*}{ Experiment } & \multirow[b]{2}{*}{$\underline{H} / \mathrm{U} 235$} & \multicolumn{3}{|c|}{ Calculated Results (Ref. 8) } \\
\hline & & $\begin{array}{l}\text { Tota } 1 \\
\text { Leakage }\end{array}$ & 25 & $k_{\text {eff }}{ }^{a}$ \\
\hline L5 & 27.1 & .4380 & .8175 & $1.0085+.0036$ \\
\hline L6 & 44.3 & .4501 & .4722 & $1.0117 \pm .0030$ \\
\hline L7 & 76.1 & .4661 & .1962 & $1.0098 \pm .0051$ \\
\hline 4 & 972 & .1669 & .0306 & .9964 \\
\hline 3 & 1033 & .1678 & .0288 & .9949 \\
\hline t8 & 1112 & .2333 & .0251 & $1.0085 \pm .0037$ \\
\hline \multirow[t]{2}{*}{2} & 1177 & $\{.1678$ & .0255 & $1.0007 \pm .0035$ \\
\hline & & $\{.1699$ & .0252 & .9980 \\
\hline 1 & 1378 & .1729 & .0215 & .9983 \\
\hline L9 & 1393 & .1703 & .0214 & $1.0035 \pm .0035$ \\
\hline 12 & 1604 & .1197 & .0194 & .9985 \\
\hline 13 & 1634 & .1126 & .0192 & .9976 \\
\hline 14 & 1821 & .0679 & .0178 & .9980 \\
\hline \multirow[t]{2}{*}{10} & 1835 & $\{.0663$ & .0179 & $.9936 \pm .0031$ \\
\hline & & $\{.0670$ & .0177 & .9957 \\
\hline 15 & 1905 & .0475 & .0173 & .9980 \\
\hline 21 & 1955 & .0388 & .0170 & .9934 \\
\hline 16 & 1981 & .0329 & .0169 & $.9939+.0008$ \\
\hline 22 & 2004 & .0269 & .0167 & .9938 \\
\hline 23 & 2052 & $\{.0141$ & .0165 & $.9949 \pm .0003$ \\
\hline & & $\{.0134$ & .0165 & .9957 \\
\hline
\end{tabular}

ancertainty is two standard deviacions for RCF01 results. Eigenvalues without uncertainties are from PTMG. 


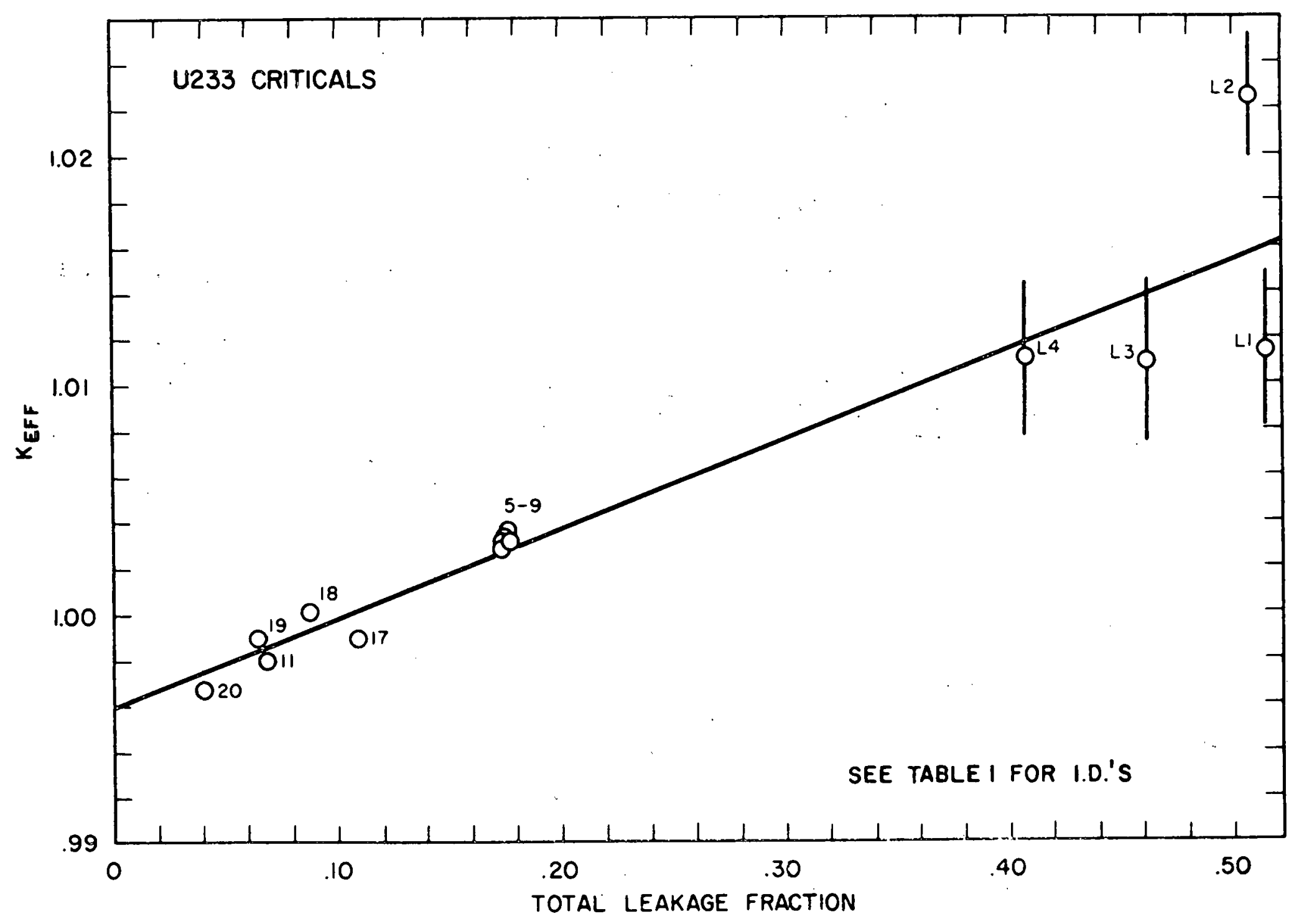

Calculated Eigenvalie Versus Total Leakage Fraction for Homogeneous U23. Criticals

FIGUES . 


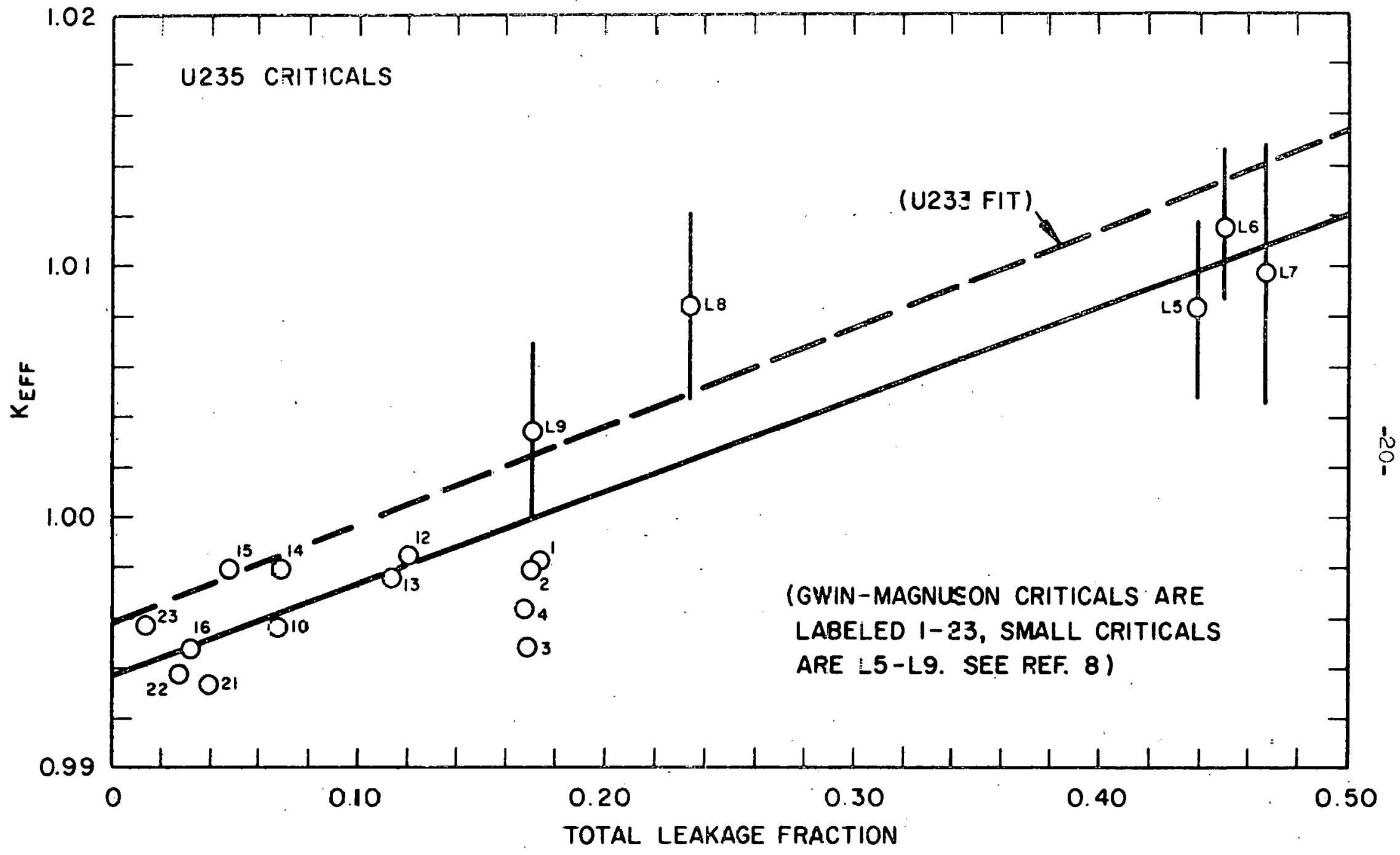

Calculated kigenvalue Versus Total Leakage Frastion

for Hornçerenus U235 Criticals

FIGURE 2 
(1) multigroup averaging and limited $\mathrm{P}_{\ell}$ treatment in RCPO1

(2) oxygen scattering cross section and angular pattern (MeV range)

(3) fission spectrum of U233 and of U235.

Since the trend in calculated eigenvalue error is nearly the same for U233 and for U235 systems, it is tempting to seek a common source of difficulty (e.g., Items (1) and (2) above), but this has not proved fruitful.

For U233 criticals, evidence on the separate effects of leakage and flux spectrum hardening is afforded by the boron-poisoned Gwin-Magnuson experiments. Figure 3 shows $\mathrm{K}_{\mathrm{eff}}$ for these systems plotted against $\delta^{23}$, the ratio of epithermalto-thermal U233 fissions. If the bias drift in.Figure 3 for the unpoisoned cores is attributed to the spectrum hardening which accompanies increased leakage, then additional hardening obtalned solely by boron poisoning should continue the trend, but this does not occur. Although the range of hardening is limited, this evidence suggests that the more likely source of difficulty is leakage itself.

It seems unlikely that the trend is due to energy-dependent errors of eta vithin the thermal range (which are emphasized as the flux spectrum hardens) since substantial errors would be required. Furthermore, calculational approximations (including data processing) are deemed to be relatively unimportant. This is supported by the good agreement obtained with the Oak Ridge Analysis (Ref. 7) and also by a comparison of RCP01-calculated leakage with results obtained by H. Henryson with the VIM Monte Carlo Program (Ref. 15.). RCPOI employed multigroup averaged scattering cross sections with a $P_{3}$ angular treatment. 


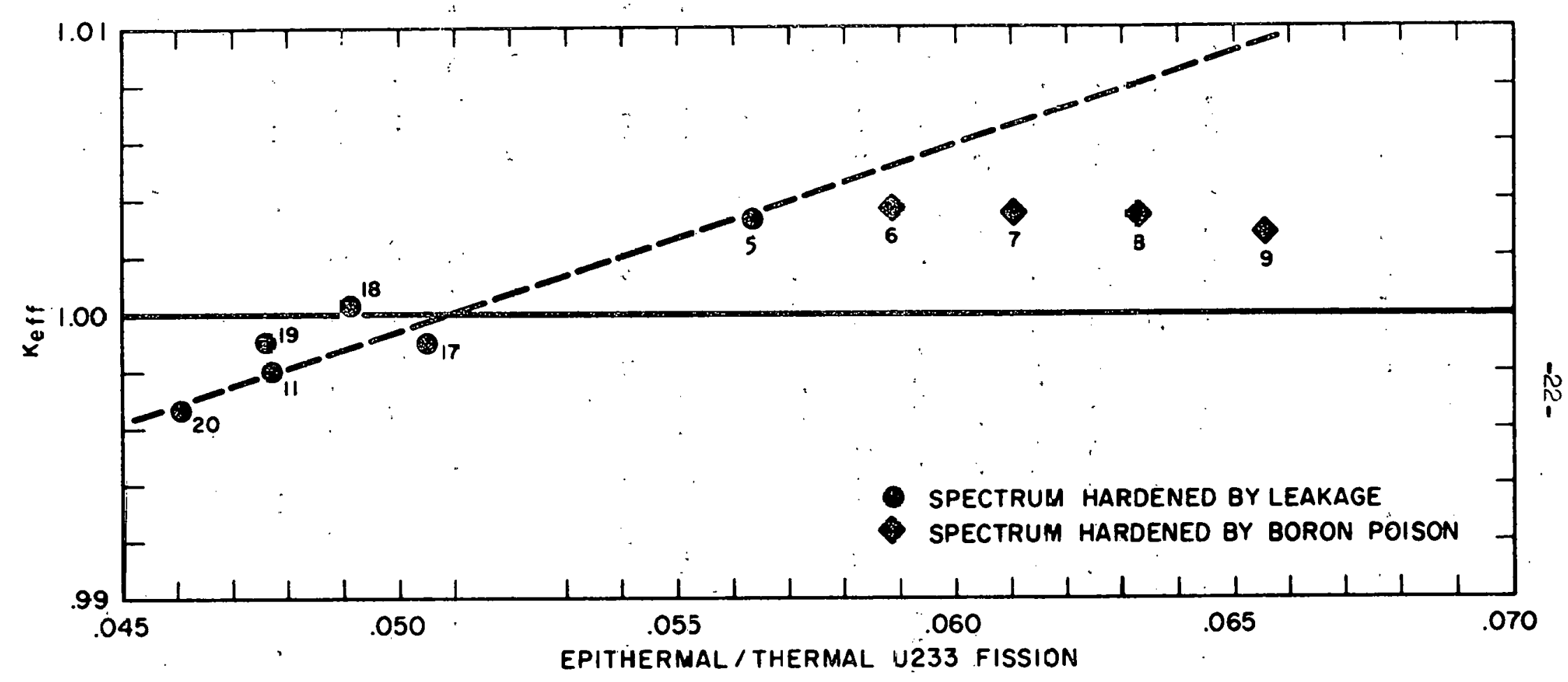

Eigenvalues of Gwin-Magnuson 2233 Criticals as a Function of Ept thermal/Thermal U233 Fission Ratio FIGURE 3 
VIM employed a strictly pointwise representation of the data and a detailed elastic scattering angular treatment (20 equal $\cos \theta$ intervals). The comparison, using ENDF/B-IV data, was made for a small cylinder of $\mathrm{U} 235-\mathrm{H}_{2} \mathrm{O}$ in vacuum, with a spatially flat fission source. Results for total leakage (10 MeV - $1.12 \mathrm{eV}$ ) were:

\begin{tabular}{rr} 
RCPO1: & $0.5285 \pm 0.0006$ \\
VIM: & $0.5267 \pm 0.0007$ \\
\hline RCP01-VIM: & $0.0018 \pm 0.0009$
\end{tabular}

Agreement is very good, allowing for statistics (one standard deviation), and if anything RCPOl slightly overestimates leakage relative to VIM.

The effect of a leakage underprediction on criticality can be characterized quantitatively in terms of an error in the age to thermal energies of fission neutrons by means of a simple linear relationship between $8 K_{\text {eff }}$ and $l_{n}\left(1-L_{F}\left(E_{c}\right)\right)$

$$
\delta K_{\text {eff }}=a+b \ln \left(1-L_{F}\left(E_{c}\right)\right),
$$

where $L_{F}\left(E_{c}\right)$ is the calculated neutron leakage to energy $E_{c}$ and $b=$ $\frac{8 L^{2}\left(E_{c}\right)}{L^{2}\left(E_{c}\right)}$ is the relative error in the square of the slowing down length (age) to energy $\mathrm{E}_{c}$. The constant a is included since it is possible that all the calculated results could deviate from unity by a practically constant value due to error in the assumed number of neutrons produced per fission. 
With the calculated leakage fractions to cutoff energies of $E_{c}=5.53 \mathrm{keV}$ $\left(L_{F 1}\right)$ and $E_{c}=0.625 \mathrm{eV}\left(L_{F 2}\right)$, weighted least-squares analyses have been made using Eqn. 1 (Ref. 8). The results for the fitted constants $a$ and $b$ are summarized in Table 4. Within statistics the trend in calculated eigenvalues is independent of fuel type, and the age to thermal energies is underpredicted by $3-4 \%$. For U235, this is consistent with a direct calculation of the U235 fission neutron age to indium-resonance in water: ENDF/B-IV data yield $25.49 \mathrm{~cm}^{2}, 3.4 \%$ be low the measured value of $26.4 \pm 0.3 \mathrm{~cm}^{2}$ (RePs. 16,17 ).

\section{Sensitivities of Ca lculated Eigenvalues to Nuclear Data}

\section{Sensitivities of calculated eigenvalues to several: nuclear} data changes were determined for selected U233 and U235 assemblies. These changes include the hydrogen thermal absorption cross section, the uranium capture and fission resonance integrals, the uranium inelastic cross sections, the ENDF/B version of oxygen, and representations of the fission neutron spectra,

A reference eigenvalue was computed for each assembly with $P$ TMG and ENDF/B-IV data. Then for each change in data a $\delta K_{\text {eff }}$ was determined relative to this reference value. The sensitivities of $\mathrm{K}_{\text {eff }}$ to the various parameters are summarized in Tables 5-8. The following points are noteworthy:

1) The uranium capture and fission resonance integrals were varied as shown in Table 5. In each case this was achieved by a uniform percentage change of the smooth multigroup cross sections. There are significant sensitivities for the U235 systems but not for U233. The relative importance of these sensitivities can be seen from the resonance integrals shown in Table 6. The ENDF/B-IV U235 has a resonance alpha which is $7( \pm 4) \%$ below the best integral value, 
Table 4 - Results of Studies Using Egn. 1

$$
\begin{aligned}
& \frac{\text { Correlation }}{\delta K_{\text {eff }}=a+b \ln \left(1-L_{F 1}\right)} \\
& 8 K_{\text {eff }}=a+b \ln \left(1-L_{F 2}\right)
\end{aligned}
$$

$\begin{array}{cc}\frac{a}{\text { U233 Assemblies }} \\ \frac{b}{-0.005 \pm 0.002} & -0.048 \pm 0.011 \\ -0.006 \pm 0.001 & -0.035 \pm 0.009\end{array}$

1035 Assemblies

$\begin{array}{cc}\frac{a}{a} & \frac{b}{b 35 \text { Assemblies }} \\ -0.007 \pm 0.002 & -0.037 \pm 0.017 \\ -0.007 \pm 0.002 & -0.030 \pm 0.012\end{array}$

$8 K_{e f f}-a+b \ln \left(1-L_{F 1}\right)$

$\delta K_{\text {eff }}=a+b \ln \left(1-L_{F 2}\right)$

$$
-0.007 \pm 0.002
$$


resulting in a fission integral which is too large and a low capture integral. Each of these could account for about $0.5 \%$ of the eigenvalue difference between small. and large cores.

2) Reducing the hydrogen $2200 \mathrm{~m} / \mathrm{sec}$ absorption cross section from $0.332 \mathrm{~b}$ to $0.330 \mathrm{~b}$ increases the reactivity of the thermal assemblies by $0.3 \%$ with negligible effect on the high-leakage as semblies.

3) A $20 \%$ reduction of the inelastic cross sections for both fuel types produced negligible changes of reactivity.

4) Sensitivities to the ENDF/B version of oxygen are worth as much as $0.6 \%$ in $\mathrm{K}_{\text {eff }}$ for the high-leakage assemblies and are negligible for the large assemblies. The successive versions of oxygen (ENDF/B-I to ENDF/B-IV) show an increase in backscattering, which reduces leakage.

5) The fission neutron spectrum significantly affects fast neutron leakage. Sensitivity of eigenvalue to mean energy (for a Maxwellian shape) and to the difference between Watt and Maxwellian shapes (for the same mean energy) is shown in Tables 7 and 8 . This matter is discussed further in Section II.B.4 below. 


\section{Table 5 - Sensitivities of Eigenvalues to Uranium} Capture and Fission Resonance Integrals

Change in Eigenvalue

\begin{tabular}{|c|c|c|c|c|c|c|}
\hline H/U233: & 119.4 & 154 & 381 & 581 & 1533 & 2106 \\
\hline $\begin{array}{l}\text { Smooth capture } \\
\text { integral increased } \\
6.0 \mathrm{~b} \\
\quad \text { ? }\end{array}$ & -.0021 & -.0017 & -.0007 & -.0005 & -.0002 & -.0001 \\
\hline $\begin{array}{l}\text { Smooth fission } \\
\text { integral increased } \\
13.0 \mathrm{~b} \quad \ldots\end{array}$ & +.0020 & +.0016 & +.0009 & +.0008 & +.0005 & +.0005 \\
\hline $\mathrm{H} / \mathrm{U} 235 \mathrm{I}^{-}$ & 27.1 & 44.3 & 76.1 & 1112 & 2052 & \\
\hline $\begin{array}{l}\text { Smooth capture } \\
\text { integral increased } \\
6.0 \mathrm{~b}\end{array}$ & -.0077 & -.0053 & -.0028 & -.0003 & -.0002 & \\
\hline $\begin{array}{l}\text { Smooth fission } \\
\text { integral increased } \\
10.0 \mathrm{~b}\end{array}$ & +.0080 & +.0053 & +.0027 & +.0005 & +.0004 & \\
\hline
\end{tabular}


Table 6 - Uranium Resonance Capture and Fission Integrals

$\begin{array}{llll}\text { U233 } & \text { ENDF/B-IV (Mat. 1260) } & 733 & 132 \\ \text { U233 } & \text { BNL-325, 3rd ed. (Ref. 18) } & 735 \pm 13 & 138 \pm 6 \\ \text { U235 } & \text { ENDF / B-IV (Mat. 1261) } & 268 & 136 \\ \text { U235 } & \text { BNL-325, 3rd ed. } & 259 \pm 5 & 142 \pm 6\end{array}$


Table 7 - Sensitivities of U233 Critical Assemblies to Changes in Nuclear Data

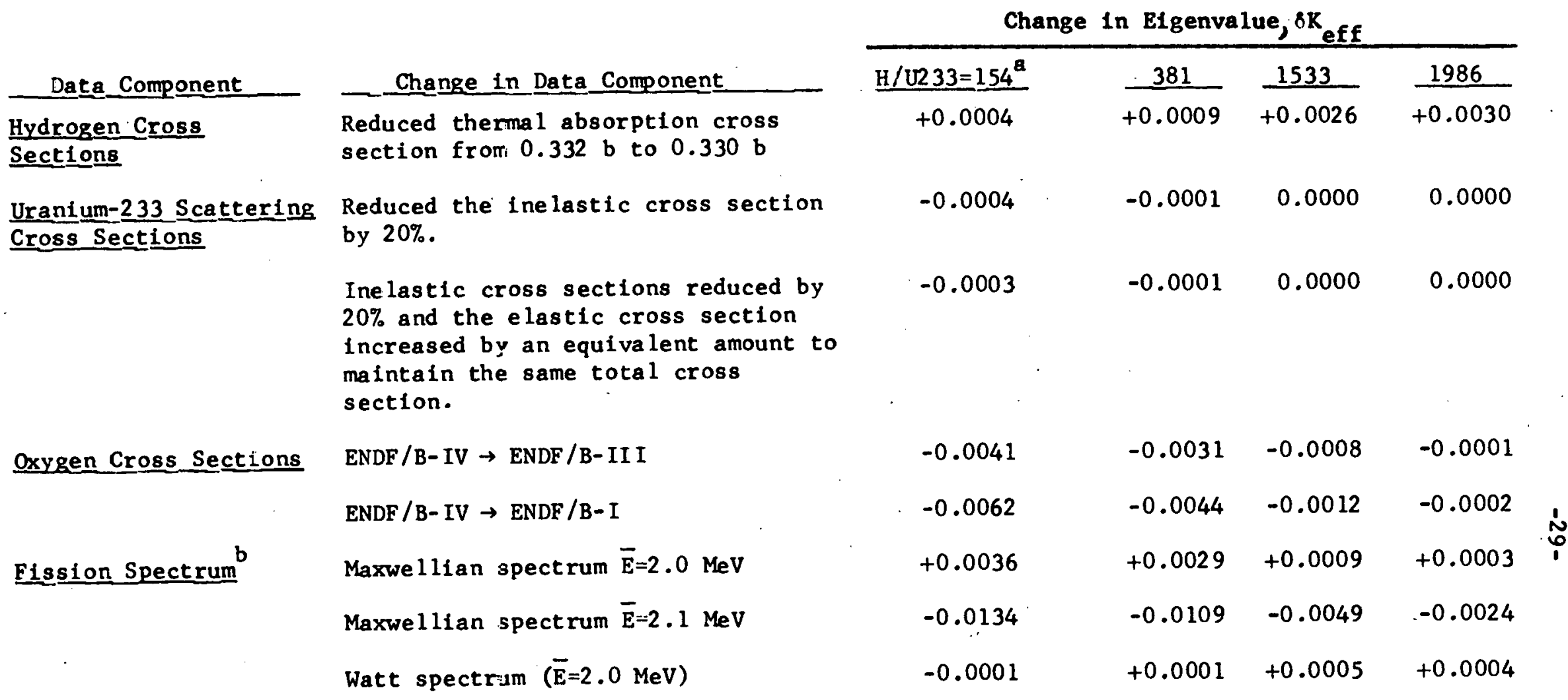

axperiment ID's are those of Ref. 8 (see Table 1).

${ }^{b} A 118 K_{\text {eff }}$ are relative to the ENDE/B-IV fission neutron spectrum for $U 233$. 
Table 8 - Sensitivities of U2 35 Critical Assemblies to Changes in Nuclear Data

Data Component

Hydrogen Cross

Sections

Uranium-235

Scattering

Cross Sections

Sxygen Cross

Fission

Spectrum
Change in Data Component

Reduced thermal absorption cross section from 0.332 b to $0.330 \mathrm{~b}$

Reduced the inelastic cross section by $20 \%$.

Inelastic cross section reduced by $20 \%$ and the elastic cross section increased by an equivalent amount.

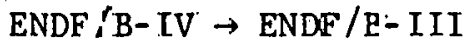

ENDF 'B-IV $\rightarrow$ ENDF/E-I

ENDF'B-III 0235 fission neutron spectrum

Maxwellian spectrum $\overline{\mathrm{E}}=2.0 \mathrm{MeV}$

Maxwe1lian spectrum $\overline{\mathrm{E}}-2.1 \mathrm{MeV}$

Watt spectrum $(\bar{E}-2.0 \mathrm{reV})$

\begin{tabular}{|c|c|c|c|c|}
\hline \multicolumn{5}{|c|}{ Change in Eigenvalue,,$K_{\text {eff }}$} \\
\hline $\mathrm{H} / \mathrm{U} 235-27.1(\mathrm{~L} 5)^{\mathrm{a}}$ & $44.3(16)$ & $1112(\underline{L} 8)$ & $1177(2)$ & $1835(10)$ \\
\hline+0.0001 & +0.0001 & +0.0021 & +0.0020 & +0.0028 \\
\hline-0.0016 & $-0.00-1$ & 0.0000 & 0.0000 & 0.0000 \\
\hline-0.0009 & -0.00016 & 0.0000 & 0.0000 & 0.0000 \\
\hline-0.0033 & $-0.00 \equiv 4$ & -0.0013 & -0.0008 & -0.0001 \\
\hline-0.0049 & $-0.00 \leq 0$ & -0.0018 & -0.0012 & -0.0002 \\
\hline$\div 0.0049$ & $+0.00 \leq 1$ & +0.0027 & \pm 0.0020 & +0.0009 \\
\hline-0.0022 & -0.0023 & -0.0012 & -0.0009 & -0.0004 \\
\hline-0.0157 & -0.0165 & -0.0087 & -0.0067 & -0.0031 \\
\hline-0.0053 & -0.0054 & -0.0020 & -0.0015 & -0.0004 \\
\hline
\end{tabular}

axperiment ID's are those c.f Fief. 8.

${ }^{\mathrm{b}} \mathrm{A} 11 \delta \mathrm{K}_{\text {eff }}$ are relative to the ENDF/B-IV fission neutron spectrum for U235. 


\section{Fission Spectra}

Four recent differential experiments show that the prompt neutron spectrum for low-energy U235 fission is significantly harder than that of ENDF/B-IV, a Maxwellian with $\bar{E}=1.985 \mathrm{MeV}$. A description of the experiments and an analysis of them by J. M. Adams appeared in the Proceedings of the Specialists Meeting on Inelastic Scattering and Fission Neutron Spectra, which

was held at Harwell in April 1975. Although it did not provide an exact fit to the data, the Watt model fit quite well and was clearly better than a Maxwellian. The Adams best-fit Watt spectrum had a prompt mean energy of $2.016 \mathrm{MeV}$.

A recent simultaneous least squares adjustment of data for U233 and U235 systems has provided best-fit fission spectra for both nuclides (Ref. 19). Among the data included in the analysis were thermal parameters (including Cf252 $\bar{v}$, thermal $\bar{v}$ ratios, $\eta, \sigma_{f}, \sigma_{c}$ ) for $U 233$ and U235, K2 values* from the Gwin-Magnuson criticals, eigenvalues of small homogeneous criticals, neutron age, capture and fission resonance integral and differential prompt fission spectra. For U235, a good fit was obtained with a Watt shape $\left(\bar{E}_{p}=2.027 \pm\right.$ $.00 / 4 \mathrm{MeV})$. This result is based on four differential experiments, three of which were used by Adams. A more complex prompt spectrum model (two fully accelerated fragments plus a stationary source) produced an equally good fit to the differential data and a substantially higher mean energy of $2.073 \pm .005 \mathrm{MeV}$. This is denoted the Standard model. For U233, based on the differential experiment of L. Green et al. (Ref. 20), a good fit was obtained for a Standard model with $\bar{E}_{\mathrm{p}}=2.082 \mathrm{MeV}$. The Watt and Maxwellian models fall to provide adequate representation of these data.

* $\mathrm{K} 2$ is described in Section 5 below. 
The effects of these alternative spectra on $\mathrm{K}_{\mathrm{eff}}$ of the homogeneous criticals are shown in Figures 4 and 5. For U233 systems (Figure 4), the Standard model removes the trend in calculated $K_{\text {eff }}$ versus leakage observed with straight ENDF/B-IV data (Figure 1).

For U235 systems (Figure 5), where the situation is complicated by the resonance absorption sensitivity, three combinations are illustrated. In part $A$ of this figure, the effect of a 10b reduction of the ENDF/B-IV U235 fission resonanc integral is shown by solid symbols for the three high-leakage criticals. (For the others, the effect is negligible.) Part B shows the effect of the reduced fission integral plus use of an equilibrium spectrum based on a Watt prompt spectrum with $\bar{E}_{p}=2.027 \mathrm{MeV}$. This combination removes most of the eigenvalue variation with leakage. Finally, part $C$ shows the effect of an equilibrium spectrum based on the much harder Standard molel. Both the Watt and Standard models can, with suitable cholce of 0235 resonance fission and capture integrals, eliminate the trend of calculated $k_{\text {eff }}$ with leakage. In efther case, there remains a defect of $\mathrm{K}_{\text {eff }}$ which is most readily removed by an $\sim 0.6 \%$ increașe of $\bar{v}$.

With ENDF/B-IV data, the calculated age to indium resonance $(1.47 \mathrm{eV})$ for a $\mathrm{U} 235$ fission source in $\mathrm{H}_{2} \mathrm{O}$ is well below experiment. The equilibrium spectrum based on the Watt prompt spectrum with $\bar{E}_{p}=2.027 \mathrm{MeV}$ provides slightly better agreement. The harder Standard model spectrum, with $\bar{E}_{p}=2.073 \mathrm{MeV}$, leads to very good agreement as shown in Table 9. 


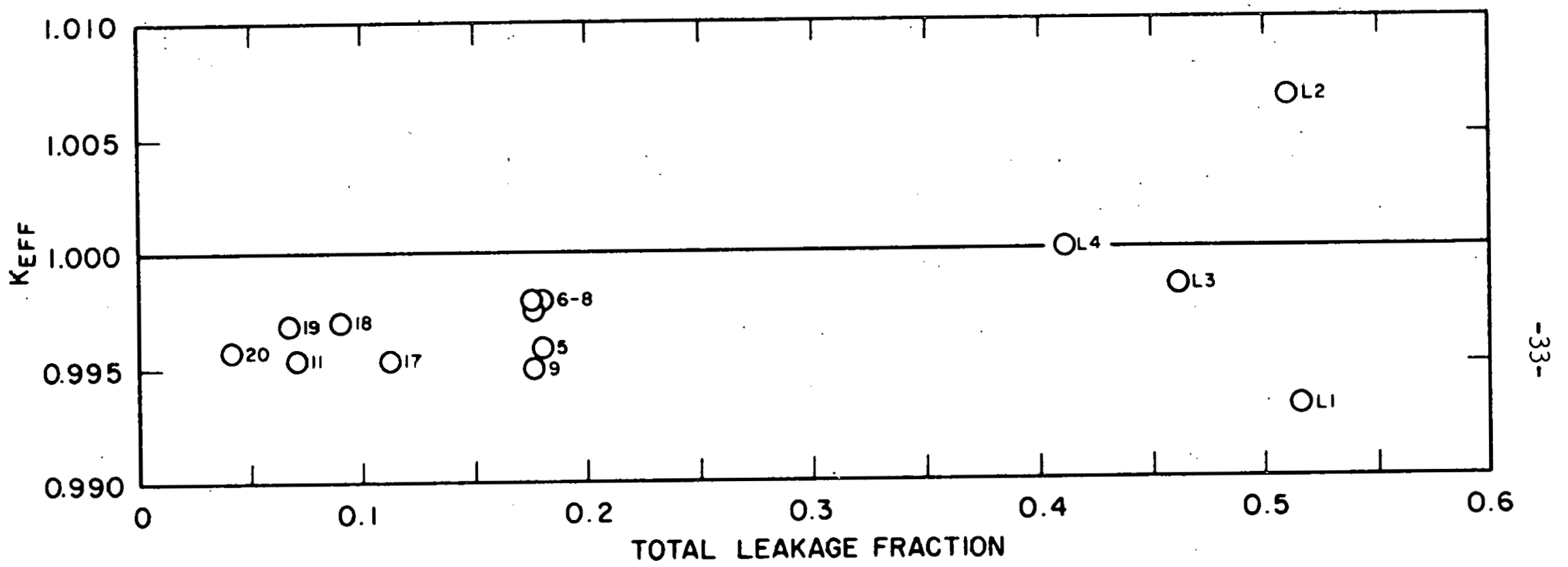

Calculated Eigenvalue Versus Total Leakage Fraction for Homogeneous U233 Criticals, Obtained with the Standard Fission Spectrum Model 

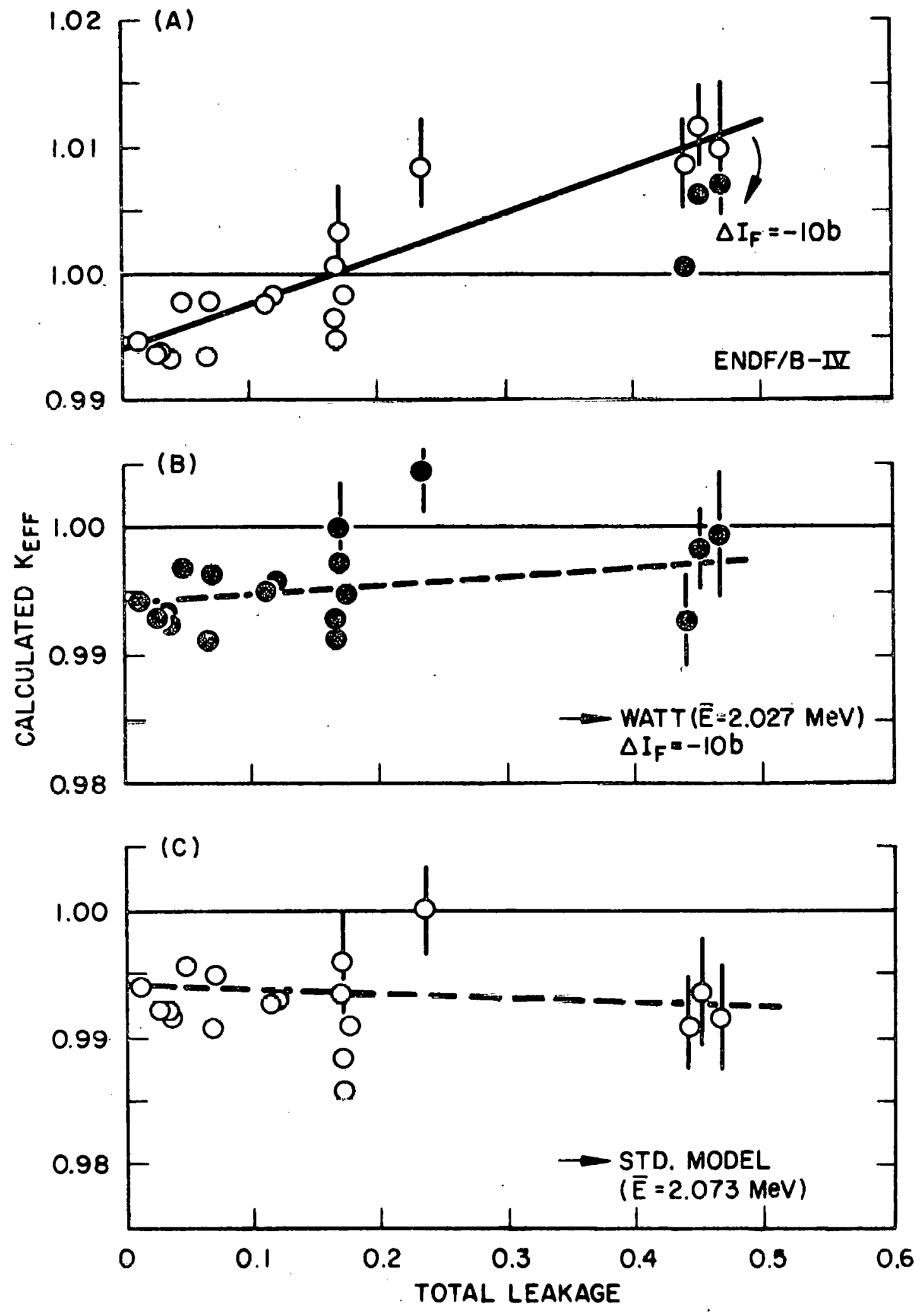

Effects of Alternative Fission Spectra on Eigenvalues of U235 Criticals (Solid symbol.s include a $10 \mathrm{~b}$ reduction of the U234 fission resoncrice integral. See text section III.B.4) 
In another paper at the 1975 Harwell Specialists Meeting, A. Fabry reviewed current evidence on fission spectra derived from integral experiments. The spectrum mean energy derived from dosimetry measurements is now $2.00-2.05 \mathrm{MeV}$, and this is consistent with the mean energy implied by the fission age-toIndium resonance in $\mathrm{H}_{2} \mathrm{O}$. He also emphasized the importance of integral spectrumaverage cross sections, particularly $\sigma_{f}^{\mathrm{U} 235}, \bar{\sigma}_{f}^{\mathrm{U23} 38}$ and their ratio.

Table 10 shows integral experimental values recomended by Fabry along with calculated values. The ENDF/B-IV calculation produces a low value of $\vec{\sigma}_{f}^{-U 38}$. Some improvement is obtained with the Watt shape, and very good agreement is shown by the Standard spectrum. It should be mentioned that $\bar{\sigma}_{f}^{\mathrm{U} 238}$ was not used in the fit so that this is an independent test of the spectrum. 
Table 9 - Flux Age to $1.47 \mathrm{eV}$ in $\mathrm{H}_{2} \mathrm{O}$ (U235 Fission Source)

$$
\text { Age }\left(\mathrm{cm}^{2}\right)
$$

Experiment (Ref. 16, 17)

ENDF/B-IV Calculation

ENDF/B-IV (except Watt Model, $\bar{E}_{\mathrm{p}}=2.027 \mathrm{MeV}$ )

ENDF/B-IV (except Std. Model, $\bar{E}_{\mathrm{p}}=2.073 \mathrm{MeV}$ )
$26.4 \pm 0.3$

25.49

25.88

26.33 
Table 10 - Fission Spectrum Averaged Cross Sections

\begin{tabular}{|c|c|c|c|}
\hline & $\begin{array}{l}\bar{\sigma}_{\mathrm{f}}^{\mathrm{U} 235} \\
(\mathrm{mb})\end{array}$ & $\begin{array}{l}\sigma_{\mathrm{f}}^{\mathrm{U} 238} \\
(\mathrm{mb})\end{array}$ & $\bar{\sigma}_{\mathrm{f}}^{\mathrm{U} 235} / \bar{\sigma}_{\mathrm{f}}^{\mathrm{U} 238}$ \\
\hline $\begin{array}{l}\text { Integral Experiment } \\
\text { (A. Fabry) }\end{array}$ & $1220 \pm 31$ & $313.5 \pm 10$ & $3.89 \pm .08$ \\
\hline ENDF/B-IV Calculation & 1244 & 294 & 4.23 \\
\hline $\begin{array}{l}\text { ENDF/B-IV (except Watt Spec., } \\
\left.\qquad E_{p}=2.027 \mathrm{MeV}\right)\end{array}$ & 1242 & 304 & 4.08 \\
\hline $\begin{array}{l}\text { ENDF/B-IV (except Std. Spec., } \\
\left.\qquad E_{p}=2.073 \mathrm{MeV}\right)\end{array}$ & 1235 & 312 & 3.96 \\
\hline
\end{tabular}




\section{Thermal Criticality Parameter Constraint.}

A constraint on the thermal criticality parameters of U233 has

been derived by Gwin (Ref. 2I) from the Gwin-Magnuson homogeneous criticals near the zero-leakage limit. This is $K 2=\left(\bar{\eta}_{U}^{-1}\right) \frac{\bar{\sigma}_{a}^{U}}{\bar{\sigma}_{a}^{H}}$, relating the therma1-

average eta for $\mathrm{U} 233$ and the $\mathrm{U} 233$ and hydrogen thermal absorption cross sections. Results are shown in Table 11 along with thnse for $\mathbb{T} 35$, for comparison. $\Lambda 100$ shown are $K \dot{2}$ values obtained in Ref. $\gamma$ and corresponding " $R$ " factors. The uncertainty on $\mathrm{K} 2$ is meant to account for all sources of error in the analysis (mainly fissile inventory, calculated epithermal multiplication and absorption, and calculated leakage).

It is essential to determine $\mathrm{K} 2$ from well-thermalized systems near the zeroleakage limit $(F P=1.0)$ since inferences about thermal eta, derived from analysis of critical systems, should not be influenced by errors of calculated criticality steming from inability to calculate leakage or from uncertainties of calculated epithermal absorption rates. This is 1 llustrated in Figure 6 which shows K2 values calculated for the Gwin-Magnuson U233 Criticals with ENDF/B-IV and with artificially enhanced fast leakage* Errors in calculated leakage can be caused by high-energy data inadequacies (as is evident for ENDF/B-IV) and calculational approximations, and by systematic errors in interpreting the experiments.

With the "g" factors of Table 11, ENDF/B-IV gives K2 values of 2220 and 2137 for $\mathrm{U} 233$ and $\mathrm{U} 235$, respective1y. These are $0.9 \%$ and $0.8 \%$ below the corresponding experimental values.

\footnotetext{
* In Figure 6, $\mathrm{K} 2$ is plotted versus the quantity FP. F can be viewed as the product of fast multiplication factor and resonance escape probability (ep), and $P$ is the nonleakage probability. At FP $=1.0$, fast multiplication fust balances the small fast absorption and leakage. The augmented-leakage points were obtained by artificially hardening the fission spectrum.
} 
Table 11 - Thermal Criticality Parameter Constraint K2 Derived from the Gwin-Magnuson Criticals

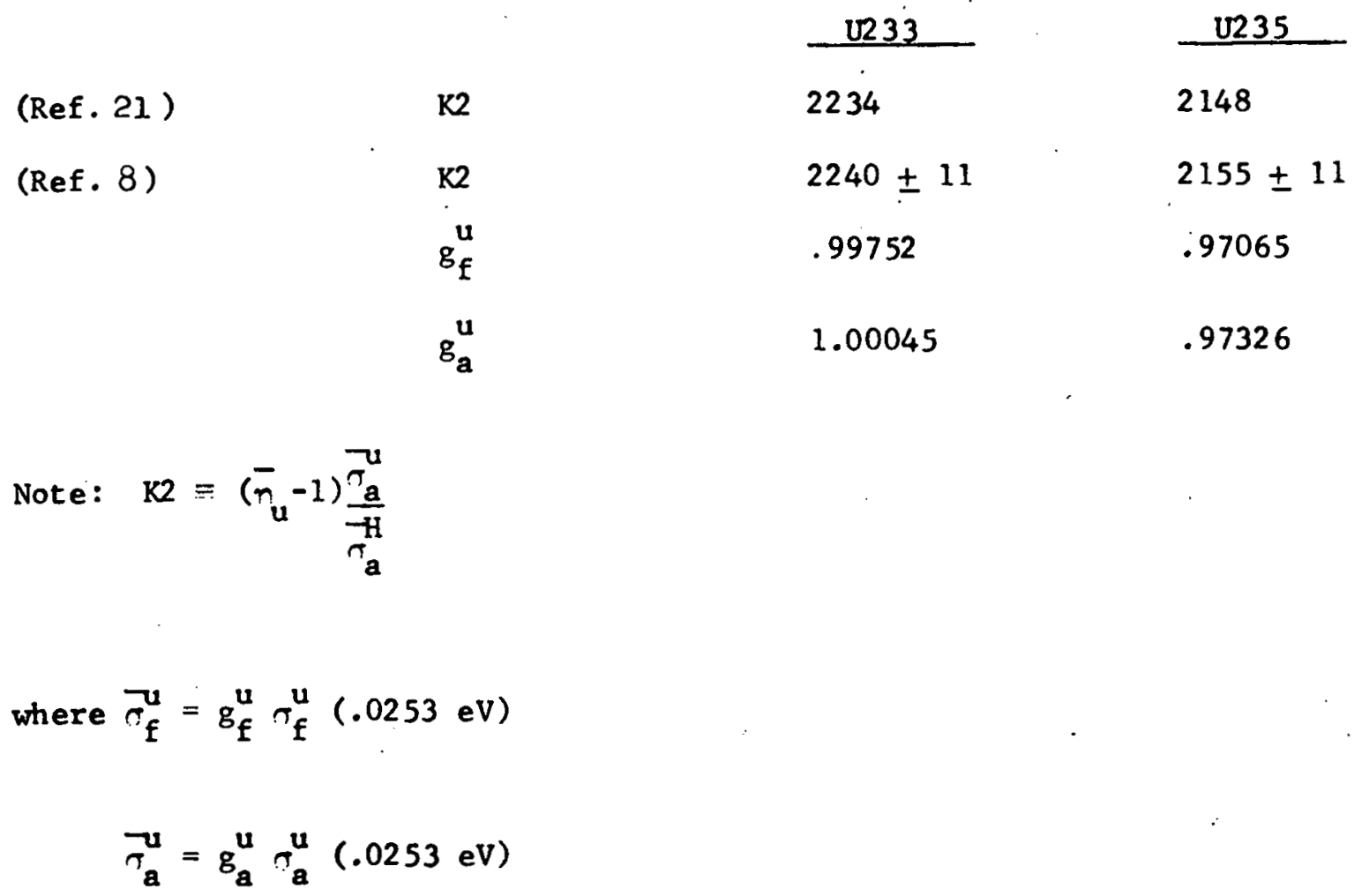




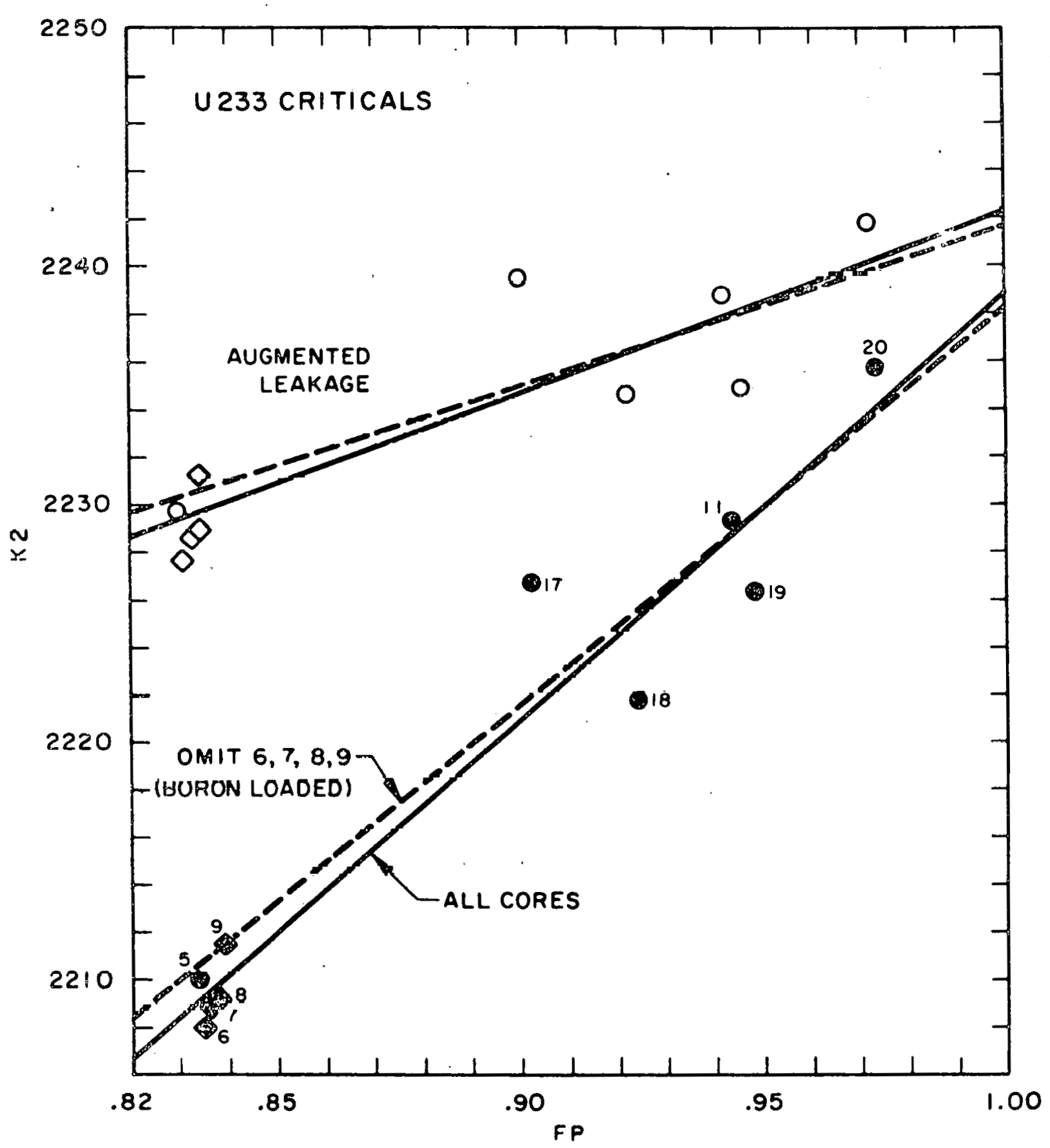

Thermal Criticaity Parameter $K 2$ Versus FP, Calculated with ENDF/B-IV and with Augmented Leakage for

U233 Criticals

FIGURE 6 


\section{Summary of Results for Homogeneous Criticals}

Homogeneous aqueous U233 and U235 critical assemblies, spanning a wide range of spectrum hardness (from $1 \%$ - $50 \%$ epithermal fission) and corresponding leakage (from $1 \%$ - 45\%), were analyzed with ENDF/B-IV data and Monte Carlo methods. At the zero-leakage limit, these criticals determine an experimental constraint

$$
K 2=\left(\pi_{U}^{-1}\right) \frac{\frac{\sigma^{U}}{\sigma^{H}}}{a}
$$

on the thermal criticality parameters $(K 2=2240 \pm 11$ and $2155 \pm 11$ for U233 and U235, respectively).

F'or U233 systems, calculated $K_{\text {eff }}$ ranged from $0.996-1.014$, and a similar effect was observed for U235. Errors of interpretation and of calculational methods are not very significant. The spread in $K_{\text {eff }}$ values is attributed primarily to deficiencies of ENDF/B-IV data, which can be of two types:

(1) energy-dependent errors of 11

(2) leakage underprediction.

Based on sensitivity studies and consideration of data uncertainties, the following i.tems appear to be relatively unimportant: hydrogen and oxygen ${ }_{s}^{\circ}$, and the fission and capture resonance integrals of U233. For U235, the fission and capture resonance integrals can each be worth approximately $0.5 \%$ at $45 \%$ lcakage. For the well-thermalized systems, uncertainties of fissile thermal $\sigma_{f}$ and $\sigma_{c}$ are worth a few tenths percent, and the hydrogen $\sigma_{A}$ is of similar importance. Normalization of $\bar{\nu}$ affects all systems equally. 
The primary factor is the fission spectrum, and this is significantly model dependent. Recent differential experiments imply a spectrum that is harder than ENDF/B-IV and not Maxwellian. Although the Watt shape is better, a more complex model (such as the Standard model) is required to fit the differential data. For U233, the Standard Model with $\bar{E}_{p}=2.082 \mathrm{MeV}$ (a11 other data from ENDF/B-IV) eliminates the $\mathrm{K}_{\text {eff }}$ trend with leakage.

For U235, the Standard model with $\bar{E}_{p}=2.073 \mathrm{MeV}$ provides a good fit and eliminates the $K_{\text {eff }}$ trend (with appropriate values of capture and fission integrals). A Watt shape with $\bar{E}_{p}=2,027 \mathrm{MeV}$ provides as gond a fit and also eliminates the $K_{\text {eff }}$ trend (again with appropriate values of capture and fission integrals). In either case, further measures such as an $\sim 0.5 \%$ increase of $\bar{v}$ are required to completely eliminate the $\mathrm{k}_{\text {eff }}$ bias. The Standard madel also brings the calcuiated 2235 fission neutron age in $H_{2} O$ into good agreement with experiment, while the sof'ter spectra do not. (For ENDF/B-IV, the age is $3.4 \pm 1.1 \%$ below experiment.) The Standard model also gives excellent agreement

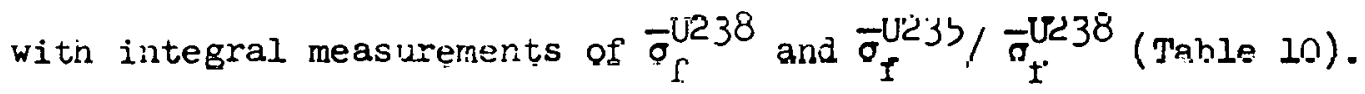


III. Thorium-U233 and Thorium-U235 Lattice Experiments $\left(\mathrm{H}_{2} \mathrm{O}\right.$ and $\mathrm{D}_{2} \mathrm{O}$ Moderated)

\section{A. Survey of Experiments}

This section summarizes a number of lattice experiments deemed potentially useful for data testing, as shown in Table 12 . Very few such experiments are available with $\mathrm{U} 233$ fuel. Aside from the critical experiments in direct support of LWBR (the SB and BMU series and the detalled ce11), there are only the $\mathrm{BNL} \mathrm{U}^{3} 33 \mathrm{O}_{2}-\mathrm{ThO}_{2}$ exponentials and the very hard spectrum Bettis ETA-II critical (which used the BNL fuel rods).

There are several U235-fueled Tho 2 criticals available. Among these are experiments run in the late 1950 's at B\&W and at ANL: the $\mathrm{H}_{2}$ O-moderated TUPE and CETR lattices, the $\mathrm{H}_{2} \mathrm{O}-\mathrm{D}_{2} \mathrm{O}$ SSCR experiments, and the $\mathrm{D}_{2} \mathrm{O}$-moderated THUD lattices. One series of experiments, with 19-element cluster rods, was run at Chalk River in the center of a ZED-2 lattice of CANDU-type rods.

As a supplement to the lattice critical experiments, measurements of shielded resonance capture in single rods are useful for testing thorium resonance capture data. These and the BNL exponentials are the only departures taken from the restriction to critical experiments.

These experiments have been selected as the most promising candidates for thermal reactor data testing. Some of them - the TUPE's, three THUD's, the BNL exponentials, one BMU and the detailed cell - have been analyzed with Monte Carlo methods and ENDF/B-IV data. These studies are described in Section B. Aside from $K_{e f f}$, the following integral parameters have been computed where there are measured values available: 
$0^{02}=$ ratio of epithermal/thermal capture in thorium.

$\delta^{23}\left(\delta^{25}\right)=$ ratio of epithermal/thermal fission in U233 (or U235).

$8^{02}=$ ratio of fission in thorium to fission in U233 (or U235).

$\mathrm{CR}^{*}=$ ratio of capture in thorium to fission in U233 (or U235) the modified conversion ratio. 
Table 12

Summary of Th-U233 and Th-U235 Exponential and Critical Experiments of Potential Use for Data Testing

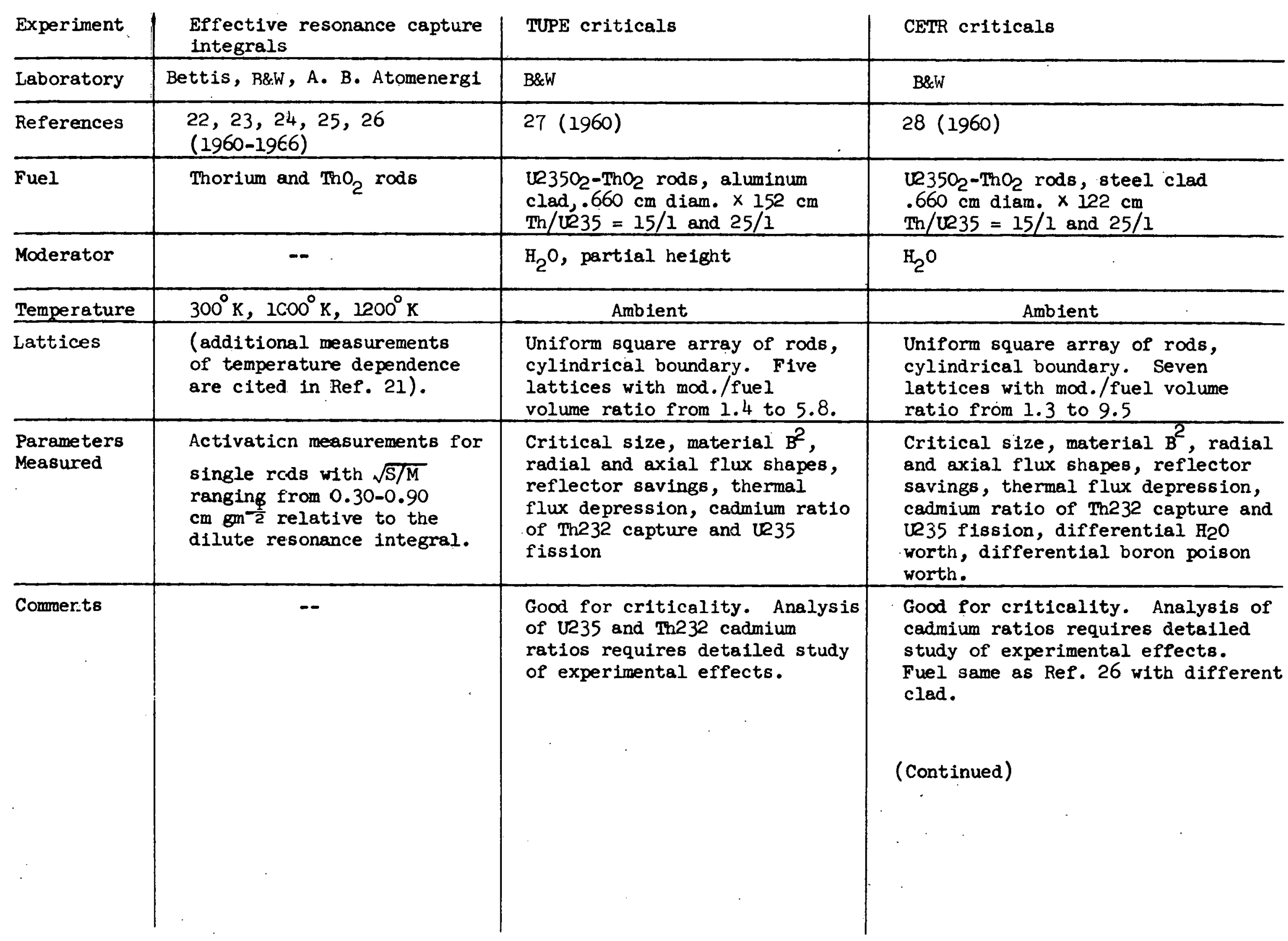




\begin{tabular}{|c|c|c|c|}
\hline Experiment & SSCR criticals & THUD criticals & ZED-2 19-element-rod lattices \\
\hline Laboratory & 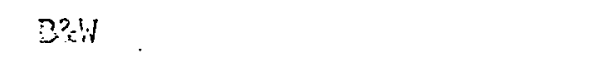 & ANL & CRNL \\
\hline References & $29(1961)$ & $30(19.51)$ & $31,32(-968)$ \\
\hline Fuel & $\begin{array}{l}\mathrm{L} 35 \mathrm{O}_{2}-\mathrm{ThO}_{2} \text { rods, } .660 \\
\mathrm{~cm} \text { diam. } \times 152 \mathrm{~cm}, \text { alum- } \\
\text { inum clad, Th/ } 235 \text { atom } \\
\text { ratio } 15 / 1\end{array}$ & $\begin{array}{l}\mathrm{U}^{2} 35 \mathrm{~S}_{2}-\mathrm{ThO}_{2} \text { rods, } .660 \mathrm{~cm} \\
\text { diam. } \mathrm{x} 152 \mathrm{~cm} \text {, aluminum } \\
\text { clad, Th/ } / 235 \text { atom ratio } \\
15 / 1 \text { and } 25 / 1\end{array}$ & $\begin{array}{l}\text { 19-element clusters of ThO con- } \\
\text { taining } i .5 \mathrm{w} / \mathrm{O} \mathrm{UO}_{2} \text { ( } 93 \text { atom of U235) }\end{array}$ \\
\hline Moderator & $\mathrm{D}_{2} \mathrm{O}-\mathrm{H}_{2} \mathrm{O}\left(60.4\right.$ mole $\left.\% \mathrm{D}_{2} \mathrm{O}\right)$ & $\begin{array}{l}\mathrm{D}_{2} 0(99.4 \%-97.0 \% \text { purity }) \\
\text { partial moderator height }\end{array}$ & $\mathrm{D}_{2} \mathrm{C}$ (coolant: air, $\left.\mathrm{D}_{2} \mathrm{O}, \mathrm{H}_{2} \mathrm{O}, \mathrm{HB} 4 \mathrm{O}\right)$ \\
\hline Temperature & Ambient & Ambient & Ambient \\
\hline Lattices & $\begin{array}{l}\text { Unifo:m square array of } \\
\text { rods, cylindrical boundary, } \\
\text { mod./ Euel volume ratio } 1.4 \text {. }\end{array}$ & $\begin{array}{l}\text { Uniform triangular array of } \\
\text { rods, cylindrical boundary. } \\
45 \text { lattices on four pitches, } \\
\text { fror } 1.9 \mathrm{~cm} \text { to } 5.7 \mathrm{~cm} \text {. }\end{array}$ & $\begin{array}{l}\text { Triangular array. Seven cluster-rod } \\
\text { (center and first hex) in lattice of } \\
\text { 19-element } U 0_{2} \text { CANDU-type rods. } \\
\text { Pitches of } 22 \mathrm{~cm} \text { and } 28 \mathrm{~cm}\left(\mathrm{~B}^{2} \text { also }\right. \\
\text { at pitches of } 24 \mathrm{~cm} \text { and } 32 \mathrm{~cm}) \text {. }\end{array}$ \\
\hline $\begin{array}{l}\text { Parameters } \\
\text { Measured }\end{array}$ & $\begin{array}{l}\text { Critical size, reflector } \\
\text { savings, radial and axial } \\
\text { flux shapes, material B, } \\
\text { thermal flux depressicn, } \\
\text { cadmium ratios of Th232 } \\
\text { capture and U } 25 \text { fission. }\end{array}$ & $\begin{array}{l}\text { Critical size, reflector } \\
\text { savings, differential D } 0 \\
\text { worth, cadmium ratio of Th232 } \\
\text { capture, tinermal flux de- } \\
\text { pression, fast Iission factor. }\end{array}$ & $\begin{array}{l}\text { Material } B^{2} \text {; neutron fine structure; } \\
\text { relative } \mathrm{U} 233, \mathrm{U} 35 \text { and Pu239 } \\
\text { fission ratios; } 002, \mathrm{CR} \text {. }\end{array}$ \\
\hline Comments & $\begin{array}{l}\text { Good Ior criticality. } \\
\text { Analysis of cadmium ratios } \\
\text { requires detailed study of } \\
\text { experimental effects. Fuel } \\
\text { rods same as Ref. } 27 \text {. }\end{array}$ & $\begin{array}{l}\mathrm{D}_{2} \mathrm{O} \text { purity determination in } \\
\text { question. Good for criticality. } \\
\text { Analysis of Th232 cadmiun ratio } \\
\text { and fast fission factor re- } \\
\text { quires detailed study of exper- } \\
\text { imental effects. Fuel rods } \\
\text { same as Ref. } 27 \text {. }\end{array}$ & (Continued) \\
\hline
\end{tabular}


Table 12 (Cont'd)

\begin{tabular}{|c|c|c|c|}
\hline Experiment & BNL exponentials & ETA-I Critical & ETA-II Critical \\
\hline Laboretory & BNL & Bettis & Bettis \\
\hline References & $33,34(1966,1970)$ & $35,36(1974)$ & $35(1974)$ \\
\hline Fuel & $\begin{array}{l}\mathrm{UR}_{33 \mathrm{O}_{2}}^{-\mathrm{THO}_{2}} \text { rods, } 1.09 \\
\mathrm{~cm} \text { diam } \times 107 \mathrm{~cm}, \\
\text { zircaloy-2 clad, Th/ } / 233 \\
\text { atom ratio } 32.5 / 1\end{array}$ & $\begin{array}{l}\mathrm{UR}_{35 \mathrm{O}_{2}-\mathrm{ThO}_{2} \text { rods, } .660 \mathrm{~cm}} \\
\text { diam } \times 152 \mathrm{~cm} \text {, aluminum clad, } \\
\mathrm{Th} / \mathrm{L} 35 \text { atom ratio } 15 / 1\end{array}$ & $\begin{array}{l}\mathrm{U} 233 \mathrm{O}_{2}-\mathrm{ThO}_{2} \text { rods, } 1.09 \mathrm{~cm} \text { diam } x \\
107 \mathrm{~cm}, 21 \mathrm{rcaloy}-2 \mathrm{clad}, \mathrm{Th} / \mathrm{U} 33 \\
\text { atom ratio } 32.5 / 1\end{array}$ \\
\hline Moderetor & $\mathrm{H}_{2} \mathrm{O}$ and $\mathrm{I}_{2} \mathrm{O}$ & $\begin{array}{l}\mathrm{D}_{2} \mathrm{O} \text { ( } 99 \% \text { purity) fully } \\
\text { reflected }\end{array}$ & $\mathrm{D}_{2} \mathrm{O}(98.4 \%$ purity $)$ \\
\hline Temperature & Ambient & Ambient & Ambient \\
\hline Lattices & $\begin{array}{l}\text { Uniform triangular array of } \\
\text { rods, cylindrical boundary. } \\
21 \mathrm{H}_{2} \mathrm{O} \text {-moderated lattices } \\
\text { with mod./fuel volume ratio } \\
\text { from } 1.0 \text { to } 9.3 \text { and varying } \\
\text { concentrations of } \mathrm{H}_{3} \mathrm{BO}_{3} \text {. } \\
\text { Eight } \mathrm{D}_{2} \mathrm{O} \text {-moderated lattices } \\
\text { with mod./fuel volume ratio } \\
\text { from } 2.2 \text { to } 11.5\end{array}$ & $\begin{aligned} \text { Inner: } & 2304 \text { rods in square } \\
& \text { array of } 3 \times 3 \text { rod } \\
& \text { clusters; cylindrical } \\
& \text { boundary } 61 \mathrm{~cm} \text { diam. } \\
& \text { Mod./fuel vol. ratio } \\
& =2.02 \\
\text { Driver: } & \mathrm{H}_{2} \mathrm{O} \text { moderated lattice } \\
& \text { of TRX slightly- } \\
& \text { enriched } \mathrm{VO}_{2} \text { rods. }\end{aligned}$ & $\begin{array}{l}\text { Inner: } 864 \text { rods in square array of } \\
2 \times 2 \text { rod clusters, cylindrical } \\
\text { boundary, } 56 \mathrm{~cm} \text { diam., } \\
\text { mod./fuel vol. ratio }=1.70 . \\
\text { Driver: } \mathrm{H}_{2} 0 \text { moderated lattice of } \\
\text { TRX slightly-enriched } \mathrm{vO}_{2} \\
\text { rods. }\end{array}$ \\
\hline $\begin{array}{l}\text { Parameters } \\
\text { Measured }\end{array}$ & $\begin{array}{l}\text { Material } B^{2} \text {, reflector } \\
\text { savings, thermal flux de- } \\
\text { pression, p02, } 802 \text {. }\end{array}$ & $\begin{array}{l}\text { ○02, CR*, } \mathrm{\rho} 02, \delta 25 ; \text { Th232 } \\
\text { capture Doppler }\end{array}$ & $.02, \mathrm{CR}^{*}, \mathrm{p}^{02}, .023$ \\
\hline Commerts & -- & $\begin{array}{l}\text { Central parameters in asymptotic } \\
\text { spectrum; } K_{\text {eff depends signifi- }} \text { dend } \\
\text { cantly on the driver and requires } \\
\text { full core analysis since coupling } \\
\text { to the driver not measured. Very } \\
\text { hard spectrum }(\rho 02=10.5) \text {. Fuel } \\
\text { rods same as } B \& W 15 / 1 \text { (Ref. } 27) \text {. }\end{array}$ & $\begin{array}{l}\text { Central parameters in asymptotic } \\
\text { spectrum; } K_{\text {eff depends significantly }} \\
\text { on the driver and requires full core } \\
\text { analysis since coupling to the driver } \\
\text { not measured. Very hard spectrum } \\
(\rho 02=8.89) \text {. Fuel rods same as BNL } \\
(\text { Ref. } 33) . \\
\text { (Continued) }\end{array}$ \\
\hline
\end{tabular}




\begin{tabular}{|c|c|c|c|}
\hline Experiment & LWBR SB criticals & LWBR BMU criticals & LiVR detailed cell \\
\hline Laboratory & Bettis & Bettis & Bettis \\
\hline References & $37(196 \pi)$ & $38(1975)$ & $39\left(1971_{4}\right)$ \\
\hline Fuel & 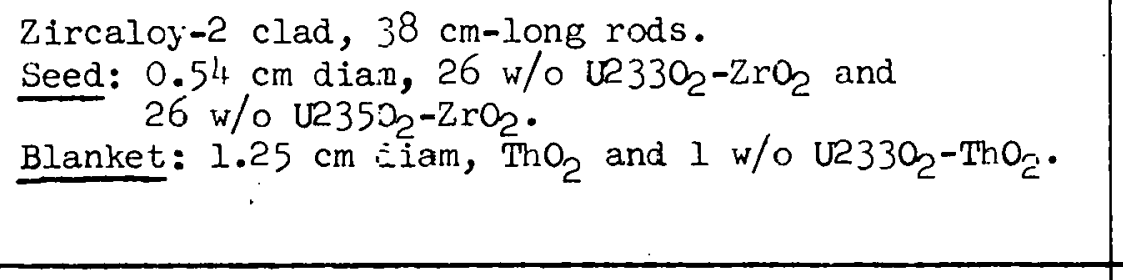 & $\begin{array}{l}\text { Axially zoned } \mathrm{U} 233 \mathrm{O}_{2}-\mathrm{Tr} \mathrm{O}_{2} \\
\text { and ThOn in Zircaloy-4 clad. } \\
\text { Seed: } 0.52 \mathrm{~cm} \text { dian rods of } \\
\text { four types. } \\
\text { Blanket: } 1.4 \mathrm{~cm} \text { diam rods ot } \\
\text { tour types. }\end{array}$ & $\begin{array}{l}\text { Twelve types of } \\
\mathrm{U} 2 \mathrm{SO}_{2}-\mathrm{ThO}_{2} \text { and } \mathrm{ThO}_{2} \\
\text { seed and blanket } \\
\text { rods in Zircaloy-4. }\end{array}$ \\
\hline Moderator & $\mathrm{H}_{2} \mathrm{O}$ & $\mathrm{H}_{2} \mathrm{O}$ & $\mathrm{H}_{2} \mathrm{O}$ \\
\hline Temperature & $\begin{array}{l}\text { Ambient (two of the wet-blanket, assemblies } \\
\text { were run also at } 1.80^{\circ} \mathrm{F} \text { ) }\end{array}$ & $\begin{array}{l}\text { Ambient (except BMU-IC at } \\
410^{\circ} \mathrm{F} \text { ) }\end{array}$ & $\begin{array}{l}\text { Ambient (except } \\
\text { Core III b at } 477^{\circ} \mathrm{F} \text { ) }\end{array}$ \\
\hline Lattices & 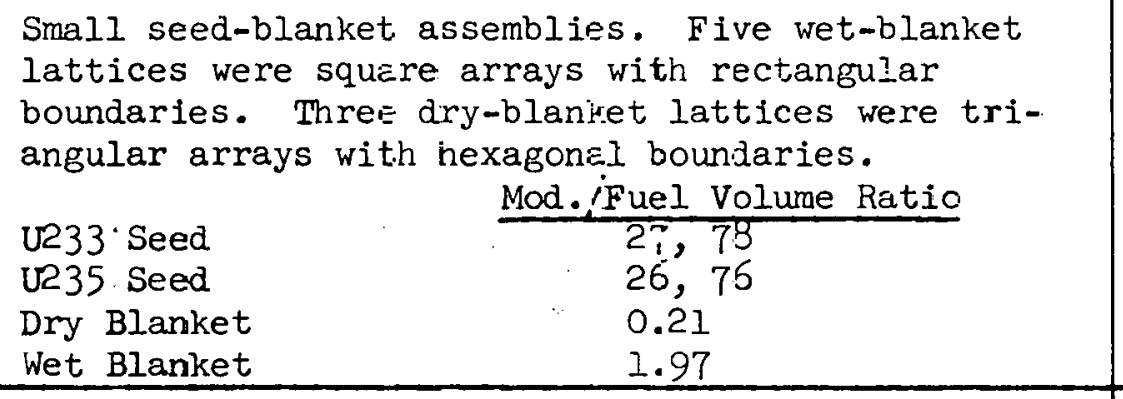 & $\begin{array}{l}\text { Multiply-zoned seed-blanket } \\
\text { assemblies. Three BMU-1 } \\
\text { lattices were triangular } \\
\text { arrays with hexagonal } \\
\text { boundary (single nodule). } \\
\text { Five BMU-2 lattices were } \\
1-, 3-\text {, and 4-module } \\
\text { assemblies. }\end{array}$ & $\begin{array}{l}\text { Triangular array with } \\
\text { hexagonal, } 270-\mathrm{cm}- \\
\text { high multiply-zoned } \\
\text { seed and blanket. } \\
\text { Seven configurations } \\
\text { with movable seed at } \\
\text { different heights. }\end{array}$ \\
\hline $\begin{array}{l}\text { Parameters } \\
\text { Measured }\end{array}$ & $\begin{array}{l}\text { Critical size. Radial and axicl flux shapes } \\
\text { (U235 fiss, U233 Ziss, Th cap, Dy) p02, oc5, } 823 \text {, } \\
\text { thermal disadvantage factors, fast advantege factors } \\
\text { in selected locations. }\end{array}$ & $\begin{array}{l}\text { Critical size; radial and } \\
\text { axial flux shapes: region } \\
\text { power fractions; o2 and } \\
823 \text { in selected locations; } \\
\text { central worths of structural } \\
\text { materials; Cf } 252 \text { meutron } \\
\text { importance. }\end{array}$ & $\begin{array}{l}\text { Critical size; region } \\
\text { power fractions; } \\
\text { axial and radial flux } \\
\text { shapes; } 623 \text {, pO2, } \\
602 \text {, at selected lo- } \\
\text { cations. }\end{array}$ \\
\hline Comments & $\begin{array}{l}\text { Good for criticality. Interpretation of parameters } \\
\text { requires detailed study of experimental effects. } \\
\text { Lack of asymptotic region and small size complicate } \\
\text { analysis. }\end{array}$ & $\begin{array}{l}\text { Good fcr criticality. In- } \\
\text { terpretation of integral } \\
\text { parameters difficult due to } \\
\text { geometrical complexity. }\end{array}$ & $\begin{array}{l}\text { Good for criticality. } \\
\text { Interpretation of } \\
\text { integral parameters } \\
\text { difficult due to } \\
\text { geometrical complexity. }\end{array}$ \\
\hline
\end{tabular}


B. Results of Analysis of Th-U233 and Th-U235 Lattice Integral Experiments.

This section surveys results of current analyses of Th-U233 and Th-U235 lattice experiments (mostly with ENDF/B-IV data) supplemented by previously published results from other analyses with closely related data sets.

\section{Resonance Integrals for Thorium Capture}

Measurements of the dilute resonance capture integral of thorium have usually been made by the cadmium ratio method relative to the dilute resonance integral of gold. In this method, resonance and thermal activation ratios are compared by irradiating dilute gold and thorium detector foils, bare and cadmium-covered, in a pseudo $1 / \mathrm{E}$ flux spectrum. Normalization depends on the thorium and gold thermal capture cross sections and the gold dilute resonance integral:

$$
I_{\text {Th2 } 32}=\frac{\left(A_{\text {res }} / A_{\text {ther }}\right)_{\text {Th232 }}}{\left(\mathrm{A}_{\text {res }} / A_{\text {ther }}\right)_{A u}} \times \frac{\pi_{\text {Th232 }}}{\pi_{\text {Au }}} I_{A u}
$$

The measured resonance and thermal specific activations ( $A_{\text {res }}$ and $A_{t h e r}^{\prime}$ ') of Eqn. 2 must be suitably corrected for cadmium-cutoff energy, detector foil shielding and deviation of the neutron flux spectrum from $1 / E$ behavior.

Grenêche (Ref. 40) has recently reviewed the available integral experiments On the basis of fourteen measurements he obtains a dilute resonance integral

$$
\begin{aligned}
I_{\text {Th232 }}=85.8 & \pm 0.9 \mathrm{~b} \text { (experimenta }) \\
& \pm 1.6 \mathrm{~b} \text { (normalization). }
\end{aligned}
$$


This represents all capture above $0.5 \mathrm{eV}$ and is normalized as follows:

$$
\begin{aligned}
\tau_{\mathrm{Au}} & =98.8 \pm 0.3 \mathrm{~b} \\
\tau_{\mathrm{Th} 232} & =7.40 \pm 0.08 \mathrm{~b} \\
I_{\mathrm{Au}} & =1560 \pm 22 \mathrm{~b}
\end{aligned}
$$

The BNL 325 (Ref. 18) value of the dilute Th2.32 resnnance capture integral $1885 \pm 3 b$.

Complementing lattice experiments as a test of shielded resonance capture are measurements of effective resonance integrals for thorium metal and $\mathrm{ThO}_{2}$ rods of various diameters. The experimental methods, problems of interpretation and results have been summarized by Hellstrand (Ref. 22 ).

For thorium, the experiments were done by activation techniques in which a cadmium-covered rod was irradiated in a pseudo-1/E flux spectrum. Thorium captures were sampled by counting the capture activity of a ground-up portinn of the $\mathrm{ThO}_{2}$ rod or (for a metal rod) of a thorium metal detector foil. Normalization was explicitly to the dilute resonance integral of thorium:

$$
I^{\prime}(S / M, T)=\left(\frac{A_{\text {res }}^{\prime}(S / M, T)}{A_{\text {res }}} \times I_{\text {Th232 }} \times I_{\text {Th2 }}\right.
$$

where $I^{\prime}$ and $A_{r e s}^{\prime}$ are the effective resonance integral and specific thorium resonance capture activation for a rod of surface/mass ratio $\mathrm{S} / \mathrm{M} \mathrm{cm} / \mathrm{gm}$ at temperature $\mathrm{T}$. In some experiments, normalization was directly to the gold resonance integral via Eqn. 2 . 
In comparison to lattice measurements, the thorium activation counting techniques are similar, but there is the additional complication of determining the actual flux spectrum impinging on the rod. In this sense an effective resonance integral measurement is more difficult to interpret than a lattice experiment, although in principle it is more specific (i.e., not subject to interference from competing reactions).

On the basis of two experiments. (Ref. 23, 25) for metal and three for oxide rods (Ref. 24, 25 and 26), Hellstrand (Ref. 22) recommends the following room-temperature effective resonance integrals:

$$
\begin{array}{ll}
\text { Thorium metal } & I^{\prime}=5.05+15.5 \sqrt{\mathrm{S} / \mathrm{M} b} \\
\mathrm{ThO}_{2} & I^{\prime}=5.85+16.2 \sqrt{\mathrm{S} / \mathrm{M} b}
\end{array}
$$

Here, $S / M$ is the surface-to-mass ratio $\left(\mathrm{cm}^{2} / \mathrm{gm}\right)$ of metal or of oxide. These expressions apply over the range $0.30<\sqrt{\mathrm{S} / \overline{\mathrm{M}}}<0.90$, with an assigned uncertainty of $\pm 4.5 \%$, and include ail capture above $0.5 \mathrm{eV}$.

A connection with lattice measurements of thorium resonance capture can be established via the IWBR thorium capture data evaluation (Ref. 41). The LWBR data set produced calculated effective resonance integrals for $\mathrm{ThO}_{2}$ rods which are well represented by the expression:

$$
I^{\prime}=5.74+15.54-\sqrt{\mathrm{s} / \mathrm{M}} \mathrm{b}\left(300^{\circ} \mathrm{K}\right)
$$

The calculated effective resonance integral is approximately $3 \%$ below the Hellstrand recommendation. Analysis of several lattices with the LWBR thorlum data have shown (Ref. 42) that it produces approximately $3 \%$ more resonance capture than does ENDF/B-IV. Hence, it is concluded that ENDF/B-IV thorium produces effective resonance capture integrals approximately $6 \%$ below the Hellstrand recommendation. 


\section{TUPE Lattices (Th-U235- $\left.\mathrm{H}_{2} \mathrm{O}\right)$}

The TUPE (Thorium-Uranium-Physics-Experiment) criticals were operated at Babcock and Wilcox in the late 1950's (Ref.27). There were five $\mathrm{H}_{2} \mathrm{O}$-moderated simple lattices constructed from $\mathrm{U} 235 \mathrm{O}_{2}-\mathrm{ThO}_{2}$ rods having $\mathrm{Th} / \mathrm{U} 235$ atom ratios of $15 / 1$ and $25 / 1$. The lattices were square arrays at four pitches, with moderator/fuel volume ratios ranging from 1.38 to 5.79 .

The five uniform lattices have been analyzed with ENDF/B-IV data and the RCP01 Monte Carlo program. The cores were described explicitly in three dimensions, including the lattice plates, core support structure and tank, with a black absorbing boundary placed outside the tank.

Table 13 and Figure 7 present eigenvalues obtained in the full-core analyses with ENDF/B-IV data. These show relatively good agreement with experiment, although there is a distinct downward trend in the tighter lattices.

Material bucklings, inferred from careful measurements of radial and axial activation shapes, were reported in Ref. 27 . For comparison with the full-core Monte Carlo results, eigenvalues have been calculated from a zero-leakage cell Monte Car1o, with leakage correction obtained from MUFT7, with the measured material buckling. Fast advantage factors and thermal disadvantage factors were obtained from the RCP01 cell region fluxes for the fast (10 MeV - $820 \mathrm{KeV}$ ) and thermal $(0-0.625 \mathrm{eV})$ groups. The MUFT7 calculation used a resonance absorption treatment based on integral transport theory, with the same detailed cross section profile as used in RCP01. This produced reaction rates in good agreement with the cell $\mathrm{RCP} 01$ over the range $0.625 \mathrm{eV}$ $5530 \mathrm{eV}$ in which it was applied. An alternative calculation was done with the 
Table 13 - Calculated Criticality of TUPE Lattices (Ful1 Core RCP01)

\begin{tabular}{|c|c|c|c|c|c|}
\hline $\begin{array}{l}\text { Lattice } \\
\text { Ident. } \\
\text { (Ref. 27) } \\
\end{array}$ & $\begin{array}{l}\text { Mod/Fuel } \\
\text { Volume } \\
\text { Rat1o } \\
\end{array}$ & $\begin{array}{c}\text { Number } \\
\text { of } \\
\text { Rods } \\
\end{array}$ & $\begin{array}{l}\text { Moderator } \\
\text { Height }(\mathrm{cm})\end{array}$ & $\begin{array}{l}\text { Calculated } \\
\text { Net Leakage }\end{array}$ & $\begin{array}{l}\text { Calculated } \\
\mathrm{K}_{\text {eff }} \pm \sigma^{*}\end{array}$ \\
\hline $\begin{array}{l}15 A \\
15 B \\
15 D\end{array}$ & $\begin{array}{l}1.379 \\
1.642 \\
2.945\end{array}$ & $\begin{array}{r}1108 \\
880 \\
514\end{array}$ & $\begin{array}{l}127.21 \\
133.44 \\
135.05\end{array}$ & $\begin{array}{l}0.313 \\
0.325 \\
0.317\end{array}$ & $\begin{array}{r}1.0002 \pm .0014 \\
.9947 \pm .0013 \\
1.0056 \pm .0014\end{array}$ \\
\hline $25 \mathrm{D}$ & 3.636 & 1176 & 140.50 & 0.206 & $1.0075 \pm .0013$ \\
\hline $25 \sqrt{2 B}$ & 5.794 & 1146 & 135.27 & 0.165 & $1.0060 \pm .0013$ \\
\hline
\end{tabular}

* Monte Carlo statistical error at one standard deviation. 


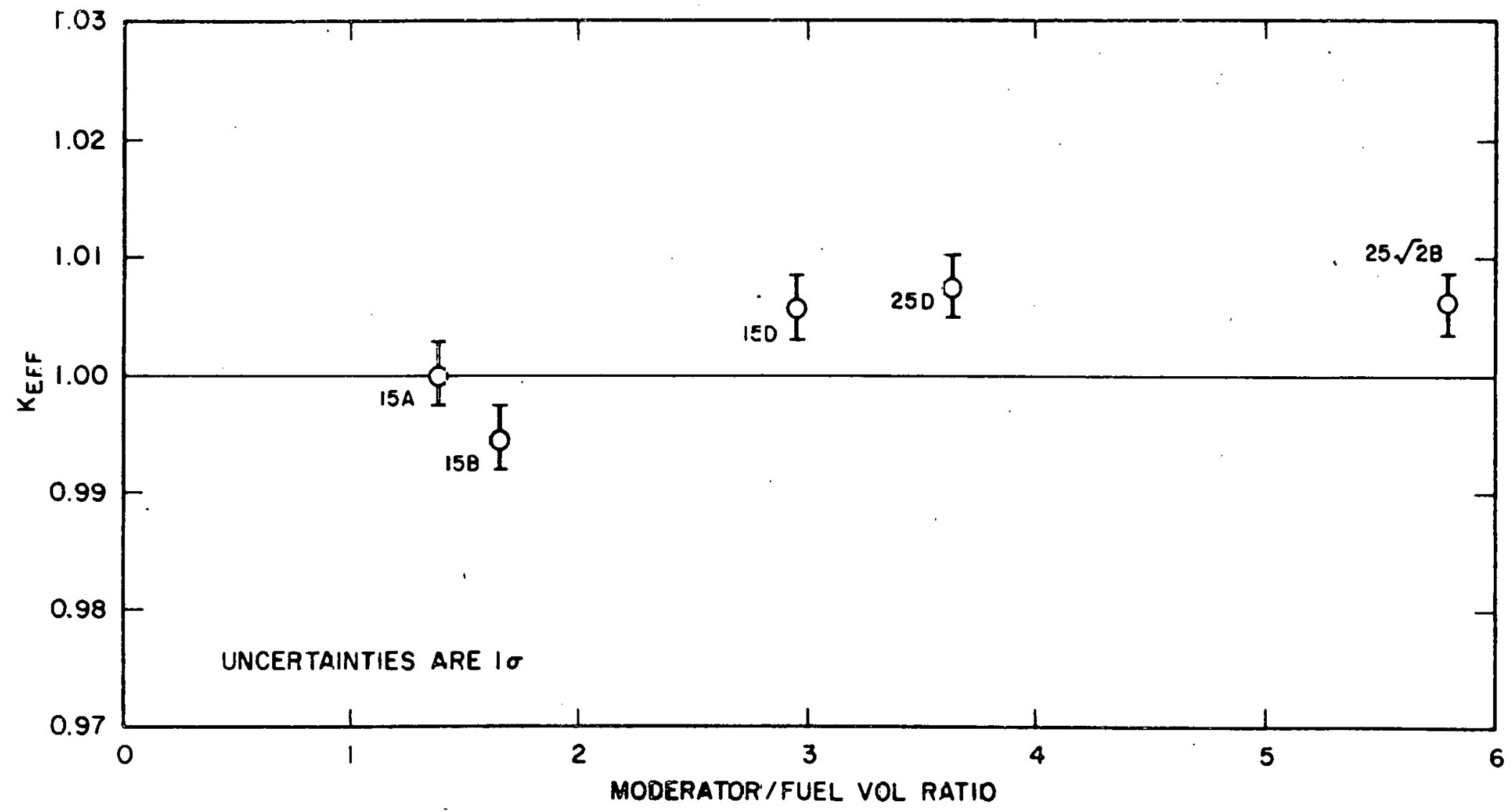

Calculated $\mathrm{K}_{\text {eff }}$ Versise Mcderator/Fuel Volume Ratio fcr

FIGURE 7 
PTMG program. This used the small measured axial buckling $\left(\sim 0.0004 \mathrm{~cm}^{-2}\right)$ and did an explicit radial traverse of the homogenized core out through the reflector. The calculation was otherwise similar to MUFT7.

Results are shown in Table 14 and in Figure 8. Two points are noteworthy:

(1) The P TMG leakage-corrected eigenvalues are somewhat higher than the full-core RCPO1 but in generally reasonable agreement, in view of the approximations (e.g., homogenization and few-group flux weighting) in PTMG.

(2) For the 15/1-fueled lattices, use of the measured $B^{2}$ values in MUFT produces eigenvalues significantly below those calculated with the explicit radial traverse by $P$ MMG or by the full-core RCPO1. Since MUFT7 and P7MG contain basically similar approximations, except for the explicit spatial treatment in $P$ TMG, this suggests that the measured bucklings are too large. It is clear from the PTMG results that this is due to nonasymptotic spectra in the smaller cores (Ref. 27) - that is, the calculated radial flux shapes agree reasonably well with measurement, but these are not the asymptotic shapes. For the 25/1-fueled lattices, which have smaller bucklings, agreement is satisfactory. 

Table 14 - Comparison of $K_{\text {eff from MUFT } 7 \text { and P7MG }}$
With the Full-Core RCP01 Results

\begin{tabular}{|c|c|c|c|c|c|}
\hline \multirow{2}{*}{$\begin{array}{l}\text { Lattice } \\
\text { Ident. }\end{array}$} & \multirow{2}{*}{$\begin{array}{l}\text { Measured } \\
\text { Material } \mathrm{B}^{2} \\
\left(\mathrm{~cm}^{-2}\right) \times 10^{4} \\
\end{array}$} & \multicolumn{2}{|c|}{$\mathrm{K}_{\mathrm{eff}} \pm \sigma^{*}$} & \multirow{2}{*}{$\begin{array}{l}\frac{\text { (MUFT 7) }}{\text { (Ful1 Core }} \\
\text { RCP01) }\end{array}$} & \multirow{2}{*}{$\begin{array}{l}\frac{(P 7 M G)}{(F u 11 \text { Core }} \\
\text { RCP01) }\end{array}$} \\
\hline & & MUFT7 & P7MG & & \\
\hline $15 A$ & $85.31 \pm .26$ & $.9756 \pm .0014$ & $1.0044 \pm .0014$ & $.9754 \pm .0020$ & $1.0042 \pm .0020$ \\
\hline $15 B$ & $94.25 \pm .29$ & $.9758 \pm .0018$ & $1.0010 \pm .0018$ & $.9810 \pm .0022$ & $1.0063 \pm .0022$ \\
\hline $15 D$ & $114.20 \pm .70$ & $.9883 \pm .0019$ & $1.0137 \pm .0019$ & $.9828 \pm .0024$ & $1.0081 \pm .0024$ \\
\hline $25 D$ & $64.01 \pm .46$ & $1.0046 \pm .0033$ & $1.0117 \pm .0033$ & $.9971 \pm .0035$ & $1.0042 \pm .0035$ \\
\hline $25 \sqrt{2 B}$ & $53.55 \pm .11$ & $1.0060 \pm .0029$ & $1.0129 \pm .0029$ & $1.0000 \pm .0032$ & $1.0069 \pm .0032$ \\
\hline
\end{tabular}

* Both normalized to the same cell RCP01. Uncertainties stem from Monte Carlo statistics at one standard deviation. The MUFT7 calculations used measured material $\mathrm{B}^{2}$. 


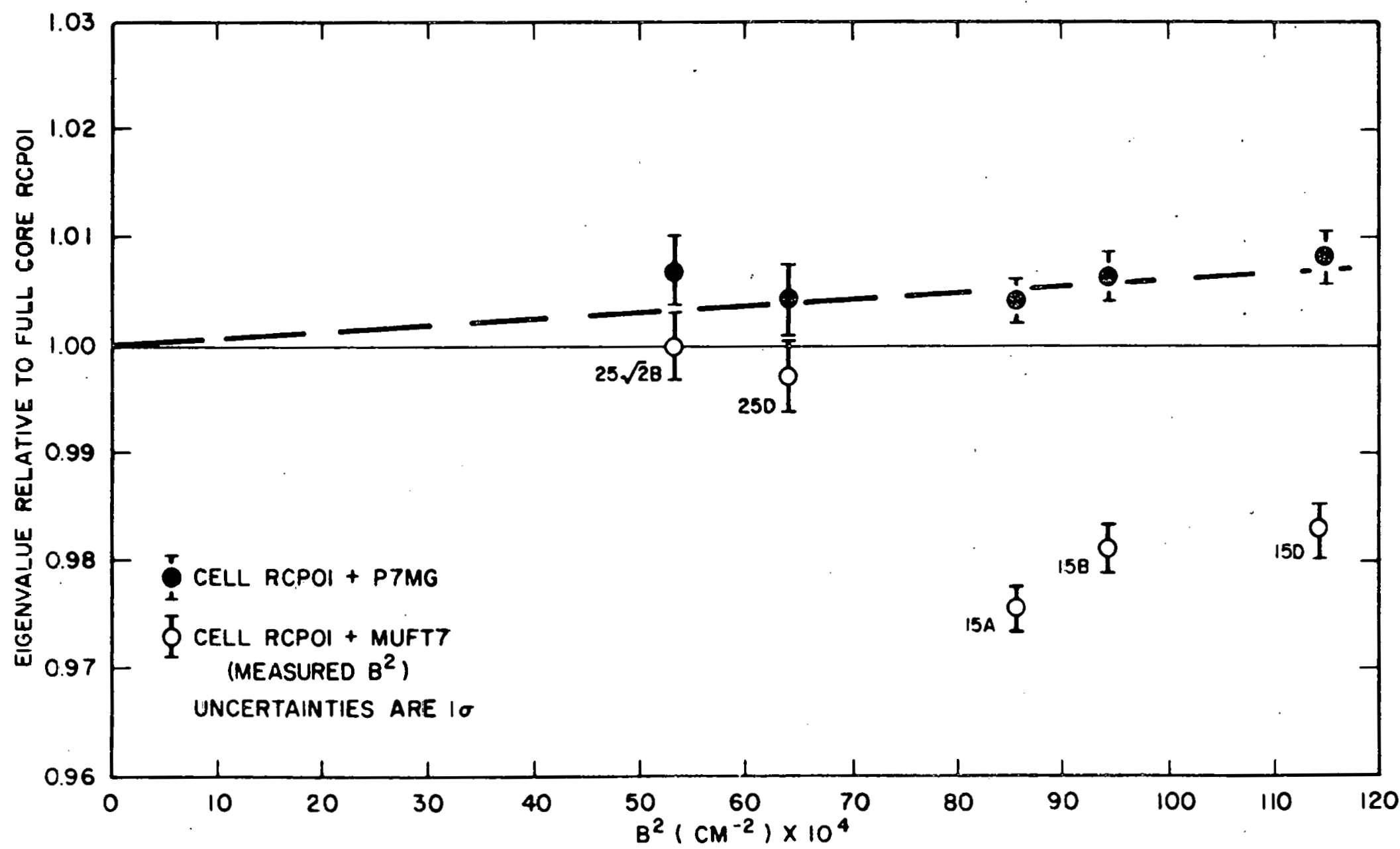

Comparison of $\mathrm{K}_{\text {eff }}$ Values for TUPE Lattices Obtained by Different Methods FIGURE 8 
Two additional studies of TUPE lattices with ENDF/B-IV data have been reported:

At GE-San Jose (Ref. 43), lattices $15 \mathrm{~A}$ and $15 \mathrm{~B}$ were analyzed with $\mathrm{BWR}$ methods. These methods consisted of multigroup mixed one- and two-dimensional transport theory and transport-corrected diffusion theory techniques. The epithermal spectrum was computed in 68 groups with determination of spatial weighting of the fuel, clad and moderator, and evaluation of the two-dimensional Dancoff interaction. Resolved resonances were evaluasc. with the intermediate resonance approximation. The space-dependent thermal spectrum was computed by use of the 30 group integral transport theory. At Combustion Engineering (Ref. 44), lattice 15B was analyzed with the same methods used for the BNL exponentials. In a CEPAK point calculation, the leakage was accounted for by a total $\mathrm{B}^{2}$ obtained from the measured core dimensions and the radial and axial reflector savings. Also, a PDQ spatial calculation was done with the core explicitly modeled in two dimensions in the horizontal plane. Four-energy-group diffusion parameters were generated in CEPAK for use in PDQ.

Eigenvalue results are compared in Table 15. These show good agreement for the spatially dependent calculations. For the point calculations with measured $\mathrm{B}_{\mathrm{m}}^{2}$, the CEPAK result is not as low as obtained with MUFT7. Cadmium ratios of Th232 capture and U235 fission artivatinns were measured with thorium metal foils and U235-Al foils respectively (Ref. 27). Statistics, from reproducibility, appear to be good for $U 235\left(\sim 1 \%\right.$ in $\left.\varepsilon^{25}\right)$; for thorium capture, uncertainties of $0^{02}$ range from $2 \%$ (for core $25 \sqrt{ } 2 \mathrm{~B}$ ) to 
nearly 6\% (for core 15B). Interpretation of these measurements would require detailed study of experimental effects - mainly cadmium cutoff energy and flux perturbation by the detector foils and cadmium sleeves. No attempt has been made to analyze these measurements, and such an effort is judged to be unpromising.

This conclusion is supported by the calculated $\rho^{02}$ values shown in Table 16. The GE-San Jose and Bettis results agree well but are far below experiment. Since it seems unlikely that the calculations are in error by anywhere near this amount (in view of the good eigenvalues), much of the differences must be attributed to problems with the measurements or their interpretation. This suggests that useful information about thorium resonance capture is not likely to be gained by analysis of these measurements. A similar conclusion was reached in Ref. 44. 
Table 15 - Comparison of ENDF/B-IV Calculated Eigenvalues for TUPE Lattices

Laboratory

A) GE-San Jose (Ref. 43)

Combustion Engineering (Ref. 44)

Bettis (Ref. 42)

B) Combustion Engineering

Bettis

C) Bettis
Method

BWR Methods

PDQ

RCPO 1/P TMG

CEPAK

RCP01/MUFT 7

Full core RCPO 1

$\begin{array}{cc}\text { TUPE 15A } & \text { TUPE 15B } \\ 1.006 & 1.005 \\ 1.0044 \pm .0014 & 1.0023 \\ & .9873 \\ & .9758 \pm .0018\end{array}$

$1.0002 \pm .0014$

$.9947 \pm .0013$ 
Table 16 - Comparison of Calculated and Measured Values of $e^{02}$ for TUPE Cores

\begin{tabular}{|c|c|c|c|}
\hline & $15 A$ & $15 B$ & $\begin{array}{l}\text { Cut off } \\
\text { Energy }\end{array}$ \\
\hline Experiment: & $2.70 \pm .09$ & $2.09 \pm .12$ & \\
\hline Calculation: & & & \\
\hline GE-San Jose (Ref..43) & 1.65 & 1.42 & $0.4 \mathrm{eV}$ \\
\hline Bettis RCPOl/PTMG (Ref. 42) & $\begin{array}{l}1.69 \\
1.56\end{array}$ & $\begin{array}{l}1.43 \\
1.33\end{array}$ & $\begin{array}{l}0.4 \mathrm{eV} \\
0.625 \mathrm{eV}\end{array}$ \\
\hline
\end{tabular}




\section{THUD Lattices (Th-U235- $\left.\mathrm{D}_{2} \mathrm{O}\right)$}

The THUD (Thorium-Uranium-Deuterium) lattice critical experiments were run at Argonne National Laboratory in the late 1950's (Ref. 30). There were 45 uniform single-rod lattices with two types of fuel: $U 235 \mathrm{O}_{2}-\mathrm{ThO}_{2}$ rods with Th/U235 atom ratios of $15 / 1$ and $25 / 1$ (the same rods used in the TUPE criticals run at Babcock and Wilcox). The lattices were triangular arrays at four pitches (of 2,3,4, and $6 \times 0.953 \mathrm{~cm}$ ). At each pitch, several lattices were run differing in number of fuel rods and moderator critical height.

The $\mathrm{D}_{2} \mathrm{O}$ purity, initially better than $99 \%$, decreased by $2 \%$ over the $2 \frac{1}{2}$ year duration of the program. At the end, an independent analysis obtained a purity $1.6 \%$ below the last ANL determination, and this discrepancy was not explained.

To test overall consistency of interpretation, we chose to analyze a specific lattice for which measurements were made at the beginning, middle, and end of the program (designated core 91, 233, and 456, respectively). This lattice had 745 fuel rods with Th/U235 of $25 / 1$ at the $2 \times 0.953 \mathrm{~cm}$ pitch. Core 456 was also analyzed with a $\mathrm{D}_{2} \mathrm{O}$ purity $1.6 \%$ below the ANL determination. Composition data for the fuel were those used in analysis of the TUPE lattices (obtained from Ref. 27).

The lattice was described explicitly in three dimensions by the RCPO1 Monte Carlo program, including corner posts, grid sheets, cross-shaped control rod guides and the tank. 
Table 17 shows eigenvalues obtained in the full core analyses with ENDF/B-IV data. Within statistics, the three cores have consistent eigenvalues, averaging $1.0010 \pm .0013(\sigma)$. For core 456 , a $1.6 \%$ reduction of $\mathrm{D}_{2} \mathrm{O}$ purity reduced the calculated eigenvalue by $0.22 \pm 0.31$ percent.

In order to do sensitivity studies, core 456 was analyzed with PTMG, which performed an explicit radial traverse of the homogenized lattice out through the reflector. Zero-leakage cell reaction rates were normalized to a Monte Carlo cell calculation.

For THUD 456, PTMG showed a small (0.17\%) decrease in eigenvalue due to the $1.6 \%$ reduction of $\mathrm{D}_{2} \mathrm{O}$ purity, in good agreement with RCP01. Epithermal/ thermal reaction ratios were reduced by $9 \%$, however. Thus, the $\mathrm{D}_{2} \mathrm{O}$ purity ambiguity is quite significant for such quantities as $p^{02}$ (ratio of epithermal) thermal thorium captures) and $\delta^{25}$ (ratio of epithermal/thermal U235 fissions) although it has little effect on eigenvalue.

There is another ambiguity, which has to do with the composition of the 25/1 fuel. Different chemical analyses obtained values for the $\mathrm{Th} / \mathrm{U}$ atom ratio of 25.33 and 24.65 , as shown in Tables XLII and XLV of Ref. 30 . Although the former value seems to be preferred and has been used by BSW (Ref. 27 and private communication from Warren Wittkopf), there remains a significant uncertainty in this regard. $K_{\text {eff }}$ results quoted here are for $T h / U=25.33$. Use of the 24.65 value would raise $\mathrm{K}_{\text {eff }}$ by $0.75 \%$ for these THUD lattices. It would raise $k_{\text {eff }}$ for the $25 \sqrt{2}$ B and 250 TUPE lattices by $0.9 \%$, worsening agreement with the 15/1-fueled TUPE lattices. 
Table 17 - Calculated Criticality of THUD Lattices (Ful1 Core RCP01)

\begin{tabular}{|c|c|c|c|c|c|}
\hline $\begin{array}{l}\text { Lattice } \\
\text { Ident. }\end{array}$ & $\begin{array}{c}\text { Date of } \\
\text { Run } \\
\end{array}$ & $\begin{array}{c}\mathrm{D}_{2} \mathrm{O} \\
\text { Purity }(\%) \\
\end{array}$ & $\begin{array}{l}\text { Moderator } \\
\text { Height }(\mathrm{cm}) \\
\end{array}$ & $\begin{array}{l}\text { Calculated } \\
\text { Net leakage }\end{array}$ & $\begin{array}{l}\text { Calculated } \\
\mathrm{K}_{\text {eff }} \pm \sigma^{*}\end{array}$ \\
\hline 91 & $3 / 58$ & 98.5 & 132.84 & .269 & $1.0024 \pm .0023$ \\
\hline 233 & $11 / 58$ & 97.9 & 135.08 & .268 & $1.0018 \pm .0024$ \\
\hline \multirow[t]{2}{*}{456} & $12 / 59$ & 97.2 & 139.09 & .267 & $.9987 \pm .0021$ \\
\hline & & & & Average & $1.0010 \pm .0013$ \\
\hline 456 & $12 / 59$ & $95.6(?)$ & 139.09 & .271 & $.9965 \pm .0023$ \\
\hline
\end{tabular}

* One stiandard deviation. 
It is noteworthy that neutron leakage out of the reactor tank was calculated to be $\sim 10 \%$. This suggests that questions of room return could be significant for these lattices.

There were a limited number of integral parameter measurements for these cores - specifically, Th232 capture cadmium ratios obtained with metal foils. Interpretation of these measurements would require detailed study of experimental effects such as cadmium cutoff. Since, in most cases, only one irradiation was made and uncertainties are not quoted, it is judged that such an undertaking is not warranted.

\section{BNL Exponential Lattices (Th-U233- $\mathrm{H}_{2} \mathrm{O}$ and $\mathrm{D}_{2} \mathrm{O}$ )}

A series of exponential experiments were carried out at the Brookhaven National Laboratory (Ref. 33, 34) in the early 1960 's. They were fueled with $\mathrm{U}^{2} 33-\mathrm{ThO}_{2}$ elements arranged in uniform triangular pitch lattices in light and heavy water. Measurements were made of the material buckling $\mathrm{B}_{\mathrm{m}}^{2}$, reflector savings, dysprosium disadvantage factor, ratio of epicadmium to subcadmium capture in thorium $\left({ }_{0}^{02}\right)$, and the ratio of Th232 fission to $U 233$ fission $\left({ }_{02}^{23}\right)$. Much of the basic data for the BNL experiments has been compiled by Price (Ref. 33 ), and the most recent survey of the data is presented in the paper by Windsor et al. (Ref. 34). 
Recent calculations of the light water lattices with moderator-to-fuel volume ratios ranging from $0.997: 1$ to $3.004: 1$. have been reported by Sehgal et al. (Ref. 45). This analysis, which used ENDF/B-IV cross sections in RABBLE/HAMMER cell calculations, produced values of $\mathrm{K}_{\text {eff }}$ shown in the third column of Table 18. Other calculations were reported by Shapiro et al. (Ref. 44) for lattices with volume ratios ranging from $0.997: 1$ to $4.2722: 1$. The analytic model used in this study was based on the CEPAK code and used ENDF/B-IV data and $L$ factors for Th232 and U233 resonance reaction rates which were corrected for resonance interference between Th232 and U233. These results are shown in the fourth column of Table 18. They typically are 0.5 to $1 \%$ higher than the corresponding results of Sehga 1 and exhibit the same upward trend with increasing moderator-to-fuel volume ratio (Figure 9).

More recent studies of the light water lattices have yielded differing results. Weiss and Malaviya (Ref. 46) have analyzed all eight unpoisoned light water lattices using the HAMMER computer code and ENDF/B-IV cross sections. Resonance self-shielding was accounted for with the Nordheim approximation. As shown in column 5 of Table 18, criticality was underpredicted by an amount varying from 0.1 to $1.3 \%$. However, the trend in the calculated $K_{\text {eff }}$ versus moderator-to-fuel volume ratio is opposite to that seen in the studies in Refs. 44, 45. The causes for this difference were not discussed in Ref. 46. 


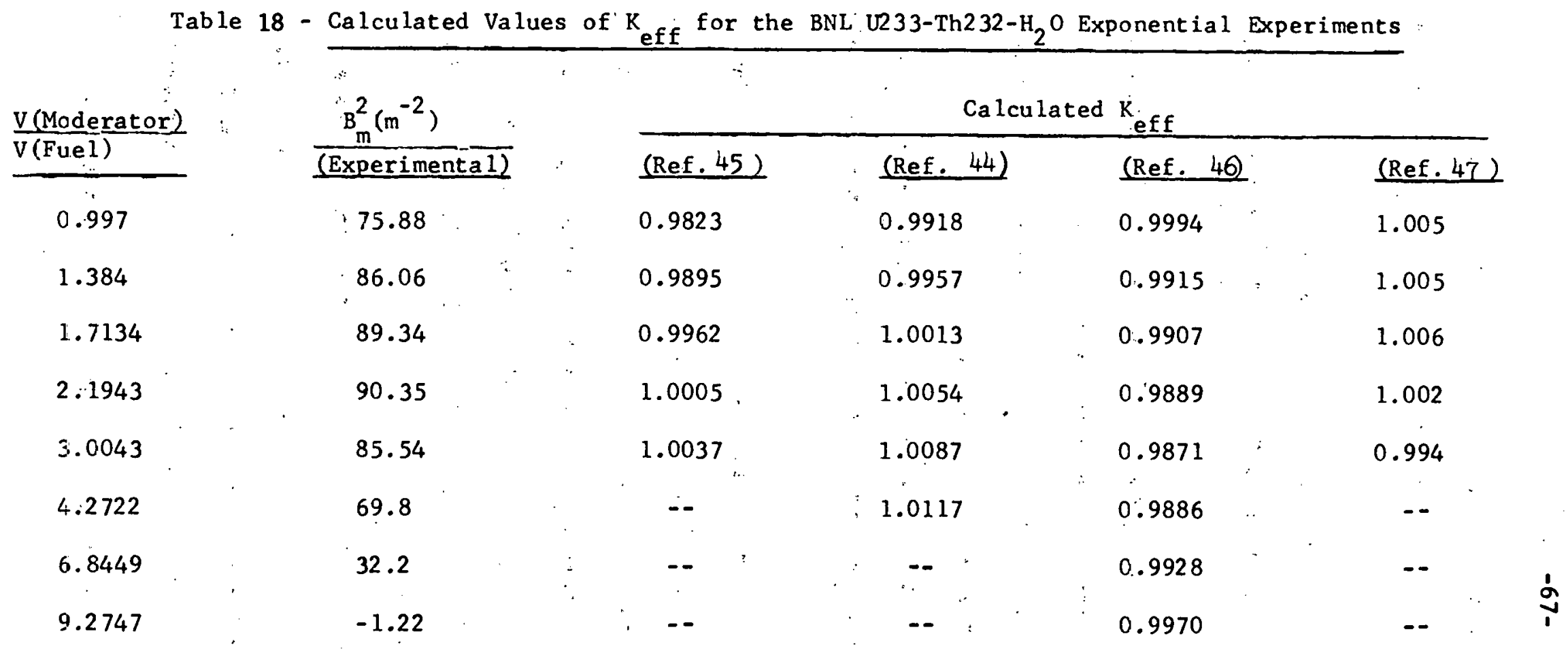


Bhatt et al. (Ref. 47) have reported an analysis of those BNL exponential lattices with $(M / F) \leq 3.0043$. These calculations used BWR lattice physics methods similar to those applied to the TUPE lattices (Table 15). The calculated critical eigenvalues, colum six of Table 18, are overpredicted by $0.5 \%$ for moderator-to-fuel ratios below 2 . For $(M / F)=3.004$, the bias changes sign.

This comparison of $\mathrm{K}_{\text {eff }}$ values depicts significant method differences, and possibly problems of interpretation, which affect the use of these experiments for nuclear data testing purposes. In an attempt to clear up some of the discrepancies, we have analyzed the unpoisoned light water lattices and all of the heavy water lattices. For the light water lattices three methods to compute $K_{\text {eff }}$ were employed. In increasing order of sophistication, they were:

1) Single lattice cell RCPOl Monte Carlo calculations corrected for neutron leakage using the MUFT7 program with measured values of the material buckling. Resonance absorption in MUFT7 was handled by a heterogeneous collision probabilistic method. Computed reaction rates in the resonance range and other energy ranges for the unbuckled MUFT calculations generally were in good agreement with the corresponding Monte Carlo cell results.

2) Similar to method 1 except that the MUFT7 calculation was replaced by PTMG. This was a one-dimensional (radial), homogenized transport calculation, with a small negative transverse buckling given by $\overline{\mathrm{B}}_{\mathrm{z}}^{2} \equiv \frac{1}{\ell_{\mathrm{z}}^{2}}$, where $\ell_{z}$ was the measured relaxation length. (Resonance absorption in PTMG was treated in a manner similar to MUFT7.) 


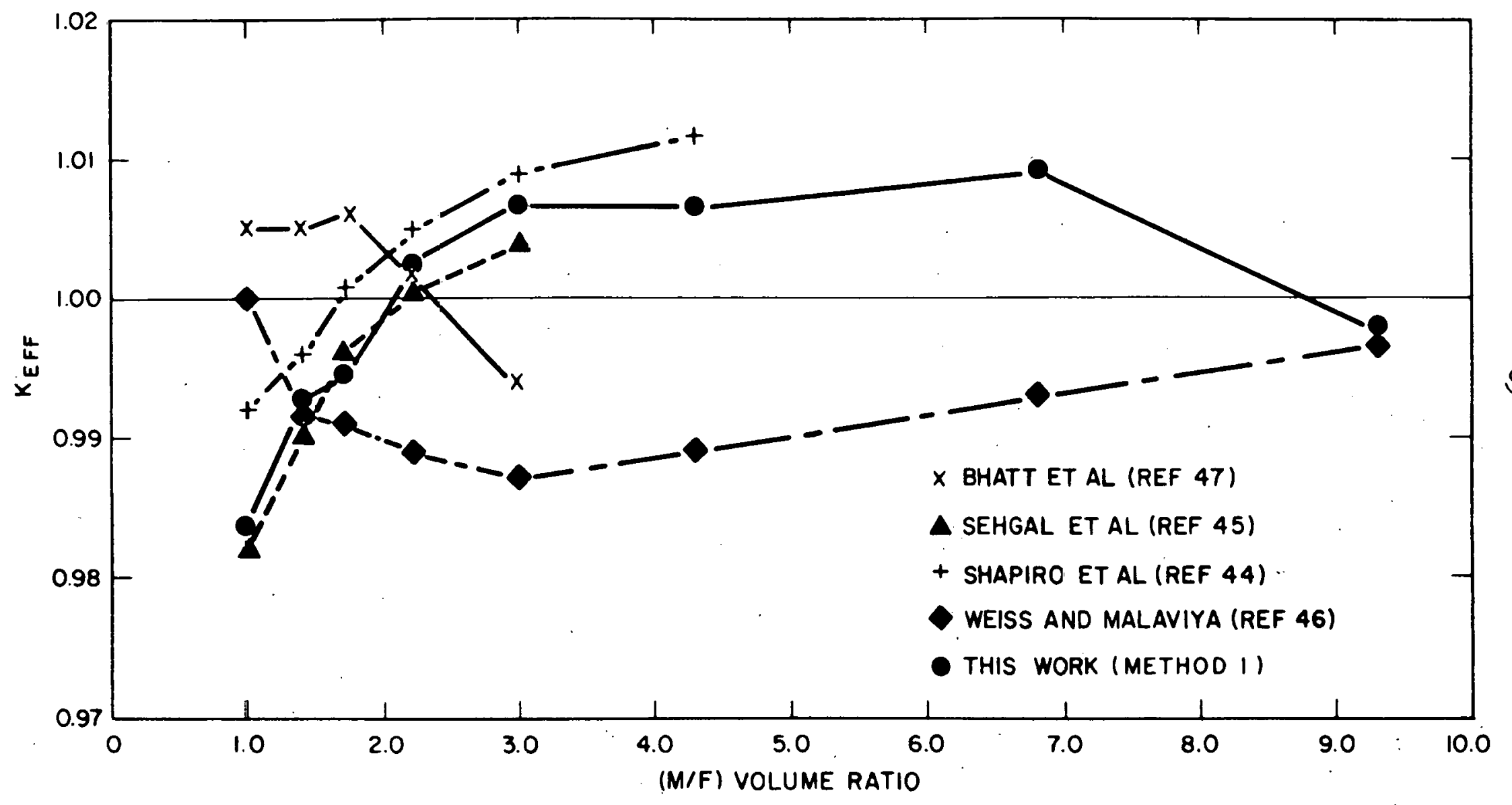

Comparison of Eigenvelues Based on ENDF/B-IV for the BNL Le33- $\mathrm{ThO}_{2}-\mathrm{H}_{2} \mathrm{O}$ Lattices

FIGURE 9 
3) Two-dimensional, explicit representation of the full lattice with the RCPO1 Monte Carlo program. The final $\mathrm{K}_{\text {eff }}$ values included a small correction for axial in-leakage which was determined using $P$ TMG and the measured $\mathrm{B}_{\mathrm{z}}^{2}$.

Our results for the light water lattices using method 1 (Table 19, column 1) are in good agreement with those of Ref. 45 and once again exhibit an upward trend with $M / F$ volume ratio for values of $M / F$ below 3.0 . The results for lattices with $M / F \geq 3.0$ show greater consistency, with the exception of the 9.27:1.0 lattice which has a negative material buckling. The Method 2 $(\mathrm{RCP} \mathrm{Cel1}+\mathrm{P} 7 \mathrm{MG})$ results appear to be nominal1y $0.5 \%$ higher than the corresponding Method 1 values of $\mathrm{K}_{\text {eff }}$ and appear to form a more consistent set. They also exhibit a slight rising trend in $K_{\text {eff }}$ for $M / F$ values below 3.0 . With perhaps the exception of the 1.38:1.0 1attice, the 2D Monte Carlo calculations (Method 3) yield the most consistent set of $\mathrm{K}_{\text {eff }}$ values (Figure 10). It appears that the greater overall consistency of interpretation that is achieved with the 2D Monte Carlo results compared with those based on Methods 1 and 2 may be due to the elimination of approximations involved in the homogenization of the lattices. Since the tight lattices have the smallest fueled radii, it is supposed that errors in effective resonance cross sections that occur near the core-reflector interface can significantly affect calculated results. Note that for the larger lattices $(M / F>3.0)$ the rising trend in $\mathrm{K}_{\text {eff }}$ vs $M / F$ does not persist for Methods 1 and 2 . 
Table 19 - Comparison of Several Methods for Computing $\mathrm{K}_{\mathrm{eff}}$ for the BNL U233-Th232- $\mathrm{H}_{2} \mathrm{O}$ Exponential Experiments

$\frac{\mathrm{V} \text { (Moderator) }}{\mathrm{V} \text { (Fuel) }}$

0.997

1.384

1.7134

2.1943

3.0043

4.2722

6.8449

9.2747

\begin{tabular}{ll} 
& Calculated $K_{\text {eff }}^{*}$ \\
\hline Cel1 RCP01+MUFT7 Cel1 RCP01+P7MG**
\end{tabular}
(Method 2)

$$
0.9835 \pm 0.0021
$$

0.9993

0.9984

1.0038

1.0104

1.0106

1.0074

1.0049

1.0026
2D Full Core RCP01-

(Method 3)
$0.9986 \pm 0.0020$
$0.9907 \pm 0.0022$
$1.0077 \pm 0.0028$
$1.0040 \pm 0.0019$
$1.0028 \pm 0.0024$
$1.0055 \pm 0.0025$
$1.0015 \pm 0.0025$
$0.9969 \pm 0.0023$

* Monte Carlo statistical errors are one standard deviation. ${ }^{* *}$ Statistical errors (not shown) are the same as for Method 1. 


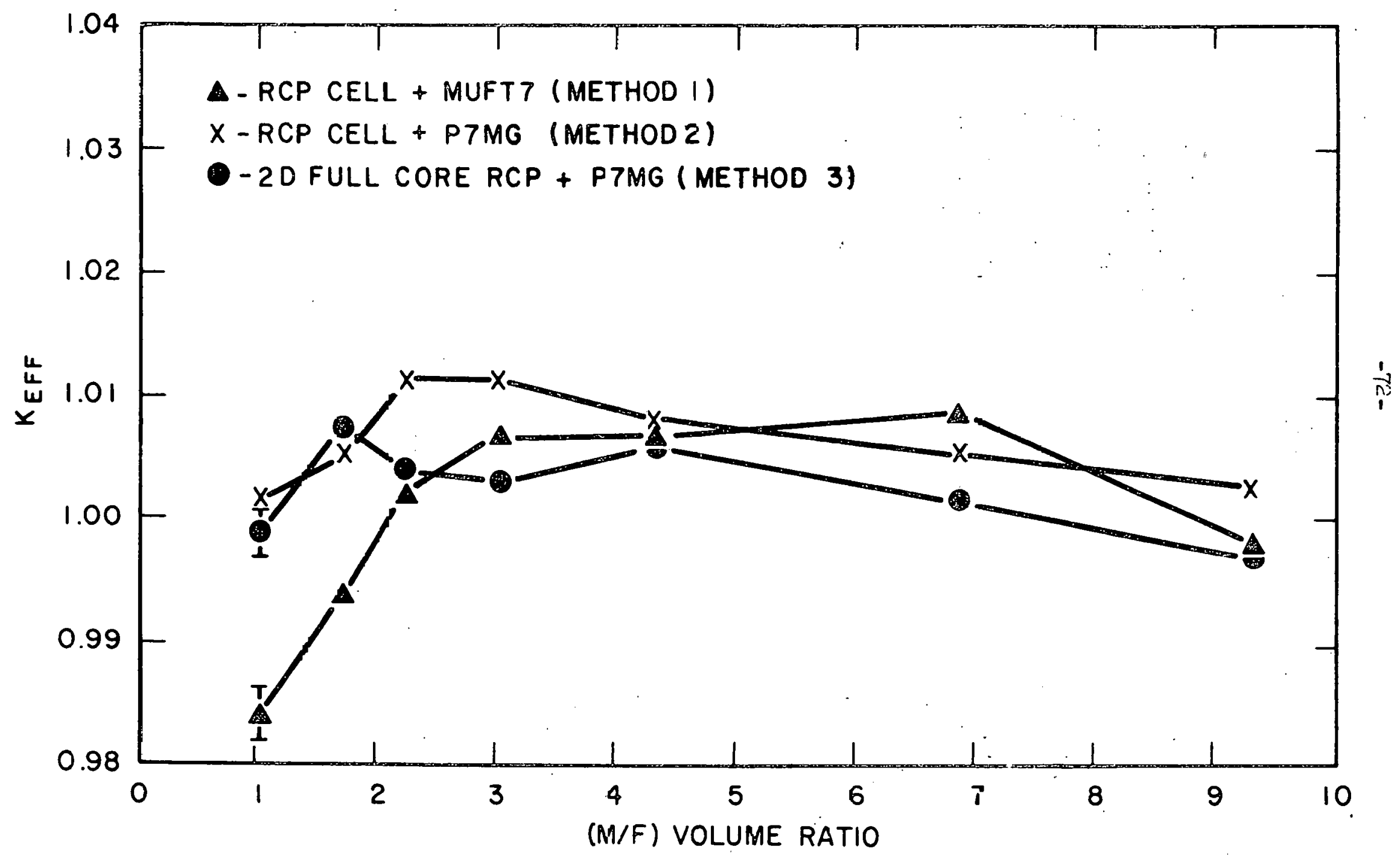

Comparison of Three Methods to Calculate $K_{\text {eff }}$

for the BNL L233-ThO2- $\mathrm{H}_{2} \mathrm{O}$ Lattices. FNDF/3-TV

Data were Used Througbout

(See text Section III.B.4)

FIGURE 10 
The BNL U233-thorium- $\mathrm{D}_{2} \mathrm{O}$ exponential lattices were also analyzed, in a manner similar to that for the light water lattices. Results are shown in Table 20 and Figure 1l. With Method 1 (RCPOI Cell + MUFT), the calculated values of $\mathrm{K}_{\text {eff }}$ form a nearly consistent set, but criticality is nominally underpredicted by 1.5\%. Results based on Method 2 (Cell RCPOI + P7MG) and Method 3 (2D full core RCP + P.TMG), with the exception of the $M / F=120.5$ lattice, also underpredict criticality by $1-2 \%$. It is not known why $K_{\text {eff }}$ calculated for the 120.5:1.0 lattice using Methods 2 and 3 is 10\% 10w. It is probably symptomatic of the fact, recognized by the experimenters, that all the $\mathrm{D}_{2}$-moderated lattices were so small as to present significant questions of interpretation. For $M / F \leq 55.2$, the full core Monte Carlo results depict a slight downward trend in $K_{\text {eff }}$ vs the $\mathrm{M} / \mathrm{F}$ volume ratio.

Also shown in Table 20 are the values of $K_{\text {eff }}$ from the Ref. 47 analysis of these $\mathrm{D}_{2} \mathrm{O}$ experiments. They are in disagreement with our calculations in that they nominally overpredict $k_{\text {eff }}$ by $\sim 1.0 \%$. There is also evidence of a slight downward trend in $K_{\text {eff }}$ versus increasing $M / F$ volume ratio. The source of the disagreement is not known.

Another key comparison of results can be made for the predicted epicadmiumto-subcadmium rates of Th232 capture $\left(\rho^{02}\right)$. Calculated values of $\rho_{c}^{O 2}$ are compared with the measurement for the light water lattice in Table 21. Generally, the calculation of $\rho_{c}^{02}$ are in good agreement with aach other, but consistently underpredict the measured values by $(5-8) \%+4 \%$. 
Table 20 - Comparison of Several Methods for Computing $K_{\text {eff }}$ for the BNL U233-Th232- $\mathrm{D}_{2} \mathrm{O}$ Exponential Experiments

\begin{tabular}{|c|c|c|c|c|}
\hline \multirow[b]{2}{*}{$\begin{array}{l}\mathrm{V} \text { (Moderator) } \\
\mathrm{V} \text { (Fuel) }\end{array}$} & \multicolumn{3}{|c|}{ Calculated $\mathrm{K}_{\text {eff }}{ }^{*}$} & \multirow[b]{2}{*}{ (Ref. 47) } \\
\hline & $\begin{array}{l}\text { Cel1 RCP01+MUFT7 } \\
\text { (Method 1) }\end{array}$ & $\begin{array}{l}\text { Cel1 RCP01+P TMG } \\
\text { (Method 2) }\end{array}$ & $\begin{array}{l}\text { 2D Full Core } \\
\text { RCPOI+P 7MG } \\
\text { (Method 3) } \\
\end{array}$ & \\
\hline 3.005 & $0.9857 \pm 0.0032$ & -- & -- & 1.0186 \\
\hline 11.716 & $0.9806 \pm 0.0020$ & 0.9911 & $0.9906 \pm 0.0029$ & 1.0201 \\
\hline 16.051 & $0.9821 \pm 0.0020$ & -- & $-\infty$ & 1.0215 \\
\hline 29.113 & $0.9822 \pm 0.0019$ & 0.9868 & $0.9846 \pm 0.0028$ & 1.0139 \\
\hline 37.828 & $0.9890 \pm 0.0020$ & -- & -- & 1.0184 \\
\hline 55.226 & $0.9792 \pm 0.0020$ & 0.9905 & $0.9795 \pm 0.0025$ & 1.0053 \\
\hline 81.212 & $0.9913 \pm 0.0027$ & $-\infty$ & -- & 1.0117 \\
\hline 120.491 & $0.9892 \pm 0.0033$ & 0.8963 & $0.9085 \pm 0.0028$ & 1. . 0006 \\
\hline
\end{tabular}

* Monte Carlo statistical errors are one standard deviation. ** Statistical errors (not shown) are the same as for Method 1. 


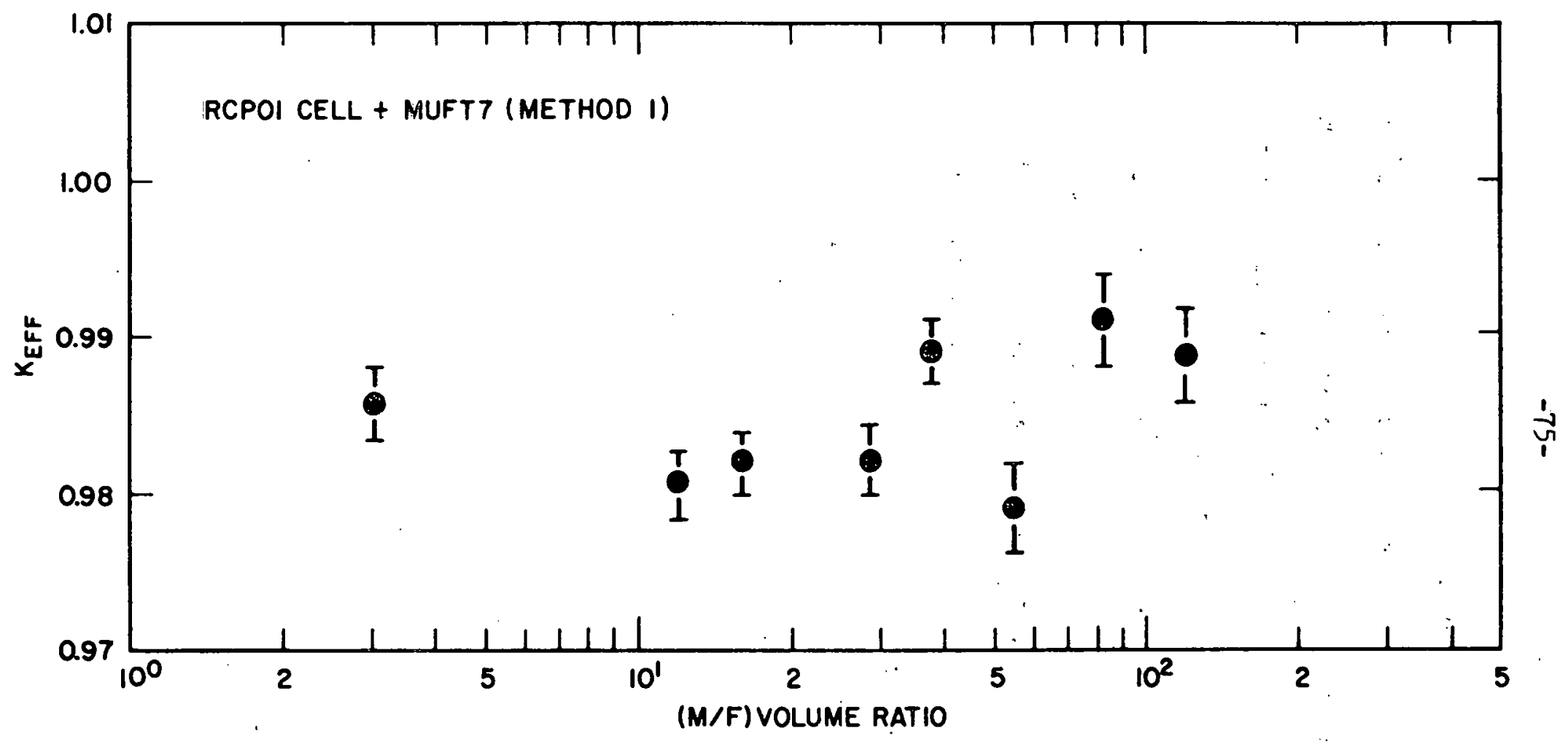

Calculated Keff (Method 1) vs. M/F Volume Ratio for the BNL U23.3-ThO2-D O Lattices

FIGURE 11 
The predicted values for $0^{\mathrm{O} 2}$ for the $\mathrm{D}_{2} \mathrm{O}$ lattices are compared with experiment in Table 22. As in the case of the light water lattices, $\rho^{02}$ tends to be underpredicted, but only slightly, with an average bias of $-2 \%$ $\pm 4 \%$. There appear to be possible problems with the interpretation of the $\rho^{02}$ values for the $81.31: 1.0$ and $120.5: 1.0$ lattices.

The analyses of the BNL exponential experiments based on ENDF/B-IV do not yield a wholly consistent set of results. The results obtained for the $\mathrm{H}_{2} \mathrm{O}$ lattices show $\mathrm{K}_{\text {eff }}$ to be overpredicted slightly by the most consistent method of interpretation (explicit 2D Monte Carlo). On the otiner hand, $\mathrm{O}^{\mathrm{O}}$ is consistently underpredicted by $\sim 8 \%$. For the $\mathrm{D}_{2} \mathrm{O}$ lattices, the $K_{\text {eff }}$ values are underpredicted by $\sim 1.5 \%$ while the values for $\rho^{02}$ are slightly low by $\sim 2 \%$. A comparison of these results with other thorium capture measurements will be made in Section III.7. 
Table 21 - Comparison of Calculated and Measured Values of $\rho^{02}$ for the Unpoisoned BNL U233-Th232- $\mathrm{H}_{2} \mathrm{O}$ Lattices

\begin{tabular}{|c|c|c|c|c|c|c|}
\hline V(Moderator) & $\mathrm{B}_{\mathrm{m}}^{2}$ & Measured $D^{02}$ & \multicolumn{4}{|c|}{ Calculated Results } \\
\hline V(Fuel) & $\overline{\left(m^{-2}\right)}$ & & Ref. (45) & Ref. (44) & Ref. (47) & This Work \\
\hline 0.997 & 75.88 & $1.380 \pm 0.042$ & 1.308 & 1.307 & 1.283 & 1.271 \\
\hline 1.384 & 86.06 & $0.928 \pm 0.038$ & 0.901 & 0.906 & 0.904 & 0.865 \\
\hline 1.713 & 89.34 & $0.754 \pm 0.024$ & 0.716 & 0.720 & 0.729 & 0.698 \\
\hline 2.194 & 90.35 & $0.607 \pm 0.026$ & 0.553 & 0.561 & 0.575 & 0.543 \\
\hline 3.004 & 85.54 & $0.435 \pm 0.013$ & 0.406 & 0.411 & 0.431 & 0.396 \\
\hline 4.2722 & 69.8 & - & $-\infty$ & -- & - & - \\
\hline 6.8449 & 32.2 & $0.218 \pm 0.008$ & - & -- & - & 0.201 \\
\hline 9.2747 & -1.22 & $0.170 \pm 0.007$ & - & -- & - & 0.158 \\
\hline
\end{tabular}


Table 22 - Comparison of Calculated and Measured Values of $\mathrm{O}^{\mathrm{O}}$ for the BNL. U233-Th232- $-\mathrm{D}_{2} \mathrm{O}$ Lattices

\begin{tabular}{|c|c|c|c|}
\hline$\frac{\mathrm{V} \text { (Moderator) }}{\mathrm{V}(\text { Fue } 1)}$ & Measured :02 & Calculated $\circ^{02}$ & $0^{02}(\text { calc. })^{10^{02}}$ (meas.) \\
\hline 3.005 & $4.71 \pm 0.18^{a}$ & 4.377 & $0.929 \pm 0.038^{b}$ \\
\hline 11.716 & $0.794 \pm 0.028^{a}$ & 0.759 & $0.956 \pm 0.035$ \\
\hline 16.051 & $0.565 \pm 0.017^{a}$ & 0.555 & $0.982 \pm 0.030$ \\
\hline 29.113 & $0.297 \pm 0.011$ & 0.297 & $1.000+0.037$ \\
\hline 37.828 & $0.234 \pm 0.008$ & 0.230 & $0.983 \pm 0.034$ \\
\hline 55.226 & $0.166 \pm 0.006$ & 0.164 & $0.987 \pm 0.036$ \\
\hline 81.312 & $0.104 \pm 0.005$ & 0.111 & $1.066 \pm 0.048$ \\
\hline 120.491 & $0.089 \pm 0.005$ & 0.079 & $0.888 \pm 0.056$ \\
\hline
\end{tabular}

Weighted average of $\rho^{02}$ determined by the cadmium ratio and thermal activation methods. All other values are hased on tho cd ratio method. ${ }^{b}$ Errors are of experimental origin only. 


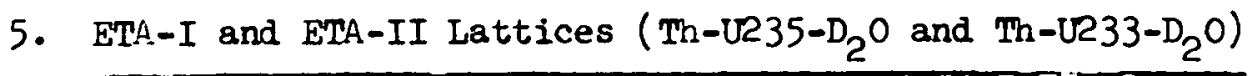

The ETA-I and ETA-II critical experiments were carried out at Bettis in 1969 and 1970. These were $\mathrm{D}_{2}$ O-moderated tight lattices designed to test thorium and U233 cross sections in very hard neutron flux spectra. For ETA-I, the 26" diameter test lattice contained 2304 $\mathrm{U} 235 \mathrm{O}_{2}-\mathrm{ThO}_{2}$ fuel rods, with $\mathrm{Th} / \mathrm{U} 235$ atom ratio of $15 / 1$. (These were the same rods that had been used ten years earlier in the TUPE and THUD experiments.) For ETA-II, there were $864 \mathrm{U} 233 \mathrm{O}_{2}-\mathrm{ThO}_{2}$ rods which had been used previously in the BNL exponential lattices. In both experiments it was necessary to use an $\mathrm{H}_{2}$ O-moderated driver lattice of $\mathrm{TRX} \mathrm{\textrm {UO } _ { 2 }}$ fuel rods in order to achieve criticality. At core center, where integral parameters were measured, the flux spectrum was nearly asymptotic, despite the strong spectrum shift between the test and driver lattices. Parameters were measured by activation techniques, as follows (see Ref. 35 for more detal1): $8^{23}\left(8^{25}\right)$

a) cadmium ratio; U233(U235)-Al detector foil.

b) thermal subtraction method, relative to Dy164-A1 detector normalized in reflector.

02 Thermal subtraction method, relative to Dyl64-A1 detector foil, normalized in reflector. $\mathrm{Ge}(\mathrm{Li})$ count of $312 \mathrm{keV} \gamma$ from fuel and $\mathrm{ThO}_{2}$ pellets.

CR* a) From same thorium and U233 (U235) activations.

b) Indirect, from $\rho^{02}$ and $\delta^{23}\left(8^{25}\right)$ as a check. ${ }_{8} 02$ Fuel and $\mathrm{ThO}_{2}$ detector pellets. $\mathrm{Ge}(\mathrm{Li})$ counting of selected fission product $Y^{\prime} s$. 
Interpretation of the parameters requires an explicit radial analysis of the full core to obtain leakage corrections. Since spatial activation shapes were not measured, $K_{\text {eff }}$ depends significantly on the calculated leakage to the driver and hence on the driver itself. Other integral parameters are relatively insensitive to the driver, however. Due to the tightness of the inner lattice, interaction between thorium and uranium is strongly emphasized as compared to a more thermalized lattice.

Integral parameters at core center were calculated for a cell by RCPO1, with leakage corrections from $P$ TMG, which performed a homogenized multigroup $P_{2}$ radial traverse. Results from the original analyses are compared with experiment in Tables 23 and 24 . For both lattices agreement with experiment is reasonably good, with 02 approximately $3 \%$ high. These analyses used the LWBR thorium cross sections (see Ref. 41 for the thorium capture cross section evaluation) which differ in several significant respects from the ENDF/B-IV file. The most notable differences affecting integral parameters are a therma $1 \lambda_{A}$ of $7.34 \mathrm{~b}$ (versus $7.40 \mathrm{~b}$ in ENDF/B-IV) and a fission cross section about $10 \%$ higher than ENDF/B-IV. The $\mathrm{U} 235$ deck had a fission resonance integral of $259 \mathrm{~b}$ above $0.625 \mathrm{eV}$, compared to $268 \mathrm{~b}$ for ENDF/B-IV material $126 \mathrm{l}$. Its thermal fission cross section was $0.8 \%$ below ENDF/B-IV. Other important data (for U233, deuterium and oxygen) were not significantly different from the ENDF/B-IV Get.

The ETA lattices have been recently reanalyzed with the same calculational methods and consistent ENDF/B-IV data. These integral parameter results are also shown in Tables 23 and 24. The major differences from the calculated parameters of Ref. 35 are: 
Table 23 - Comparison of Measured and Calculated Integral Parameters for ETA-I (U235-Th- $\mathrm{D}_{2} 0$ )

Integra 1

Parameter

02

0

$r^{25}$

02

$\mathrm{CR}^{*}$

\section{Experiment}

$10.54 \pm .15$

$1.74 \pm .02$

$.0166 \pm .0009 *$

$.867 \pm .009$

$\begin{array}{lc}\frac{\text { Calculation }}{}{ }^{+} \\ \frac{\begin{array}{l}\text { Original } \\ \text { (Ref. 35) }\end{array}}{10.92 \pm .06} & \frac{\text { ENDF/B-IV }}{10.9 \pm .06} \\ 1.78 \pm .01 & 1.86 \pm .01 \\ .0155 \pm .0002 & .0141 \pm .0001 \\ .882 \pm .003 & .857 \pm .003\end{array}$

* Measured and calculated for the central rod of the nine-rod cell. Other parameter results are for the entire cell.

+Uncertainties on calculated results are from Monte Carlo statistics. 
Table 24 - Comparison of Measured and Calculated Integral Parameters for ETA-II (U233-Th- $\mathrm{D}_{2} \mathrm{O}$ )

Integra 1

Parameter

02

0

$x^{23}$

$\varsigma^{02}$

$\mathrm{CR} *$
Experiment

$8.89 \pm .15$

$2.96 \pm .08$

$.0181 \pm .0014$

$1.047 \pm .02$
Calculation

\begin{tabular}{ll}
\hline $\begin{array}{l}\text { Origina1 } \\
\text { (Ref. 35) }\end{array}$ & ENDF/B-IV \\
\hline $9.16 \pm .05$ & $8.71 \pm .05$ \\
$2.99 \pm .02$ & $2.90 \pm .02$ \\
$.0185 \pm .0001$ & $.0165 \pm .0002$ \\
$1.050 \pm .003$ & $1.034 \pm .004$
\end{tabular}


(1) Slightly $(1.5 \%)$ reduced Th232 resonance capture (reflected in $0^{02}$ and $\mathrm{CR}^{*}$ ).

(2) $4.5 \%$ higher 8 , of which $3.5 \%$ can be attributed to the higher U235 resonance fission integral of ENDF/B-IV. (This also lowers calculated CR* by about $1 \%$ and raises $\rho^{02}$ by $1 \%$ ).

(3) Approximately $10 \%$ lower $\delta^{02}$ due mostly to the difference of $\sigma_{f}^{\operatorname{Th} 232}$. 6. LWBR Criticals ( Th-U233- $\left.\mathrm{H}_{2} \mathrm{O}\right)$

A number of critical experiments in direct support of LWBR were carried out at Bettis during the late 1960's (Ref. 37,38,39). An initial SB series of small seed-blanket assemblies was followed by the BMU experiments, which were larger, multiply-zoned seed-blanket assemblies. There was, finally, the detailed-cell critical assembly, which mocked up the moving seed-blanket arrangement of the LWBR module.

One configuration of the detailed cell (Ref. 39) and one BMU core (Ref. 38) have been analyzed with RCPOL and ENDF/B-IV data. These cores were represented explicitly in three dimensions, including all fuel rods and lattice structural components. There was some homogenization of peripheral structure.

The BMU-IB core cons 1 tet of a symmetric hexagonal seed with 810 28-inchlong fuel rods. These were approximately 0.25 -inch diameter on a 0.32 -inch trianguiar pitch. The upper 14-inches of each rod was $5 \mathrm{w} / 0 \mathrm{U} 233 \mathrm{O}_{2}-\mathrm{ThO}_{2}$, the remainaer was $9 \mathrm{w} / \mathrm{o}$. The seed rods rested on an equal number of 14 -inch-long $\mathrm{ThO}_{2}$ rods. The center seven lattice positions were occupied by a Zircaloy pipe. The seed was enclosed in a double-walled hexagonal Zircaloy can, and the 1/8-inch water gap between the walls provided channels for six hafnium control blades. The surrounding blanket contained 81142 -incia-lons $\mathrm{ThO}_{2}$ rods and $602 \mathrm{w} / 0 \mathrm{U}_{2} 33 \mathrm{O}_{2}-\mathrm{ThO}_{2}$ rods 
which were of approximately 0.625 -inch diameter, on a 0.70 -inch triangular pitch. Figure 12 shows the RCPOl representation of the core loading, and Figure 13 shows a schematic view of the axial description.

The detailed cell was a single seed and blanket core, approximately 105 inches high, with a movable central seed region. The seed was a symmetric hexagon containing 15 rows of 0.305 -inch diameter fuel rods on a 0.368 -inch triangular pitch. An inner blanket region surrounded the seed, separated from it by a double-walled hexagonal Zircaloy can. The 1/8-inch water gap between the walls provided channels for six hafnium control blades. The Inner blanket was a nonsymmetric hexagon comprising ordinary and powerflattening regions. The outer blanket comprised a driver region with 2 w/o $\mathrm{U} 233 \mathrm{O}_{2}-\mathrm{ThO}_{2}$ rods and a reflector region of $\mathrm{ThO}_{2}$ rods. Figure 14 shows the top view of the core, and Figure 15 shows the complex axial zoning in the seed and inner blanket regions. In the configuration analyzed, the seed was 2 inches below the axial reference position shown in Figure 15.

Eigenvalues obtained with RCPO1 and ENDF/B-IV data are shown in Table 23 . These are consistent with results obtained for other lattices, as is shown in the next section. Analysis of the measured parameters is rendered difficult by the complexity of these cores, and no attempt has been made to calculate them.

Table 25 - Elgunvalues of LWTR Griticals Galenlated With RCPO.l and ENDF/B-IV Data

$\begin{array}{lc}\text { Core } & \frac{K_{\text {eff }} \pm \sigma}{\text { Detailed cell }(-2 \text { inches })} \\ \text { BMU-1B } & .9940 \pm .0012 \\ & .9963 \pm .0014\end{array}$






RCPOl Planar Representation of the LWBR BMU-IB Lattice

FIGURE 12 


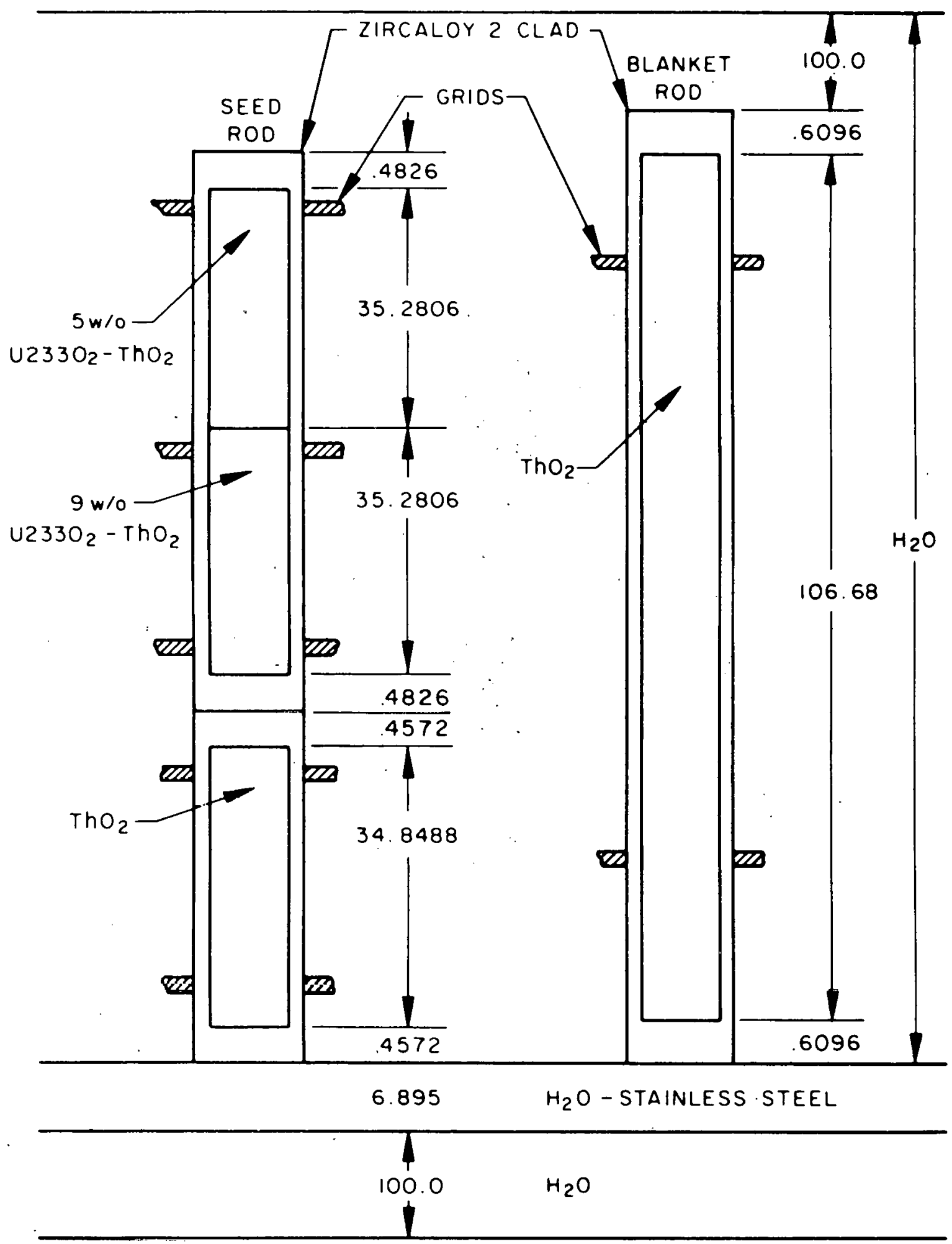

DIMENSIONS IN CM

RCPOI Axis? Kepresentation of the LWBR

BMJ-IB Lattice (Schernatic) 


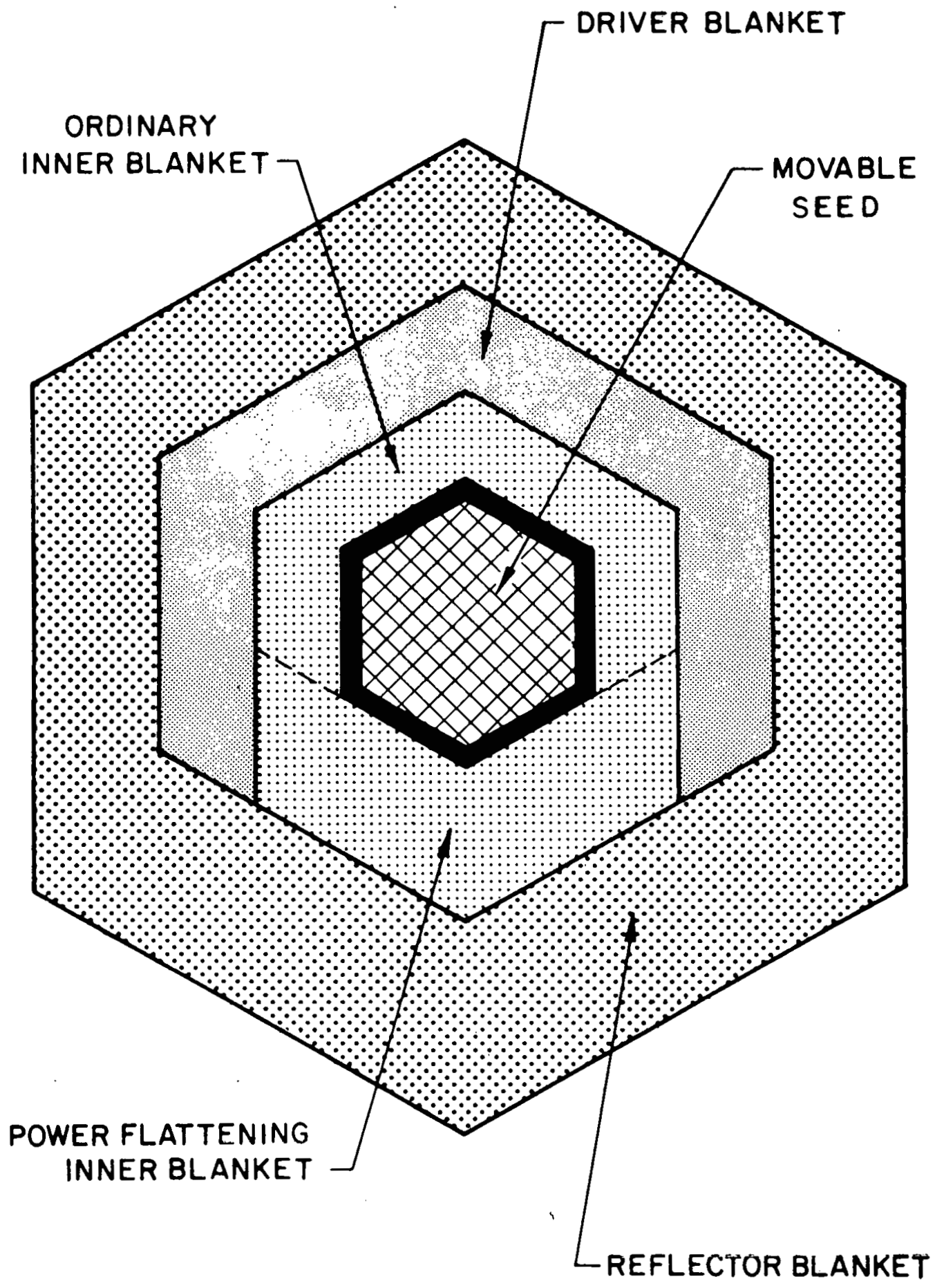

Planar View of the IWBR Detailed Cell Lattice 


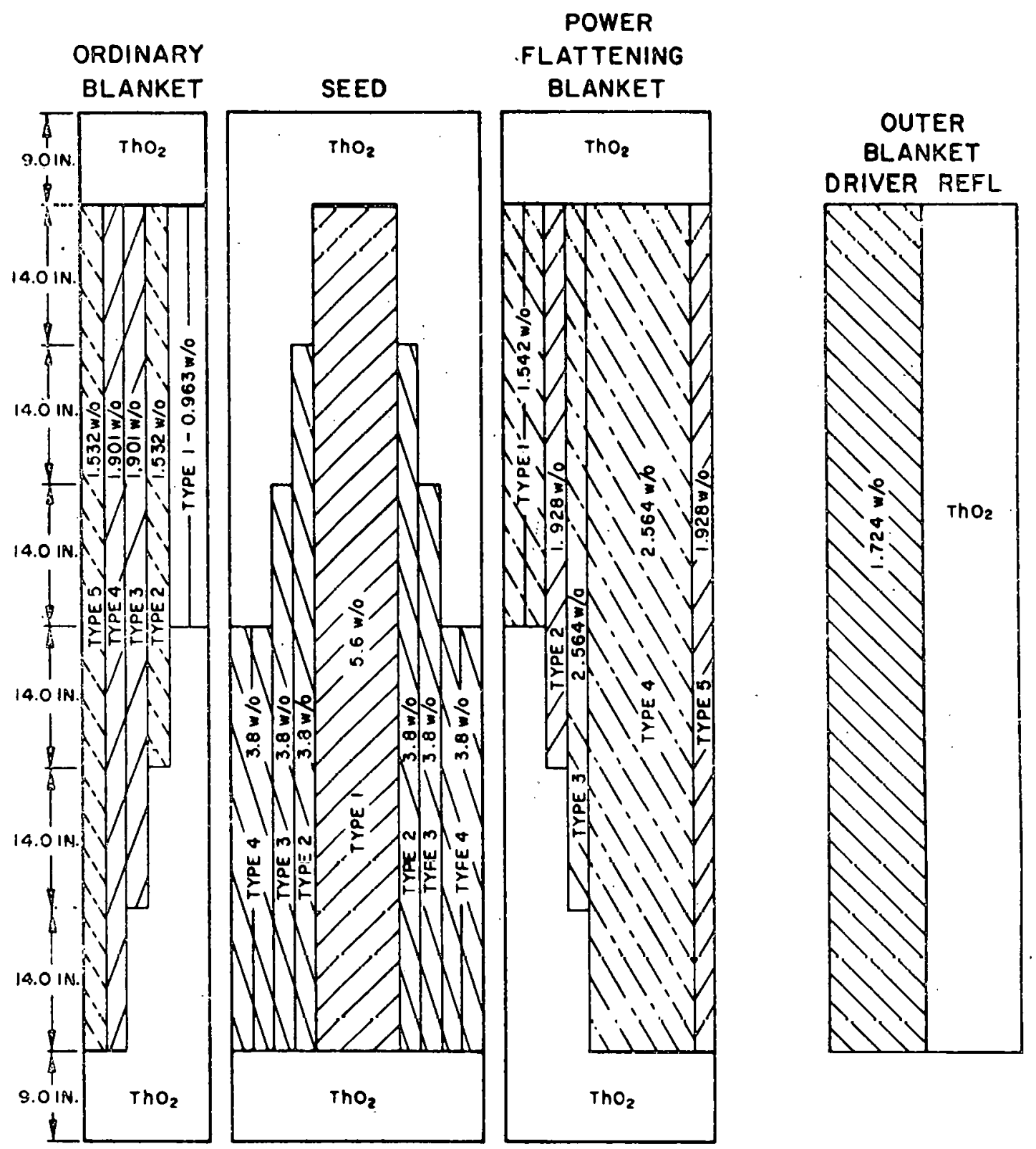

NOTE: W/O DENOTES WEIGHT PERCENT OF URANIUM/ TOTAL FUEL.SEED IS SHOWN IN AXIAL-ZERO POSITION.

Axial frrangement of the LWBR Detailed Cell Si: owing Fuel Zoning 


\section{Consistency of Calculated Results for Uranium-Thorium Lattices}

In this section analyses of thorium-uranium lattice experiments have been presented. These results are based on ENDF/B-IV data and methods similar to those described in Section II on homogeneous systems. Calculations of $\mathrm{K}_{\text {eff }}$ for homogeneous criticals revealed a significant underprediction of neutron leakage which warranted a hardening of both the U233 and U235 fission neutron spectra. Analysis of lattices introduces two new complications, namely the presence of a fertile nuclide, thorium, and spatial self-shielding. It is useful now to examine the $U 233$ and $U 235$ lattice $K_{\text {eff }}$ results for consistency with those for the corresponding homogeneous criticals and to assess the overall consistency of calculations of integral thorium capture measurements .

The effect of the Standard model U233 fission neutron (see Section II.4) spectrum on $\mathrm{K}_{\text {eff }}$ for the homogeneous $\mathrm{U} 233$ criticals, the BNL $\mathrm{H}_{2} \mathrm{O}$ moderated exponential experiments, and the two LWBR criticals considered in this work is depicted in Figures 16 and 17. Figure 16 shows $K_{\text {eff }}$ vs total neutron. leakage fraction based on ENDF/B-IV. The BNL exponentials and the LWBR cores fit nicely into the pattern that was established for the homogeneous criticals. These same $K_{\text {eff }}$ results are shown in Figure 17 when the harder Standard model U233 fission neutron spectrum is employed. Much of the rising trend in $\mathrm{K}_{\text {eff }}$ vs leakage is eliminated, with the result that most of these experiments, which are $\mathrm{H}_{2} \mathrm{O}$ moderated, form a reasonably consistent set. However, the $\mathrm{BNL} \mathrm{D}_{2} \mathrm{O}$ moderated exponentials are not consistent with this picture since $\mathrm{K}_{\text {eff }}$ is already underpredicted by $1.5 \%$ using ENDF/B-IV, for reasons that are not precisely known. It is expected that a harder U233 fission neutron spectrum would worsen this underprediction. 
$\mathrm{K}_{\text {eff }}$ versus neutron leakage fraction is plotted for comparison in Figure 18 for the $\mathrm{U} 235$ systems. It is apparent that the results for the TUPE lattices are reasonably consistent with the rising trend in $K_{\text {eff }}$ that was established for the homogeneous systems (Figure 2). A new harder U235 fission spectrum (see Section II) will help eliminate this trend in $\mathrm{K}_{\text {eff }}{ }^{\circ}$ Overall, the studies of $\mathrm{K}_{\text {eff }}$ for U233 (and U235) homogeneous and heterogeneous systems using ENDF/B-IV supports the conclusion that leakage is underpredicted. This effect is principally associated with fission spectra for $U 233$ and $U 235$ that are too soft. Newer versions of these fission spectra being proposed for ENDF/B-V are harder and should help remove the leakage bias in $\mathrm{K}_{\text {eff }}$ calculations.

It is apparent that there are only a very limited number of integral Th232 capture measurements potentially useful for data testing purposes. For room temperature $\mathrm{ThO}_{2}$ rods, these are:

(1) Effective resonance integrals of $\mathrm{ThO}_{2}$ rods.

(2) $\rho^{117}$ measurements in the Th- $\mathrm{U}_{2} 33 \mathrm{BNL}$ exponentials $\left(\mathrm{H}_{2} \mathrm{O}\right.$ and $\mathrm{V}_{2} \mathrm{O}$ moderated).

(3) $0^{02}$ measurements in the $\mathrm{D}_{2}$ O-moderated, hard-spectrum ETA-I (Th-U235) and ETA-II (Th-U233) lattices.

The consistency of these measurements can be seen from Figure 19, which shows experiment/ENDF/B-IV-calculation ratios. The experiments range from $10 \%$ high to $3 \%$ low, with experimental uncertainties ranging from $\pm 2 \%$ to $\pm 5 \%$. In addition, there are several questions of interpretation which should be mentioned: 
(1) The measured $\mathrm{ThO}_{2}$ rod resonance integrals are directly proportional to the dilute resonance integral $I$. Integral measurements of $I$ are directly proportional to the thorium thermal capture cross section. (Normalization at present is to $\sigma_{a}=7.40 \mathrm{~b}$, consistent with ENDF/B-IV.)

(2) $\rho^{02}$ measurements do not depend on any such normalization. However, calculated $\rho^{02}$ depends inversely on the thorium thermal $\sigma_{a}$. Without a firm value of $\sigma_{a}$ it is difficult to draw conclusions about resonance capture.

(3) In the ETA cores, $0^{02}$ calculations are somewhat sensitive to data other than Th232 capture itself (through leakage corrections and competing absorptions). For example, the ENDF/B-TV-calculated $8^{25}$ is $7 \%$ above experiment. A $10 \mathrm{~b}$ reduction of the $\mathrm{U} 235$ fission integral can remove about half of this difference. Such a change would lower calculated $\rho^{02}$ by $1 \%$ and raise calculated $C R^{*}$ by about the same amount. Altogether, these experiments, assuming that the ENDF/B-IV $\sigma_{a}^{\operatorname{Th} 232}=7.40 \mathrm{~b}$ is fixed, favor an amount of thorium resonance capture slightly above - or at least, not much below - ENDF/B-IV. 


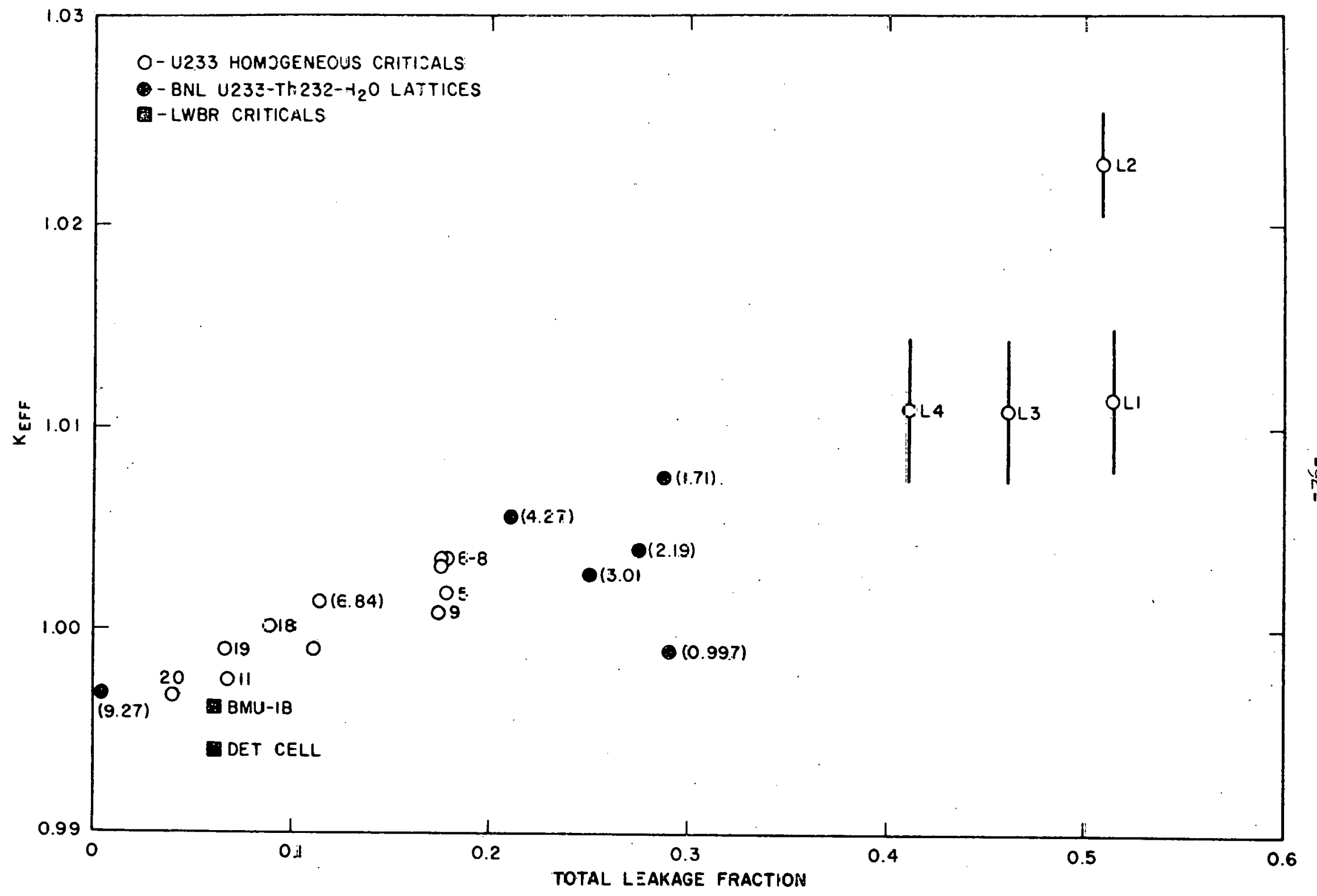

$K_{\text {eff }}$ Versus Neutron Leakage Fraction for U233 Systems

F İUURE 15 


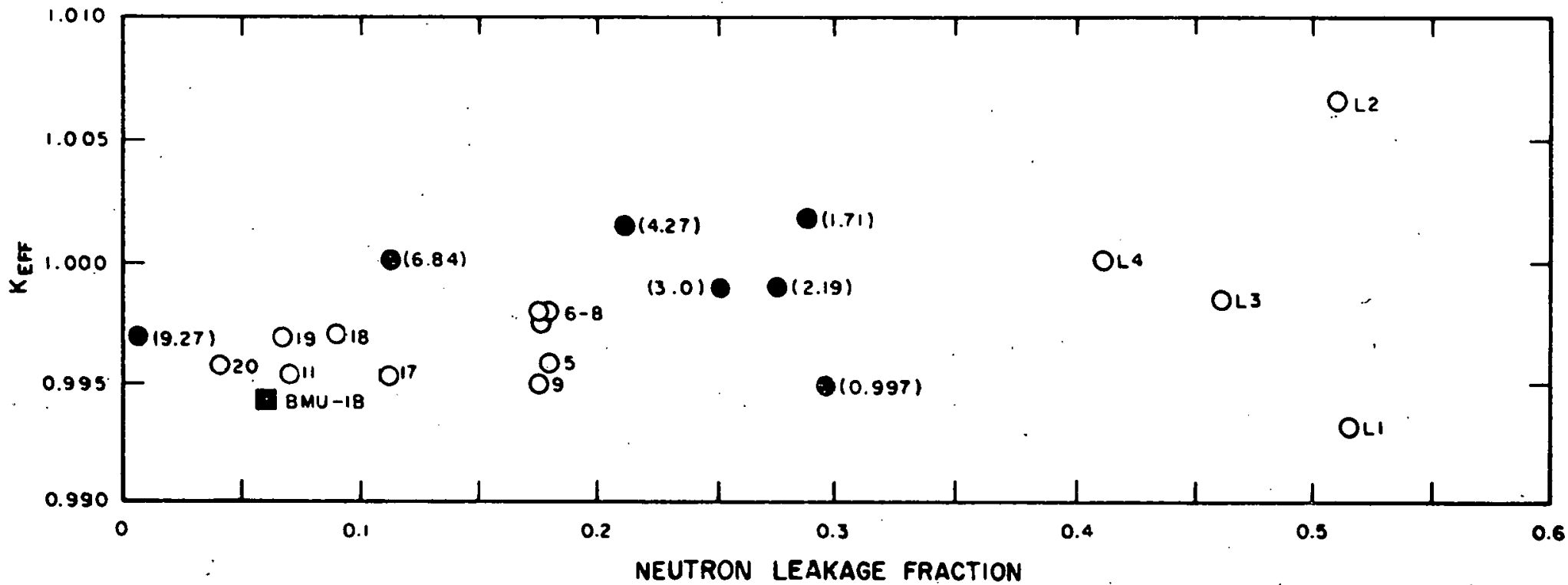

$\mathrm{K}_{\text {eff }}$ Versus Nelitron Leakage Fraction for U233 Systems, Obtained with the Standard Fission Spectrum Male? 


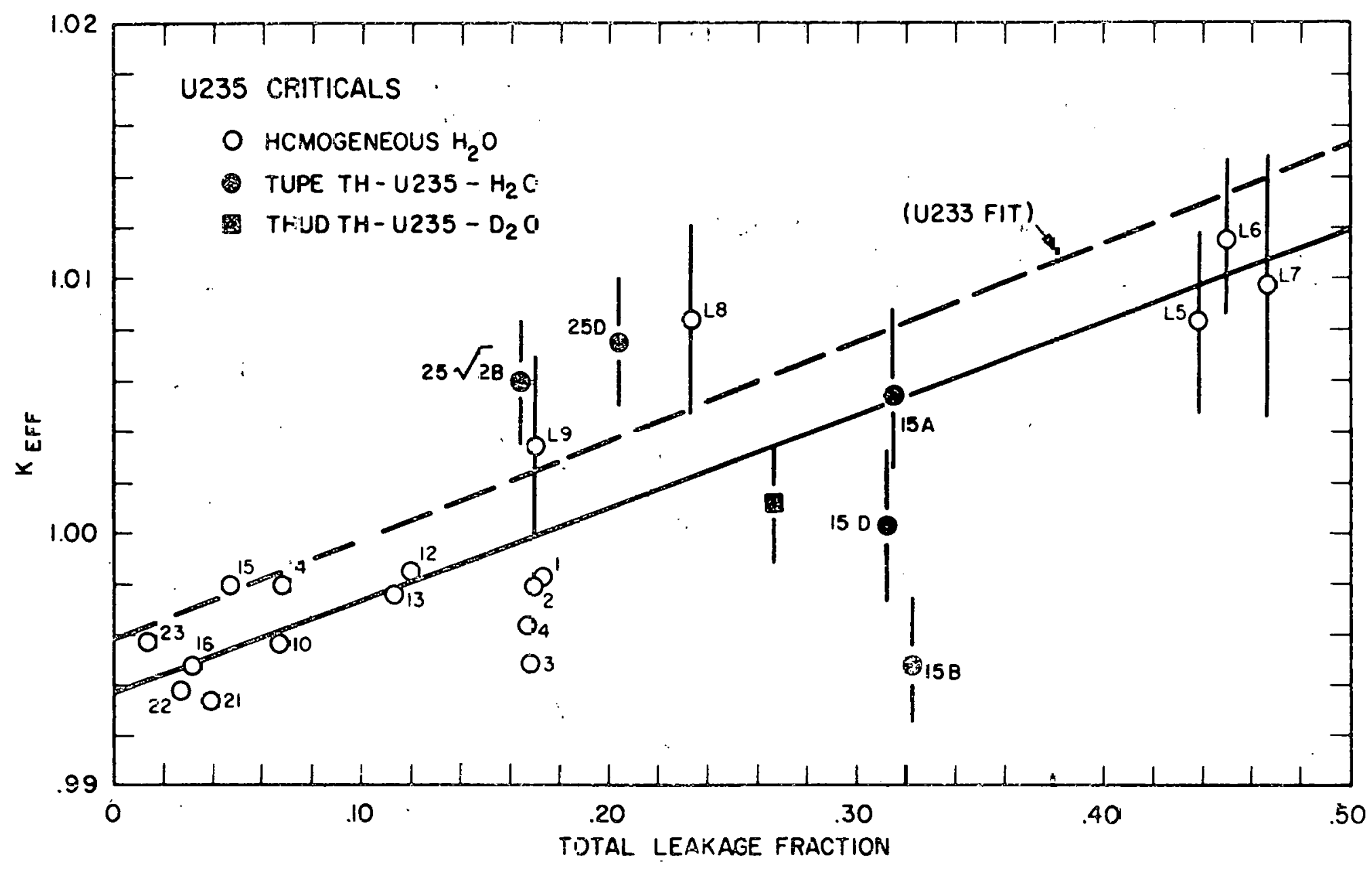

$K_{\text {eff }}$ Versus Neutron Leakage Fraction for U235 Systems PIGURE 18 


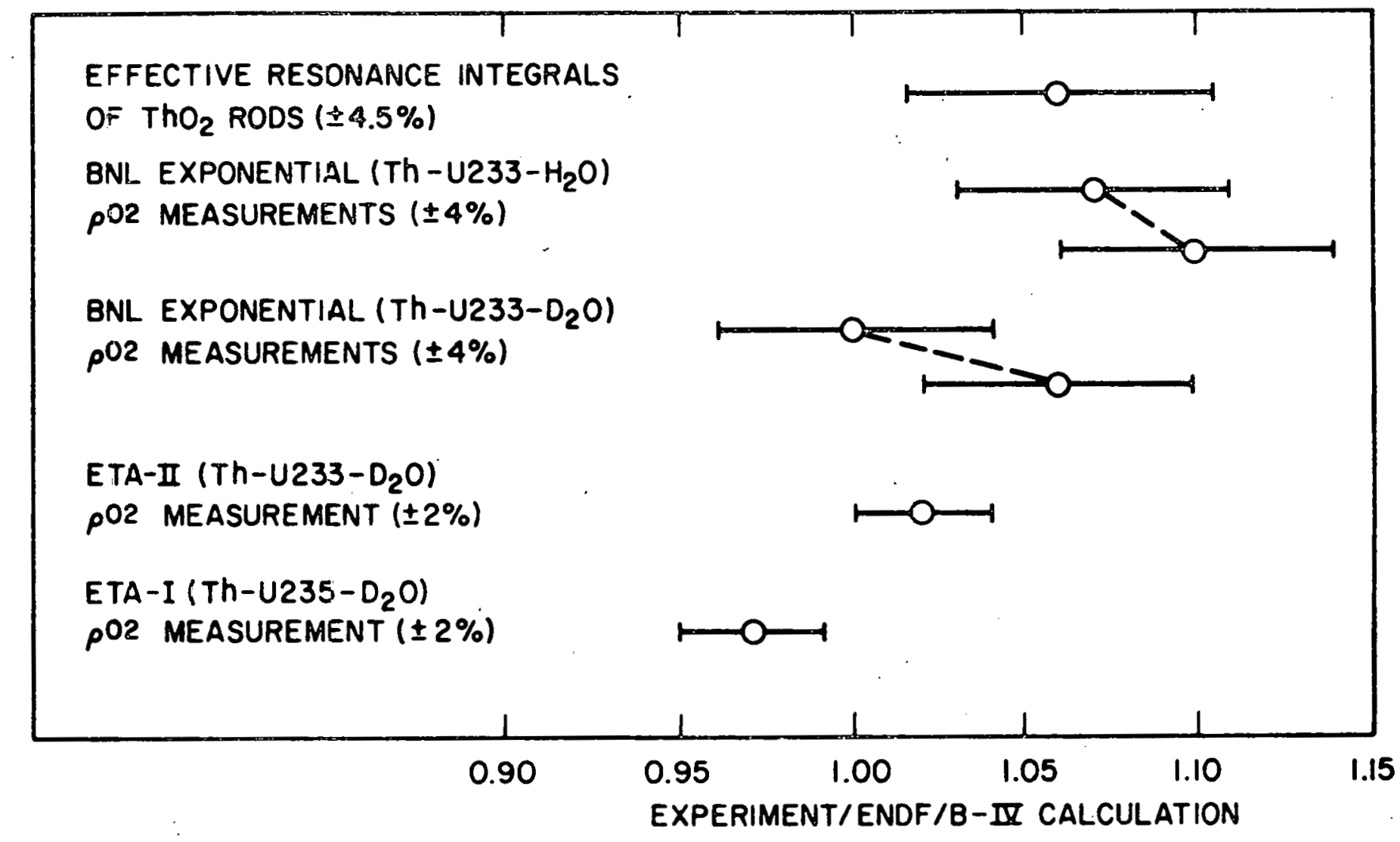

Comparison ot' Thorium Capture Fredictions

Based on ENDF/B-IV Data 
IV. U233-Thorium Graphite Moderated Experiments

In Sections II and III, the analyses of U233-thorium experiments using consistent ENDF/B-IV data and methods have been devoted entirely to water moderated systems (both $\mathrm{H}_{2} \mathrm{O}$ and $\mathrm{D}_{2} \mathrm{O}$ ). There are a number of graphite moderated U233-thorium experiments which will now be described. These include the High Temperature Lattice Test Reactor (HTLTR) experiments and a series of critical experiments related to the measurement of reactivity worths of materials used in High Temperature Gas Cooled Reactors (HTGR). These latter measurements included many U233 and thorium samples. Unlike most experiments discussed previous1y in this review, these graphite-moderated systems have not been reanalyzed by the authors. However, some analytical results will be presented. In the case of the HTLTR experiments, the analysis was based wholly on ENDF / B-IV.

\section{A. High Temperature Lattice Test Reactor Experiments}

The High Temperature Lattice Test Reactor was operated at the Battelle Pacific Northwest Laboratory to study uranium-graphite lattices at temperatures up to $1000^{\circ} \mathrm{C}$. Its purpose was to provide information on the nuclear behavior of High Temperature Gas Cooled Reactors and Molten Salt Breeder Reactors (MSBR's) in the temperature range from 500 to $1000^{\circ} \mathrm{C}$.

Only a small portion of the test lattice was required for these experiments. Typical measurements included temperature-dependent neutron multiplication factors, total temperature coefficients, Doppler coefficients, and reactivity worths of special poison materials at elevated temperatures. 
Five lattices were operated in the HTLTR series of experiments. The first (Ref. $42 j$, which was fueled with a $\mathrm{U}_{2} 35 \mathrm{C}_{2}-\mathrm{ThO}_{2}-\mathrm{C}$ fuel mixture with $\mathrm{C} / \mathrm{Th} \sim 200$ and $\mathrm{C} / \mathrm{U} 235 \sim 6000$, served to qualify many of the experimental and analytical techniques. The second (Ref.49), third (Ref.50), and fifth (Ref. 51) lattices were fueled with $\mathrm{U}^{2} 33 \mathrm{O}_{2}-\mathrm{ThO}_{2}-\mathrm{C}$ and are of spectal interest for this survey. In lattice $\equiv^{5}$, the fuel components were similar to those in the other U233 lattices, but the compositions and lattice dimensions were changed to approximate the neutronic characteristics of an MSBR core. Physical properties of these lattices can be found in Table 26 and in the references noted there.

The principal result of the HTLTR $\mathrm{U}^{2} 33 \mathrm{O}_{2}-\mathrm{ThO}_{2}$ experiments is. $\mathrm{K}_{\infty}(\mathrm{T})$; where $T$ is the lattice temperature. These results are sumarized in Tables 27-29 for the U233 lattices. Also shown are calculated results to be discussed shortly. The determination of $K_{\infty}(T)$ is based on a technique proposed by Heineman (Ref. 52) and involves measurement of the relative reactivity of a central test lattice cell and of a copper (1/v) absorber. In addition, the relative absorption rates of the materials in the test cell and the copper absorber are measured. These experimental quantities are combined with calculations of various lattice parameters to yield $K_{\infty}(T)$.

Uncertainties on the measured $K_{\infty}(T)$ were assigned on the bas 18 of random experimental errors. However, there are systematic uncertainties that can affect calculated values of $\mathrm{K}_{\infty}$. One of these is an estimated uncertainty of $\pm 1 \%$ in the amount of $\mathrm{U} 233$ in the coated particles used in the fuel mixture, which is worth 0.004 in Ko for each lattice (Ref. 49). Significant impurities (equivalent to 40 atomic parts-per-million of natural boron, plus-or-minus a 
$-98-$

Table 26 - Properties of the HTLTR U233-ThO $\mathrm{O}_{2}$ Lattices

Lattice 非

$\mathrm{C} / \mathrm{U} 233^{*}$

C/Th232**t

Fuel Rod Radius (cm)

Square Lattice

Fitch (cm)

Reference
10470

193

0.5969

1.905

49
Lattice 非3

13990

282

0.5969

1.905

50
Lattice 非

9460

146

0.9982

4.763

51

${ }^{*}$ Carbon-to-Ui 33 atom ratio.

** Carbon-to-Th232 atom ratio. 
Table 27 - Experimental and Calculated Values of $K_{\infty}$ for HTLTP Iattice \#2

\begin{tabular}{|c|c|c|c|}
\hline \multirow[b]{2}{*}{ Temperature $\left({ }^{\circ} \mathrm{C}\right)$} & \multirow[b]{2}{*}{ Measured $K_{\infty}$} & \\
\hline & & ENDF /B-IV & Leonard Th \\
\hline 20 & $1.0587 \pm 0.0014$ & 1.0544 & 1.0626 \\
\hline 150 & $1.0471 \pm 0.0017$ & 1.0428 & 1.0513 \\
\hline 300 & $1.0367 \pm 0.0014$ & 1.0334 & $1.042 \cdot 1$ \\
\hline 500 & $1.0297 \pm 0.0011$ & 1.0251 & 1.0347 \\
\hline 750 & $1.0245 \pm 0.0011$ & 1.0199 & 1.0305 \\
\hline 1000 & $1.0237 \pm 0.0012$ & 1.0176 & 1.0292 \\
\hline
\end{tabular}


Table 28 - Experimental anü Calculated Values of $K_{\infty}$ for HTLTR Latt1ce \#3

Temperature $\left({ }^{\circ} \mathrm{C}\right)$

20

150

300

555

700

1000
Measured $K_{\infty}$

$1.064 \pm 0.004$

$1.060 \pm 0.006$

$1.056 \pm 0.005$

$1.057 \pm 0.005$

$1.057 \pm 0.006$

$1.060 \pm 0.007$
Calculated Values of $K_{m}$ ENDF/B-IV Leonard Th

$\begin{array}{ll}1.1089 & 1.1141 \\ 1.0998 & 1.1058 \\ 1.0940 & 1.1005 \\ 1.0888 & 1.0966 \\ 1.0875 & 1.0962 \\ 1.0875 & 1.0976\end{array}$


Table 29 - Experinental and Calculated Values of $\mathrm{K}_{\infty}$ for HTLTR Lattice \#5 (MSBR)

Calculated Values of $K_{\infty}$

$\begin{array}{cccccc}\begin{array}{c}\text { Temperature } \\ \left({ }^{\circ} \mathrm{C}\right)\end{array} & \text { Measured } K_{\infty} & \text { ENDF/B-IV } & \text { Leonard Th } & \frac{\operatorname{Ragan}^{\mathrm{a}}}{(\operatorname{Ref} .54)} \\ 20 & 1.0291 \pm 0.0012 & 1.0473 & 1.0523 & 1.0383 \pm 0.0042 \\ 300 & 1.0127 \pm 0.0010 & 1.0301 & 1.0363 & 1.0216 \pm 0.0042 \\ 627 & 1.0065 \pm 0.0010 & 1.0211 & 1.0284 & 1.0134 \pm 0.0042 \\ 1000 & 1.0037 \pm 0.0012 & 1.0179 & 1.0267 & 1.0120 \pm 0.0042\end{array}$

${ }^{a}$ Used ENDF/B-III thorium and ENDF/B-II for other data. 
factor of three) detected in the fuel mixture of lattice 非 3 are worth $3-4 \%$ in $K_{\infty}$. There is no direct evidence that similar impurities were present in the fuel mixtures of..lattiices $\#_{1} 2$ and . 非5. These systematic uncertainties make interpretation of absolute $K_{\infty}(T)$ vallues difficult, particularly for lattice. 非 3 .

A recent EPRI study (Ref. 53) of these lattices has been carried out to assess the ability of methods and nuclear data to predict the temperature coefficient of reactivity for HTGR's. It was assumed that the possible systematic uncertainties in measured $K_{\infty}(T)$ were sufficiently temperature independent that the $K_{\infty}(T)$ data could be used to test predictions of $\frac{1}{K_{\infty}(T)} \frac{d K_{\infty}(\dot{A})}{d T}$. The calculations were based primarily on ENDF/B-IV cross section data, but sensitivities to alternate cross sections for U233 and Tli232 wete scudied.

The method used to calculate Ko employed a two group scheme:

$$
y_{\infty}=\frac{m_{1} f_{1}(1-p)\left(1+L^{2} B^{2}\right)+r_{2} f_{2} p}{1+(1-p) L^{2} B^{2}}
$$

where

$$
\begin{aligned}
& r_{1} f_{1}=\left(\frac{v_{f}}{\Sigma_{a}}\right)_{1}, \cdots_{2} f_{2}=\left(\frac{\Sigma_{E}}{\Sigma_{a}}\right)_{2} \\
& P=\frac{\Sigma_{1-2}}{\Sigma_{1 \rightarrow ?}+\Sigma_{a_{1}}} \quad L^{2}=\frac{D_{2}}{\Sigma_{a_{2}}} .
\end{aligned}
$$


The buckling, $B^{2}$, and $K_{\infty}$ also satisfy the critical equation,

$$
K_{\infty}=1=\frac{K_{\infty}\left[1+(1-p) L^{2} B^{2}\right]}{\left(1+T B^{2}\right)\left(1+L^{2} B^{2}\right)}
$$

where

$$
\tau=\frac{D_{1}}{\Sigma_{1 \rightarrow 2}+\Sigma_{a_{1}}} .
$$

Equations 4 and 5 were solved using an iteration procedure. A lattice cell calculation with zero buckling was used to estimate the parameters of Eqn. 4 and $K_{\infty}$. These values were then placed in Eqn. 5 to yleld the first estimate of $\mathrm{B}^{2}$. New cell parameters were generated using this estimate of $\mathrm{B}^{2}$, and $K_{\infty}$ and $\mathrm{B}^{2}$ were recalculated. This procedure was repeated until changes in $\mathrm{B}^{2}$ became negligible.

The $K_{\infty}(T)$ calculations of Ref. 53 using ENDF/B-IV nuclear data are shown in Tables 27-29. Also shown are the results of calculations using the Leonard thorium cross section data which were also described in Ref. 53. As shown in Table 30, the Leonard thorium set has a lower dilute resonance Integral and a $3 \%$ higher thermal absorption cross section. Reduced resonance capture overcompensates the larger thermal absorption cross section and leads to calculated $K_{\infty}(T)$ values $\sim 1 \%$ higher than for $E N D F / B-I V$. 
Although the systematic uncertainties make it difficult to draw conclusions about nuclear data from the $K_{\infty}(T)$ values alone, correlation of calculated and measured temperature coefficients permit a more unambiguous interpretation. The particular correlation employed was of the form:

$$
\begin{aligned}
& K_{\infty}^{\text {meas }} \cdot(T)=K_{\infty}^{c a l c} \cdot(T)[A+B(T-293)] \quad \text { (Eqn. 6) } \\
& \left\lceil\frac{1}{L K_{\infty}(T)} \frac{d K_{\infty}(T)}{d T} j_{\text {meas. }}=\left[\frac{1}{K_{\infty}(T)} \frac{d K_{\infty}(T)}{d T} j_{c a l c .}+\left(\frac{B}{\Lambda+B(T-293)}\right)\right.\right. \\
& \approx\left[\frac{1}{K_{\infty}(T)} \frac{d K_{\infty}(T)}{d T}\right]_{\text {calc. }}+B \quad(\text { Eqn. 7) }
\end{aligned}
$$

since $A \sim 1.0, B \sim 10^{-5}$, and $T \sim 10^{3}$. The parameter $A$ plays the role of $a$ normalizing coefficient, and the parameter B expresses the bias in the calcuiated temperature coefficients. The analyses based on ENDF/B-IV (Table 31) yield values for $B$ which are consistently positive indicating a nonconservative prediction of $\frac{l}{K_{\infty}(T)} \frac{d K_{\infty}(I)}{d T}$. Therefore, thorium resonance capture is probably overpredicted for these lattices using ENDF/B-IV, which is somewhat inconsistent with other calculated thorium capture parameters (Figure 19).

A change in the thermal eta of U233 to 2.284 (from the ENDF/B-IV value of 2.2972) produced neglf.gible effects on calculated $K_{\infty}(T)$ and $B$ values. Due to its reduced resonance capture, and hence smaller contribution to the temperature coefficient from the Doppler effect, the Leonard thorium data produced $B$ values uniformly $0.4 \times 10^{-5} \mathrm{~K}^{-1}$ lower than those based on ENDF/B-IV. 
It was concluded in Ref. 53 on the basis of the reduced temperature coefficient bias that the Leonard thorium data is preferred over ENDF/B-IV for predicting temperature coefficients of thorium fueled lattices. Finally, the $K_{\infty}(T)$ predictions for lattice \#5 can be compared with a previous study made by Ragan at the Oak Ridge National Laboratory (Ref. 54). Calculational methods and nuclear data used in the design of the MSBR were tested against the HTLTR lattice (lattice \#5) which most nearly mocked up the neutronic properties of the MSBR. The results, which are shown in the last column of Table 29, have been adjusted for known errors in the calculational strategy. The quoted uncertainty in the calculations is dominated by the $\pm 0.4 \%$ uncertainty in $\mathrm{K}_{\infty}$ due to the $\pm 1 \%$ in $\mathrm{U} 233$ content. Most of the cross sections were taken from ENDF/B-II files; those for thorium were taken from ENDF/B-III. The calculated values of $K_{\infty}(T)$ are higher than the measurements, but by only $1 \%$, and have nearly the same dependence on $\mathrm{T}$ as those generated in the more recent Ref. 53 study. 
$-106-$

Tabie 30 - Comparison of Thorium Data Sets used in HTLTR Analyses

ENDF/B-IV
Leonard Set

$$
\begin{aligned}
& \sigma_{a}(.0253 \mathrm{eV}) \\
& R I_{a}(I>0.50 \mathrm{eV})
\end{aligned}
$$

\author{
$7.40 \mathrm{~b}$ \\ $85.8 \mathrm{~b}$
}

$7.615 \mathrm{~b}$

$83.7 \mathrm{~b}$ 
Table 31 - Calculated Values ${ }^{2}$ of the Temperature Coefficient Bias Parameter $B$ for the HTLTR Lattices

\begin{tabular}{|c|c|c|c|}
\hline.. & Lattice 非 & Lattice 非 & Lattice 非 5 \\
\hline ENDF/B-IV Data & $+0.21 \pm 0.07 \times 10^{-5}$ & $1.55 \pm 0.19 \times 10^{-5}$ & $+0.41 \pm 0.09 \times 10^{-5}$ \\
\hline Leonard Thorium & $-0.18 \pm 0.07 \times 10^{-5}$ & $1.08 \pm 0.19 \times 10^{-5}$ & $+0.03 \pm 0.09 \times 10^{-5}$ \\
\hline $\begin{array}{l}\text { Leonard Thorium } \\
\text { and } \Lambda \text { ternate U233 }\end{array}$ & - & $1.11 \pm 0.19 \times 10^{-5}$ & - \\
\hline
\end{tabular}

${ }^{a}$ All values are in units of ${ }^{\circ} \mathrm{K}^{-1}$. 


\section{B. HTGR Critical Experiments}

Critical experiments in support of the HTGR program were carried out at Gulf General Atomic from 1966 - 1969 (Ref. 55). The reactivity worths of macerials used in HTGK-type reactors, including samples of U233 and Th232 which are of interest for this survey, were measured in a series of U235graphite cores.

Five cores were constructed having carbon-to-U235 (C/ti) ratios of $432,859,1718,2500$, and 5000 . This provided a wide range of spectrum hardness which could be used tc emphasize cross section data in both fast and thermal energy ranges. Each core consisted of uranium-graphite rods arranged on a triangular pitcin and had three distinct regions: 1) a center (exact) region made up of fuel elements of the desired $C / U$ ratio, 2) a driver region containing fuel elements and pure graphite elements in combination to produce the same $C / U$ ratio as the exact region, and 3) a reflector region of pure graphite elements.

This simple design was intended to allow analysis by one-dimensional transport methods. Because geometrical effects were minimized, the experiments are useful for testing cross section data. A comparison of analytical and experimental results is reported in Ref. 55, based mainly on ENDF/B-I data for the fissile nuclides. Although these measurements have not been reanalyzed, we have attempted to infer whether the original calculation/ experiment comparisons would be improved using ENDF/B-IV data. 
The reactivities of test elements were measured relative to that for reference graphite elements of the same density. Measured worths of U233 and Th232 test elements (Tables 32 and 35) are considered in Ref. 55 to be reliable to $\pm 1 \%$. The majority of the measurements were analyzed using the GAZE one-dimensional diffusion theory program. Detalls of the calculational method can be found in Ref. 55, but only the results are presented here.

Table 32 shows the calculation-to-experiment comparisons for U233. The calculations were performed using two sets of U233 data which are summarized in Table 33. In both cases ENDF/B-I U235 cross sections were used in the adjacent core regions. It is seen that the ORNL-RPI U233 cross section data (set $\$$ 作) improved the calculation-to-experiment comparisons. However, the calculated reactivity worths were still 4-9\% higher than those measured.

Sensitivities to several U233 data components were also investigated. For the heaviest loaded $U 233$ element $(\mathrm{C} / \mathrm{U}-432)$, the reactivity worths in four of the cores were recalculated for several different perturbations of the ORNL-RPI U233 data. These results are reproduced in Table 34 . Also shown are the calculated Fast/Thermal flux ratios (2.38 eV cutoff). It is to be noted that the discrepancy increases with Fast/Thermal flux ratio. Data adjustments which were effective in reducing the discrepancies include a reduction in " of $U 233$, an increase in the capture cross section below $2.38 \mathrm{eV}$, and a decrease in the epithermal ( $\mathrm{E}>2.38 \mathrm{eV})$ fission cross section. 
Table 32 - Comparison of Calculated and Measured U233 Reactivity Worths in HTGR Lattices

Calculated Calculated Measured $\underline{\text { U233 Element }}$ Worth $^{\mathrm{b}}(\mathrm{S})$ Worth ${ }^{\mathrm{c}}(\$)$ Worth (S)

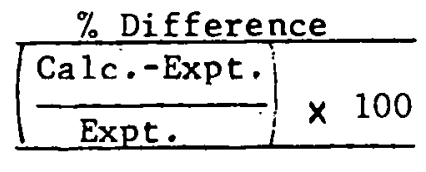

Core $\mathrm{C} / \mathrm{U}-5000$
5000

1718

432

5000

1718

432

5000

1718

432
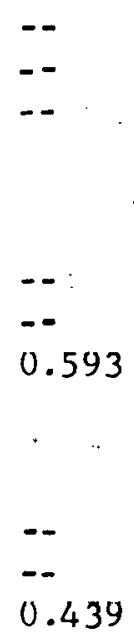

$--$

$--$

0.265

5000
1718

432
0.593

. 0.265

$5 n \cap n$

1718

432

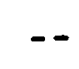

--

0.930

0.110

0.284

0.854

Core $C / U-2500$

0.080

0.187

0.584

0.076

0.186

0.565

5.0

0.5

3.2

Core $\mathrm{C} / \mathrm{U}-1 / 18$
11.5

1.5

3.7

Core $C / U-859$

$\begin{array}{lrr}0.031 & 0.025 & 19.4 \\ 0.080 & 0.079 & 1.3 \\ 0.263 & 0.243 & 7.6\end{array}$

\section{Core $\mathrm{C} / \mathrm{U}-432$}

$0 . \overline{0} 52$

0.164
$-2.0$

9.4

\footnotetext{
a Numbers signify carbon/U233 atoms in the test element.

${ }^{b}$ Used the U233 data from Ref. 56 (Set 非1).

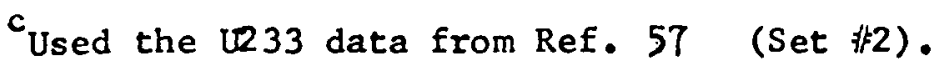

${ }^{d}$ Calculation done with the 1DF transport code.
} 
Table 33 - U233 Cross Section Data used in HTGR Analyses

$\frac{\text { Set 非 1 }}{\text { (Ref. 56) }} \quad \frac{\text { Set 非2 }}{\text { (Ref. 57) }} \quad$ ENDF/B-IV

$2200 \mathrm{~m} / \mathrm{s}$ Values

$\tau_{\mathrm{mv}}$

Tnf

\%.

$n$

"
48.2

525

0.0918

2.293

2.503
48.2

525

0.0918

2.293

2.503
45.9

525.1

0.0874

2.297

2.4978

\section{Ep1therma1 Values}

$$
\begin{aligned}
& \text { Resonance Capture } \\
& \text { Integral }
\end{aligned}
$$

Resonance Fission ${ }^{a}$

Integral

$$
\text { repi }
$$

\footnotetext{
${ }^{a}$ Epithermal values to a $0.5 \mathrm{eV}$ cutoff.
} 
An examination of the ENDF/B-IV nuclear data for U233 (Table 33) reveals that within the framework of the same calculational model its use will probably not significantly improve the calculation-to-experiment comparisons. Even though the fission Integral is slightly reduced, the capture integral. is also smaller so that the epithermal alpha is 0.176 versus the 0.182 of the ORNL-RPI set. In addition, the thermal capture is smaller, which will also tend to widen the calculation-to-experiment discrepancies.

Experimental and calculated reactivity worths for thorium-loaded elements are shown in Table 35. The thorium data were taken from the 1966 Drake and Nichols evaluation, and calculated negative worths are consistently higher than measurement by an average of $6.5 \%$. Except for the $\mathrm{C} / \mathrm{U}-432$ core, there is a slight tendency for the calculated results to become worse as the $\mathrm{C} / \mathrm{U}$ atom ratio is decreased and the flux spectrum hardens.

Despite several modeling approximations, which are discussed in Ref. 55, the calculated thoriun worths indicate that thorlum resonance capture is overpredicted by about $6 \%$. It is expected tinat this should also be true for ENDF/B-IV, although a reanalysis has not been performed to confirm this. New analyses of these experinents using consistent, ENDF/B-IV data and current generation methods will be required to draw further conclusions and are considered to be worthwile. For now, this review suggests that f'or graphite moderated systems ENDF/B-IV thorium tends to overestimate resonance capture. 
Table 34 - Summary of U233 Reactivity Worth Perturbations in HTGR Lattices ${ }^{a}$

\begin{tabular}{|c|c|c|c|c|}
\hline Core & $\underline{C} / \mathrm{U}-2500$ & $\mathrm{C} / \mathrm{U}-1718$ & $\mathrm{C} / \mathrm{U}-859$ & $\mathrm{C} / \mathrm{U}-432$ \\
\hline $\begin{array}{l}\text { Fast/Thermal Flux Ratio } \\
(2.38 \mathrm{eV} \text { Cutoff })\end{array}$ & 3.40 & 4.62 & 12.07 & 15.33 \\
\hline Measured Worth $(\$)$ & 0.565 & 0.415 & 0.243 & 0.164 \\
\hline Best Calculated Worth (\$) & 0.584 & 0.431 & 0.263 & 0.181 \\
\hline Discrepancy $(\%)$ & +3.4 & +3.9 & +8.2 & +9.4 \\
\hline Discrepancy $\%$ if ${ }^{b}$ : & & & & \\
\hline$\tau_{c}^{233}$ is increased $10 \%$ for & & & & \\
\hline a) $2.38=E \leq 14.9 \times 10^{6} \mathrm{eV}$ & +2.7 & & +6.2 & \\
\hline b) $0.1=E \div 0.414 \mathrm{eV}$ & +2.8 & & +7.8 & \\
\hline c) $0.1 \div E \div 2.38 \mathrm{eV}$ & +1.9 & & +5.8 & \\
\hline$\pi_{f}^{233}$ is decreased $10 \%$ for & & & & \\
\hline $2.38=E \leqslant 14.9 \times 10^{6} \mathrm{eV}$ & +0.9 & & 0.4 & \\
\hline $\begin{array}{l}233 \\
2.503\end{array}$ & +2.1 & & +6.6 & \\
\hline
\end{tabular}

${ }^{a}$ Calculations were made for the heaviest loaded U2 33 special element (C/U-432).

${ }^{b}$ Data changes were made one at a time. 
Table 35 - Comparison of Calculated and Measured Thorium Reactivity Worths in HTGR Lattices

Special Thorium ${ }^{a}$

$\operatorname{Th}(50)$

$\operatorname{Th}(100)$

$\operatorname{Th}(200)$

$\operatorname{Th}(300)$

$\operatorname{Th}(500)$

$\operatorname{Th}(50)$

Th (100)

I'h (200)

Th (300)

I'h (500)

Th (500)

Th (50)

Th $(100)$

Th $(200)$

Th $(300)$

Th (500)

$\operatorname{Th}(500)$

$\operatorname{Th}(50)$

Th (100)

Th (200)

Th (300)

Th (500)

Th (500)

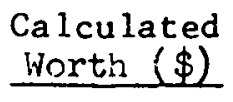

Measured Worth (\$)

\section{$\%$ Diff. $^{b}$}

\section{Core C/U-5000}

$\begin{array}{ccc}-- & -0.046 & -- \\ -- & -0.085 & -- \\ -- & -0.157 & - \\ -0.237^{b} & -0.218 & 8.0 \\ -0.349^{b} & -0.330 & 5.4\end{array}$

Core C/U-2500

$\begin{array}{llr}-0.059 & -0.053 & 10.2 \\ -0.105 & -0.094 & 10.5 \\ -0.180 & -0.171 & 5.0 \\ -0.244 & -0.232 & 4.9 \\ -0.349 & -0.342 & 2.0 \\ -0.343^{c} & -0.342 & 0.3\end{array}$

Core C/U-1718

$\begin{array}{lrr}-0.061 & -0.055 & 9.8 \\ -0.108 & -0.093 & 13.9 \\ -0.182 & -0.170 & 6.6 \\ -0.245 & -0.230 & 6.7 \\ -0.347 c & -0.331 & 4.6 \\ -0.342 c & -0.331 & 3.2\end{array}$

\section{Core C/U-859}

$\begin{array}{lll}-0.057 & -0.056 & 1.8 \\ -0.102 & -0.092 & 9.8 \\ -0.172 & -0.159 & 7.6 \\ -0.230 & -0.211 & 8.3 \\ -0.320 & -0.296 & 7.5 \\ -0.311^{c} & -0.296 & 4.8\end{array}$

(Cont inued) 
Table 35 (Continued)

Special Thorium $^{\text {E }}$

$\operatorname{Th}(50)$

$\operatorname{Th}(100)$

$\operatorname{Th}(200)$

$\operatorname{Th}(300)$

$\operatorname{Th}(500)$

$\operatorname{Th}(500)$

\section{Calculated}

Worth $(\$)$

Measured

Worth (\$)

\section{Core $\mathrm{C} / \mathrm{U}-432$}

$\begin{array}{ll}-- & -0.048 \\ -0.085 & -0.080 \\ -0.143 & -0.139 \\ -0.191 & -0.185 \\ -0.265 & -0.258 \\ -0.252 c & -0.258\end{array}$

\section{\% Diff.}

5.6
2.8
3.1
2.6
-2.4

${ }^{a}$ Number in parentheses signifies grams Th/element.

$\mathrm{b}_{\%}$ Diff. $=($ Calculated Worth-Experiment $) /$ Experiment $\times 100$.

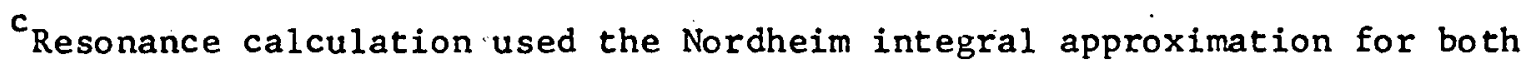
the absorber and moderator. All others used the asymptotic approximation of the moderator to the collision density. 
V. Summary

This paper has reviewed selerted U233 and Th-U233 experiments useful as thermal reactor data-testing benchmarks. Two najor questions were addreoacd:

(1) To what extent, do these experiments provide a consistent and adequately detailed test of the jifferential data?

(2) How well do current (ENDF/B-IV) differential cata predict the inteฐral results?

The existing integral experiments provide good beginning-of-life criticality information fir these systems. However, except for a few thorium capture measurements (which are fairly consistent) integral parameter results are extremely limited in number and scope.

In the area of criticality, the homogeneo: $\mathrm{U}^{2} 33-\mathrm{H}_{2} \mathrm{O}$ systems provide a clear-aut picture: With ENDF/B-IV data, calculated eigenvalues show an upward trend of approximately $2 \%$ with decreasing $\mathrm{H} / \mathrm{H}$. There is a similar pattern for homogeneous U235 systems, and these trends appear ton he due mostly to an underprediction of fast neutron leakage.

For $\mathrm{H}_{2}$ O-moderated thorium-uranium Jattices, eigenvalues based on fulienergy-range, explicit-geometry Monte Carlo calculations are generally high, consistent with the trend observed for homogeneous critfcals. This suggests that leakage is underpredicted with ENDF/B-IV for these lattices also, and that thorium capture is reascrably well predicted (Figure 16). For the BNL $D_{2}$ O-moderated exponentials, on the other hand, calculated eigenvalues are low by $1.5 \%$.

In the area of integral parameters, the number of useful measurements is limited. Although the ENDF/B-IV thorium evaluation does not reflect recent 
experimental data, predicted thorlum resonance capture in lattices is only slightly below the nominal best integral result. However, the spread of integral values is large - from $-8 \%$ above calculation to $-3 \%$ below (Figure 16). It may be noteworthy that in the $\mathrm{D}_{2}$ O-moderated systems calculated thorium capture is slightly higher (relative to experiment) than in the $\mathrm{H}_{2} \mathrm{O}-$ moderated systems.

There is a good deal of evidence from these analyses to support hardening of the prompt fission neutron spectrum of U233. The best spectrun representation is obtained with the Standard model, which uses two fully-accelerated fission fragments and a stationary source. This model yields a prompt mean enerEy of $\overline{\mathrm{E}}_{\mathrm{p}}=2.082 \mathrm{MeV}$, and effectively removes the trend in calculated $K_{\text {eff }}$ versus leakage (Figure 17 ).

The ENDE/B-IV U235 prompt fission spectrum is also too soft. In this case equally good fits to recent differential experiments are obtained with the Watt model $\left(\bar{E}_{p}=2.027 \mathrm{MeV}\right)$ and the Standard model $\left(\overline{\mathrm{E}}_{\mathrm{p}}=2.073 \mathrm{MeV}\right)$. For u235 systems, $K_{e f f}$ is also sensitive to resonance alpha (the ratio of capture/ fission integrals), and the ENDF/B-TV value is $7( \pm 4) \%$ below integral experiment. Both the Standard and Watt spectrum models can eliminate the trend of $\mathrm{K}_{\text {eff }}$ versus leakage depending on choice of resonance alphe (Figure 5). In addition, the Standard model gives good agreement with integral measurements of age in $\mathrm{H}_{2} \mathrm{O}$ and fission-spectrum-average $\sigma_{f}^{\text {Le38 }}$ (Table 9, 10). The strong model dependences reflect the fact that differential spectrum measurements do not effectively cover the full energy range of the spectra, especially below I MeV. 


\section{REFERENCES}

1. J. K. Fox, L. W. Gilley, and E. R. Rohrer, "Critical Mass Studies, Part VIII, Aqueous Solutions of U-233," ORNL-2143 (1959).

2. J. T. Thomas, J. K. Fox, and D. Callihan, Nucl. Sci. Eng., 1, 20 (1956).

3. J. T. Thomas, "Critical Experiments with Aqueous Solutions of $233 \mathrm{UO}_{2}\left(\mathrm{NO}_{3}\right)_{2}$," in "Neutron Physics Division Annual Progress Report for the Period Ending May 31, 1968," ORNL-4280, Oak Ridge National Laboratory.

4. R. Gwin and D. W. Magnuson, Nuc1. Sci. Eng., 12, 364 (1962).

5. A. Staub, et al., Nucl: Sci. Eng., 34, 263 (1968).

6. N. M. Steen, "Analysis of the Fission Neutron Spectrum of Uranium-233 and Criticality Computations for Homogeneous Uranium-233- $\mathrm{H}_{2} \mathrm{O}$ Spheres and Cylinders," WAPD-TM-997, Bettis Atomic Power Laboratory (1972).

7. S. R. McNeany and J. D. Jenkins, Nucl. Sci. Eng., 65, 441 (1978).

8. J. J. Ullo and J. Hardy, Jr., "An Analysis of U233 and U235 Critical Experiments with ENDF/B-IV Data," WAPD-TM-1299, Bettis Atomic Power Laboratory (1977).

9. G. H. Conley, "A Pattern in Monte Carlo Calculations of Critical Experiments," Transactions of the A.N.S. 11, 160 (June 1968).

10. D. E. Kusner, S. KelIman, and R. A. Dannels, "ETOG-1, A Fortran TV Program to Process Data from the ENDF/B File to the MUFT, GAM and ANISN Formats," WCAP-3845-1 (ENDF 114), December 1969.

11. C. L. Beard and R. A. Dennels, "ETOT, A Fortran IV Program to Process Data from the ENDF/B File to Thermal Library Format," WCAP-7363, Marcin 1971.

12. H. C. Honeck and D. R. Finch, "FLANGEII (Version 71-1). A Code to Process Thermal Neutron Data from an ENDF/B Tape," DP-1278, October 1971.

13. N. R. Candelore, R. C. Gast and L. A. Ondis II; "RCPOI. - A Monte Carlo Program for Solving Neutron and Photon Transport Problems in ThreeDimensional Geometry with Detailed Energy Description," WAPD-TM-1267, August 1973.

14. H. Bohl, Jr., et al., "P3MG-1, A One Dimensional Multigroup P-3 Program for the Philco-2000 Computer," WAPD-TM-2T2, 1963. 
15. E. M. Gelbard and R. E. Prael, "Monte Carlo Work at Argonne National Laboratory," Proc. NEACRP Meeting of a Monte Carlo Study Group, July 1-3, 1974, ANL-75-2 (NEA-CRP-118), Argonne National Laboratory (1975).

16. R. K. Paschall, Nucl. Sci. Eng., 20, 436-444 (1964); also 23, 256-263 (1965).

17. J. D. Spencer, "An Experimental Determination of the Neutron Age to Indium Resonance Energy in Aluminum-Water Mixtures," Ph.D. Thesis, University of Virginia (1966).

18. S. F. Maghabghab and D. I. Garber, "Neutron Cross Sections," BNL-325, Third Edition, June 1973.

19. N. M. Steen, "Status of Nuclear Data for Th232 and U233, "Transactions of the American Nuclear Society 28, 712, June 1978.

20. L. Green; J.A. Mitchell, and N. M. Steen, "The Uranium-233 Fission Neutron Spectrum from 0.8 to $10 \mathrm{MeV}, "$ Nucl. Sci. Eng. 52, 406 (1973).

21. R. Gwin, Nucl. Sci. Eng., 61, 428 (1976).

22. E. Hellstrand, "Measurement of Resonance Integrals," in Reactor Physics in the Resonance and Thermal Regions, Vol. II. Proceedings of the National Topical Meeting, San Diego, February 7-9, 1966. A. J. Goodjohn and G. C. Pomraning, Eds. The M.I.T. Press, Cambridge, Mass., 1966.

23. E. Hellstrand and J. Weitman, Nucl. Sci. Eng., 9, 507 (1961).

24. Jakob Weitman, "The Effective Resonance Integral of Thorium Oxide Rods," Nucl. Sci. Eng., 18, 246 (1964).

25. W. G. Pettus, et al., "Resonance Absorption in Thorium Metal and Oxide Rods," BAW-1286, Babcock and Wilcox (1963).

26. B. L. Palowitch and J. Hardy, Jr., "Measurement of the Effective Resonance Integral and Doppler Coefficient of Thorium Oxide Rods," WAPD-TM-627, December 1966. Also N.S.E. 29, 111 (1967).

27. N. L. Snidow, et al., "Thorium Uranium Physics Experiments," BAW-1191, Babcock and Wilcox, May 1960.

28. M. L. Batch and N. I. Snidow, "Consolidated Edison Thorium Reactor Critical Experiments with Oxide Fuel Pins," BAW-119, Rev. 1, Babcock and Wilcox, July 1960.

29. T. C. Engelder, et al., "SSCR Basic Physics Program - Critical Experiments on Lattices Moderated by $\mathrm{D}_{2} \mathrm{O}-\mathrm{H}_{2} \mathrm{O}$ Mixtures," BAW-1231, Babcock and Wilcox, December 1961. 
30. W. C. Redman, et a1., "Critical Experiments with Thoria-Urania Fuel in Heavy Water," ANL-6378, Argonne National Laboratory, December 1961.

31. A. Okazaki and $S . A$. Durrani, "Lattice Measurements with 19-Element Rods of $\mathrm{ThO}_{2}-\mathrm{U}^{2} 35 \mathrm{O}_{2}$ in Heavy Water Moderator," Part I: "Buckling, Fine Structure and Neutron Spectrum Parameters," AECL-2778 (1967).

32. A. Okazaki, "Lattice Measurements with 19-Element Rods of $\mathrm{ThO}_{2}-\mathrm{U}^{23} \cdot 5 \mathrm{O}_{2}$ in Heavy Water Moderator," Part II: "Relative Conversion Ratio and Comparison with Calculations," AECLr2779 (1968).

33. G. A. Price, et al., "Organic-Cooled, Heavy Water-Moderated U-233 Fueled Lattice Experiments," BNL-50012 ('T-434) (1966).

34. H. H. Windsor, et al., "Exponential Experiments with Lattices of Uranium233 Oxide and Thorium Oxide in Light and Heavy Water," N.S.E. 42, 150 (1970).

35. J. Hardy, Jr., J. J. Volpe, and D. Klein, "Measurement and Analysis of Parameters in Tight Th232-U235 and Th232-U233 Lattices Moderated with D20," WAPD-'IM-1089, January 1974. Also N.S.E. 55, 401 (1974).

36. B. L. Palowitch and J. Hardy, Jr., "Study of the ThO $\mathrm{O}_{2}$ Doppler Effect in Tight $\mathrm{U}^{2} 35 \mathrm{O}_{2}-\mathrm{ThO}_{2}$ Lattice Moderated with $\mathrm{D}_{2}$ O," WAPD-TM-1090, January 1974 .

37. S. Milani, et al., "Small Uranium-233 Fueled Seed-and-Blanket Critical Experiments," WAPD-TM-614, November 1967.

38. S. Milani, et al., "BMU Series of 233 U Fueled Critical Experiments," WAPD-TM-1117, January 1975.

39. S. Milani, et al., "233U Oxide-Thorium Oxide Detailed Cell Critical Experiments," WAPD-TM-1101, October 1974.

40. D. Greneche, "Evaluation of the Th232 Capture Resonance Integral," Specialists Meeting on "Resonance Parameters of Fertile Nuclei and Pu239," Saclay, 20-22 May 1974, P. Ribon, Ed., NEANDC(E) 163 U.

41. N. M. Steen, "An Evaluation of the Radioactive Neutron Capture Cross Sections of Thorium-232 for the Range 0.0 ev to $15 \mathrm{Mev}$," WAPD-TM-971, Bettis Atomic Laboratory, December 1970.

42. J. J. U110, J. Hardy, Jr., and N. M. Steen, "Review of Thorlum-U233 Cycle Thermal Reactor Benchmark Studies," to appear in the Proceedings of a Seminar entitled "Nuclear Data Problems for Thermal Reactor Applications" held at the Brookhaven National Laboratory on-May 22-24, 1978 . 
43. S. C. Bhatt, et al., "BWR Methods Comparisons with Thorium Lattice Benchmarks," Trans. Am. Nucl._Soc.227, 920 (1977).

44. N. L. Shapiro, J. R. Rec and R. A. Matzie, "Assessment of Thorium Fuel Cycles in Pressurized Water Reactors," EPRI NP-359, Electric Power Research Institute, February 1977.

45. B. R. Sehga 1, et a1., Trans. Am. Nuc1. Soc., 23, 559 (1976).

46. J. J. Weiss and B. K. Malaviya, Trans. Am. Nucl. Soc., 27, 890 (1977).

47. S. C. Bhatt, et a1., Trans. Am. Nucl. Soc..2 27, 920 (1977).

48. C. R. Rickey and T. J. Oakes, Nuc1._Sci. Eng., 47, 40 (1972).

49. E. P. Lippincott, Nucl. Sci. Eng., 47, 475 (1972).

50. T. J. Oakes, "Measurement of $k_{\infty}$ as a Function of Temperature for a $233 \mathrm{UO}_{2}-232 \mathrm{ThO}_{2}$-C Lattice," BNWL-1601, Battelle, Pacific Northwest Laboratories (February 1972).

51. E. P. Lippincott, "Measurement of the Physics Parameters for a MSTR Lattice in the HTLTR," BNWL-1633, Battelle, Pacific Northwest Laboratories (January 1972).

52. R. E. Heineman, Trans. Am. Nucl. Soc., 8, 532 (1965).

53. D. F. Newman, et al., "Evaluation of Temperature Coefficients of Reactivity for 233U-Thorium Fueled Lattices," EPRI NP-222, Electric Power Research Institute (May 1977).

54. G. L. Ragan, "Calculation of Multiplication Factor vs. Temperature for a MSBR Lattice in the HTLTR and Comparison with Experiment., "ORNL-TM4255, Oak Ridge National Laboratory (July 1973).

55. R. G. Bardes, et al., "Results of H'GR Critical Experiments Designed to Make Integra 1 Checks on the Cross Sections in Use at Gulf General Atomic," GA-8468, Gulf Atomic (February 1968).

56. M. K. Drake, "Neutron Cross Sections for U233," GA-7076, General Atomic (September 1966).

57. L. W. Weston, et al., "Measurement of the Neutron Fission and Capture Cross Sections for Le33 in the Energy Region 0.4 to $2000 \mathrm{eV}$," ORNL-TM2140, Oak Ridge National Laboratory (April 1968). 